US Army Corps of Engineers ${ }_{\circledast}$

Engineer Research and

Development Center

\title{
Mechanical Behavior of Cor-Tuf Ultra-High Performance Concrete Considering Aggregate and Paste Effects
}

Isaac L. Howard, Ashley Carey, Megan Burcham,

October 2018

Dylan A. Scott, Jameson D. Shannon, Robert D. Moser,

and Mark F. Horstemeyer
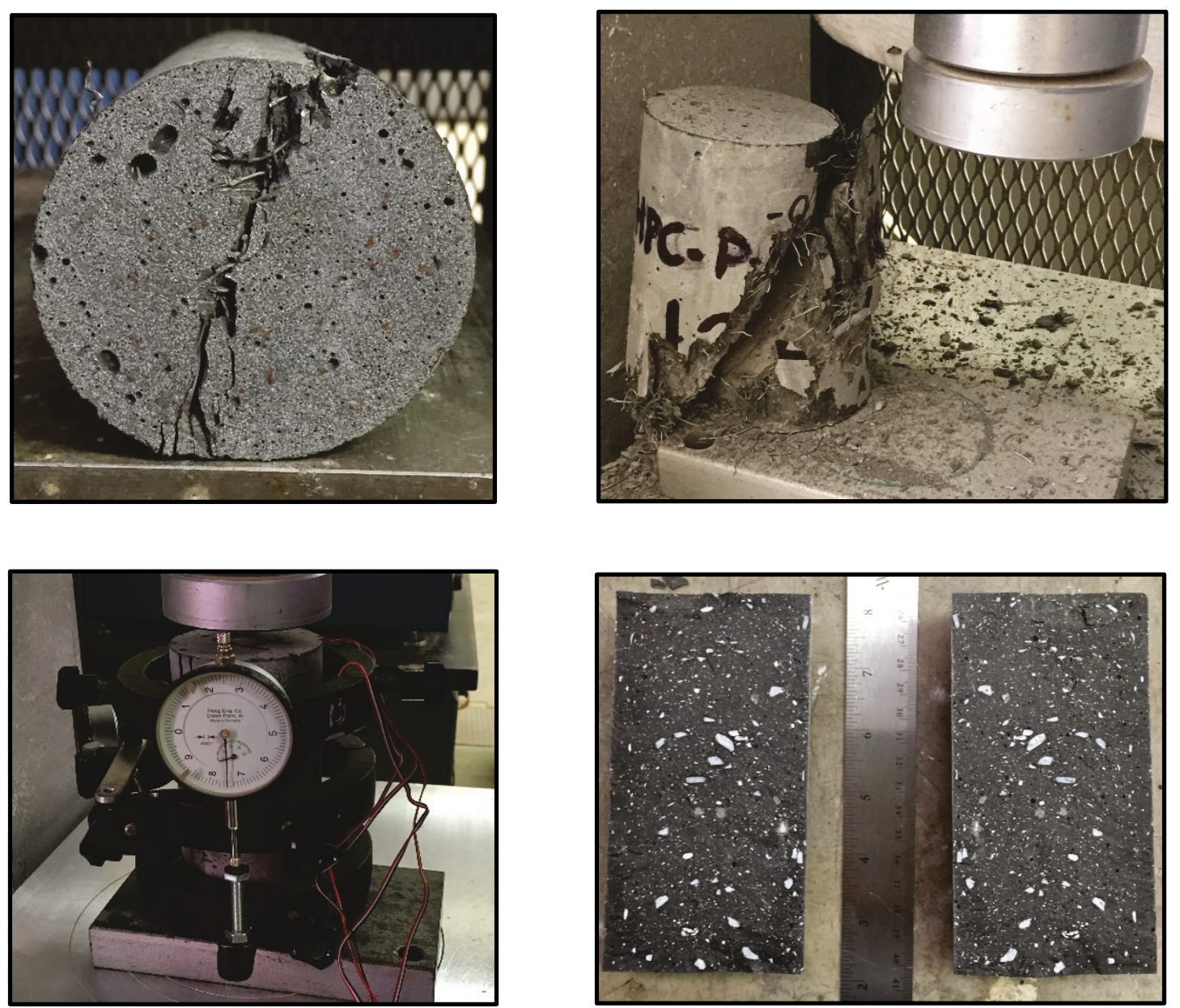
The U.S. Army Engineer Research and Development Center (ERDC) solves the nation's toughest engineering and environmental challenges. ERDC develops innovative solutions in civil and military engineering, geospatial sciences, water resources, and environmental sciences for the Army, the Department of Defense, civilian agencies, and our nation's public good. Find out more at www.erdc.usace.army.mil.

To search for other technical reports published by ERDC, visit the ERDC online library at http://acwc.sdp.sirsi.net/client/default. 


\section{Mechanical Behavior of Cor-Tuf Ultra-High Performance Concrete Considering Aggregate and Paste Effects}

Dylan Scott, Robert Moser, and Jameson D. Shannon

Geotechnical and Structures Laboratory

Concrete Materials Branch

U.S. Army Engineer Research and Development Center (ERDC)

3909 Halls Ferry Road

Vicksburg, MS 39180

Isaac L. Howard

Center for Advanced Vehicular Systems and

Civil and Environmental Engineering Department

Mississippi State University

200 Research Boulevard

Starkville, MS 39759

Ashley Carey, Megan Burcham, and Mark F. Horstemeyer

Center for Advanced Vehicular Systems and

Mechanical Engineering Department

Mississippi State University

200 Research Boulevard

Starkville, MS 39759

Final report

Approved for public release; distribution is unlimited.

Prepared for U.S. Army Corps of Engineers

Washington, DC 20314-1000

Under ERS, IVPPED, and WD63 multiscale cements contracts 


\section{Abstract}

This research primarily focused on properties from varying the constituents that make up ultra-high performance concrete (UHPC) with the ultimate goal to enable improved characterization and modeling of this material. Several variations of UHPC were made to see the differences in properties as a function of constituents. Compressive strength, elastic modulus, and tensile strength were measured at low loading rates. Fundamental test methods were used for most experiments with a smaller subset of tests with strain gages and imaging techniques. This report is intended primarily to document these experiments and the collected data. Specific conclusions are avoided herein, as the intent is to use these data in future efforts that will be more appropriate to draw more meaningful conclusions about ways to better model and ultimately improve UHPC.

DISCLAIMER: The contents of this report are not to be used for advertising, publication, or promotional purposes. Citation of trade names does not constitute an official endorsement or approval of the use of such commercial products. All product names and trademarks cited are the property of their respective owners. The findings of this report are not to be construed as an official Department of the Army position unless so designated by other authorized documents. 


\section{Contents}

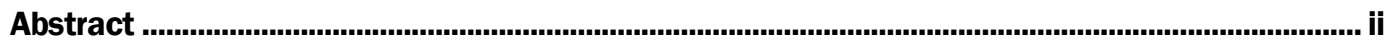

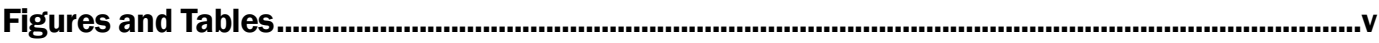

Preface .................................................................................................................................................vii

Unit Conversion Factors ................................................................................................................... vifi

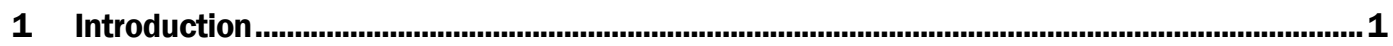

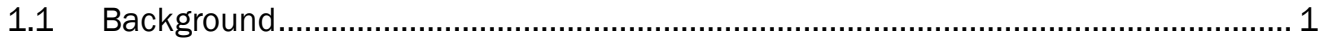

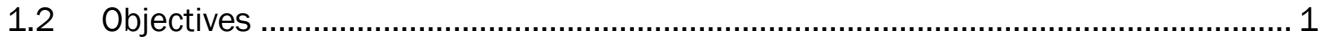

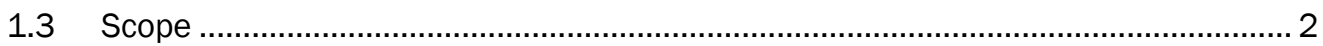

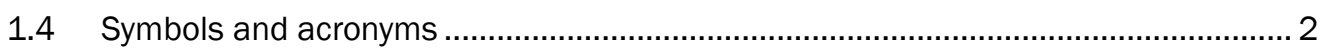

2 Experimental Program ............................................................................................................ 7

2.1 Constituent material properties................................................................... 7

2.2 Specimen preparation and curing ............................................................... 9

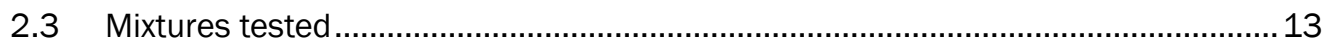

2.4 Mechanical property test methods.................................................................... 15

2.4.1 Compressive strength testing (non-instrumented)............................................. 15

2.4.2 Elastic modulus testing (non-instrumented) ................................................... 16

2.4.3 Tensile strength testing (non-instrumented) .................................................... 17

2.4.4 Compressive and tensile testing instrumented with strain gages .........................18

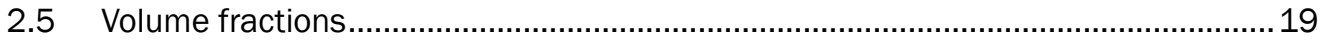

2.5.1 As-batched volume estimations .................................................................... 19

2.5.2 Volume fractions from imaging techniques........................................................ 20

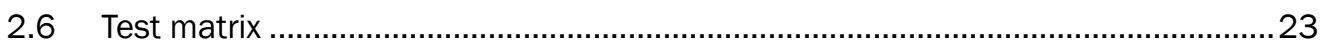

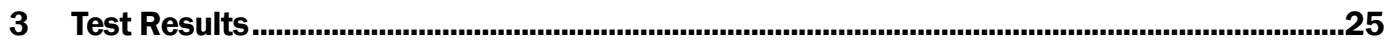

3.1 Varying proportions ...................................................................................... 25

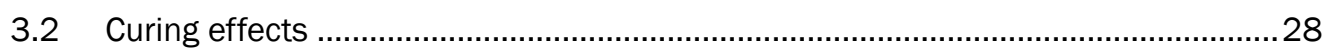

3.2.1 Curing effects measured on laboratory molded specimens.................................. 28

3.2.2 Curing assessment of cores and laboratory molded specimens ...........................36

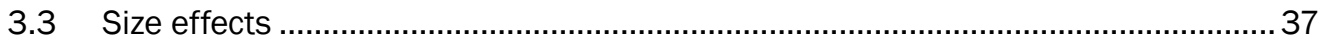

3.3.1 Size effects - Ultra-High Performance Concrete (UHPC)...................................... 37

3.3.2 Size effects - Cement paste $(C P)$....................................................................... 38

3.3.3 Size effects - Fiber Reinforced Paste (FRP)........................................................ 39

3.4 Instrumentation test results ......................................................................... 42

3.5 Volume fractions estimated from batch quantities ..............................................49

3.6 Volume fractions estimated from imaging .....................................................50

4 Summary

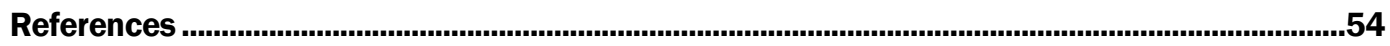




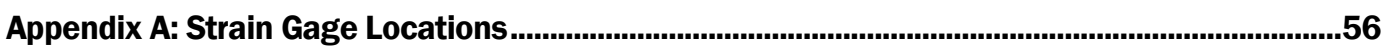

Report Documentation Page 


\section{Figures and Tables}

\section{Figures}

Figure 1. (a) Mixing dry materials and water, (b) adding admixture, (c) finished mixture, (d) vibration table, (e) specimens in curing room, (f) specimens in water bath, (g) end grinding, and (h) shelved specimens awaiting testing

Figure 2. UHPC tub provided by ERDC (a) before, (b) during, and (c) after coring. ...........................14

Figure 3. Representative compressive strength test........................................................................16

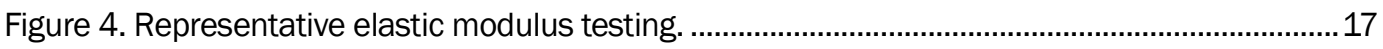

Figure 5. Representative tensile testing.

Figure 6. (a) Compressive testing, (b) elastic modulus testing, and (c) tension testing with strain gages.

Figure 7. ImageJ process for turning (a) scanning electron microscope images to a (b) binary image and then (c) isolating inclusions.

Figure 8. Geometries generated using the area fractions and length scales found through

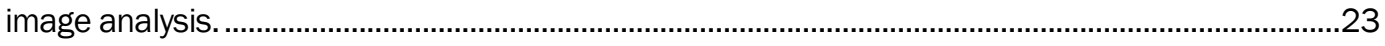

Figure 9. Average compressive strength for $791^{\circ} \mathrm{C}$-d cured specimens. ........................................26

Figure 10. Average tensile strength for $791^{\circ} \mathrm{C}-\mathrm{d}$ cured specimens.................................................

Figure 11. Average compressive strength of curing variations......................................................30

Figure 12. Average tensile strength of curing variations. ...................................................................31

Figure 13. $721^{\circ} \mathrm{C}-\mathrm{d}$ curing versus $791^{\circ} \mathrm{C}-\mathrm{d}$ curing in compression............................................31

Figure $14.801^{\circ} \mathrm{C}$-d curing versus $791^{\circ} \mathrm{C}-\mathrm{d}$ curing in compression. ...........................................32

Figure 15. $2,783^{\circ} \mathrm{C}-\mathrm{d}$ curing versus $791^{\circ} \mathrm{C}-\mathrm{d}$ curing in compression. ..........................................32

Figure 16. $721^{\circ} \mathrm{C}$-d curing versus $791^{\circ} \mathrm{C}-\mathrm{d}$ curing in tension....................................................33

Figure 17. $801^{\circ} \mathrm{C}-\mathrm{d}$ curing versus $791^{\circ} \mathrm{C}-\mathrm{d}$ curing in tension......................................................33

Figure 18. $2,783^{\circ} \mathrm{C}-\mathrm{d}$ curing versus $791^{\circ} \mathrm{C}-\mathrm{d}$ curing in tension. ..................................................34

Figure 19. Compressive strength of CP-0.15 size variation specimens. ..........................................39

Figure 20. Compressive strength of FRP variation specimens......................................................... 41

Figure 21. Tensile strength of FRP variation specimens. ............................................................42

Figure 22. Percent of ultimate compressive stress versus strain for (a) UHPC, (b) CP-0.15,

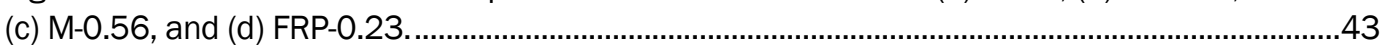

Figure 23. Percent of ultimate tensile stress versus strain for (a) UHPC, (b) CP-0.15, (c) M-

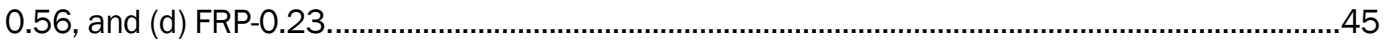

Figure 24. Truncated stress versus vertical strain plots for (a) UHPC, (b) CP-0.15, (c) M-

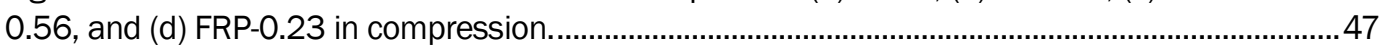

Figure 25. Poisson's ratio results from compression testing ..........................................................49

Figure 26. CT scan of UHPC showing (a) approximately 3\% steel fibers and (b) large voids

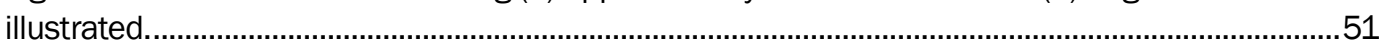

Figure A1. Strain gage locations of UHPC in compression...........................................................56

Figure A2. Strain gage locations for CP in compression. ..............................................................57

Figure A3. Strain gage locations for M in compression. .............................................................58

Figure A4. Strain gage locations for FRP in compression............................................................59 
Figure A5. Strain gage locations for UHPC in tension. .................................................................60

Figure A6. Strain gage locations for CP in tension......................................................................61

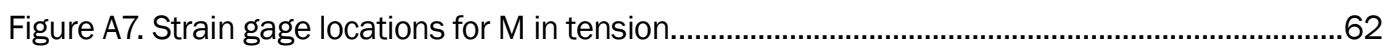

Figure A8. Strain gage locations for FRP in tension. ...................................................................63

\section{Tables}

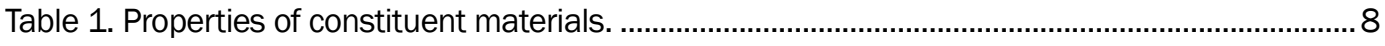

Table 2. Cement properties from mill certificates. .............................................................................. 9

Table 3. Batching quantities for $0.1 \mathrm{ft}^{3}\left(2,832 \mathrm{~cm}^{3}\right)$ of Cor-Tuf (baseline condition)........................10

Table 4. Batch proportions and identifiers for mixtures tested. ...........................................................14

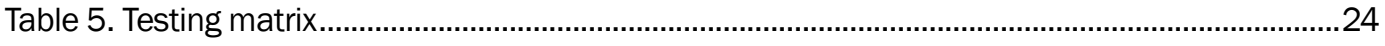

Table 6. Varying proportions test results..........................................................................................25

Table 7. Elastic modulus and ultimate strength constant for varying proportions............................28

Table 8. Curing effects test results. ...............................................................................................29

Table 9. Elastic modulus and ultimate strength constant for varying curing....................................36

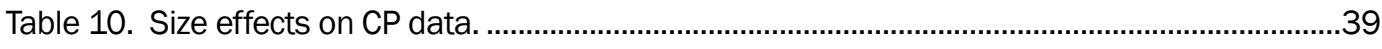

Table 11. Size effects of FRP-0.23 in compression..........................................................................40

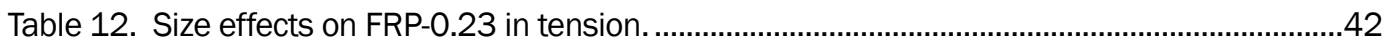

Table 13. Strain gage data for compression and tension....................................................................46

Table 14. Comparison of elastic moduli from strain gages and compressometer. ............................48

Table 15. Average volume fractions estimated from batch quantities. ..............................................49

Table 16. Comparison of average UHPC volume fractions from batching and Image J......................50 


\section{Preface}

This study was conducted for USACE through a collaboration between the U.S. Army Engineer Research and Development Center (ERDC) and the Mississippi State University (MSU) Center for Advanced Vehicular Systems (CAVS). The contents of this report were supported by three research contracts: "Engineered Resilient Systems" (ERS), "Integrated Virtual Prototyping for Product Engineering and Design" (IVPPED), and "Engineering Work Directive 0063" (WD63). IVPPED was sponsored by ERDC under Cooperative Agreement Number W56HZV-17-C-0095. The technical monitor for IVPPED was Ms. Vernessa Noye. Dr. Roger L. King was the CAVS Director and Principal Investigator for most activities documented in this report, and Dr. Clay Walden assumed the responsibility of CAVS Director near the end of this report's activities.

The work was performed by the Concrete and Materials Branch (CMB) of the Engineering Systems and Materials Division (ESMD), ERDC Geotechnical and Structures Laboratory (GSL). At the time of publication, Mr. Christopher Moore was Chief, CMB; Dr. Gordon W. McMahon was Chief, ESMD; and Dr. Michael Sharp was Technical Director for Civil Works Infrastructure. The Deputy Director of ERDC-GSL was Dr. William P. Grogan, and the Director was Mr. Bartley P. Durst.

COL Ivan P. Beckman was the Commander of ERDC, and Dr. David W. Pittman was the Director. 


\section{Unit Conversion Factors}

\begin{tabular}{|c|c|c|}
\hline Multiply & By & To Obtain \\
\hline degrees Fahrenheit & $(F-32) / 1.8$ & degrees Celsius \\
\hline inches & 0.0254 & meters \\
\hline pounds (force) per square inch & 6.894757 & kilopascals \\
\hline pounds (mass) & 0.45359237 & kilograms \\
\hline pounds (mass) per cubic inch & $2.757990 \mathrm{E}+04$ & kilograms per cubic meter \\
\hline square inches & $6.4516 \mathrm{E}-04$ & square meters \\
\hline
\end{tabular}




\section{Introduction}

\subsection{Background}

In recent years, ultra-high performance concrete (UHPC) has been studied from many perspectives including flexural and tensile properties (Roth 2008), fiber size and shape (Scott et al. 2015), and nanomechanical analysis of calcium-silicate-hydrate (Chandler et al. 2012). However, studying effects of individual constituents and, for example, how they fit into a multiscale numerical modeling framework have not been as widely studied.

UHPC is usually composed of five to eight individual materials with varying sizes and length scales. Typical materials are in one of five categories: water, cementitious material, admixture, fiber, or fine aggregate. Coarse aggregates are not incorporated into UHPC to avoid relatively large failure planes that can occur when large aggregates have a weak plane within them. This problem is lessened when only fine aggregates, such as sand, are incorporated. UHPC makes use of water reducing admixtures so less water is needed for equal fluidity. With less water, cement paste (CP) is stronger after hydration. Fibers, typically steel, but in some cases polymeric are added for improved ductility.

UHPC is not used nearly as often as traditional concrete, but it does have several applications. This report does not contain a comprehensive literature review as its primary purpose is to document a series of fundamental experiments that are intended to be utilized in companion efforts. A state-of-the-art report on UHPC and its history is available in Green et al. (2014).

\subsection{Objectives}

The data collected and documented in this report aim to further the UHPC knowledge base for improved characterization and are also intended for use in numerical modeling. A laboratory test program undertaken to measure fundamental UHPC properties, beginning with individual constituents, is documented here. The scope of this effort focuses mainly on experimental efforts with Cor-Tuf UHPC, which was developed by 
ERDC. An ultimate goal is for this report to be used alongside additional data in high-performance computing environments.

\subsection{Scope}

This effort investigated properties at low load rates and with no specimen confinement, which allowed more specimen replication, albeit producing less sophisticated measurements. The goal of this portion of a larger multiscale cementitious materials program was to understand the effects of individual UHPC components. Once fundamental understanding of individual components, proportioning, and their interfacial behavior is better understood, mathematical relations to improve the state-of-the-art in numerical modeling of UHPC should be more feasible.

Four types of specimens were evaluated: $\mathrm{CP}$, mortar (M), fiber reinforced paste (FRP), and UHPC. CP has no aggregates or fibers, $M$ has no fibers, FRP has no aggregates, and UHPC has all ingredients. A systematic evaluation containing these specimen types produced from the same ingredients (sometimes with varying proportions) is not commonplace and is the main contribution of this effort. Specimens of these varying types are intended to isolate contributions/behaviors of the three primary ingredient classifications (paste, aggregates, and fibers) that can be benchmarked to these materials combined (i.e., Cor-Tuf UHPC).

This report represents work performed beginning in 2013 under three programs: Engineered Resilient Systems (ERS), Integrated Virtual Prototyping for Product Engineering and Design (IVPPED), and Engineering Work Directive 0063 (WD63). Earlier efforts within ERS were largely conceptual, with emphasis on how laboratory measurements of individual constituents might be able to support high performance computing based modeling and simulation investigations focused on concrete multi-scale modeling. Later, specimens began to be prepared, cured, and tested (mostly within IVPPED). Thereafter, data analysis occurred mostly within WD63. Report assembly occurred progressively throughout the work.

\subsection{Symbols and acronyms}

The following symbols and acronyms are used throughout the report. 
API - American Petroleum Institute

ASTM - American Society for Testing and Materials

$\mathrm{C}_{469}$ - elastic modulus constant found from the relationship of compressive strength to elastic modulus

CAVS - Center for Advanced Vehicular Systems

CMRC - Construction Materials and Research Center

COV - coefficient of variation, standard deviation divided by mean

$\mathrm{CP}$ - cement paste

CP-o.11 - cement paste with a water to cementitious material ratio of 0.11

CP-0.15 - cement paste with a water to cementitious material ratio of 0.15

CP-0.26 - cement paste with a water to cementitious material ratio of 0.26

CT - computed topography

$\mathrm{D}$ - diameter

E - elastic modulus

$\mathrm{E}_{469}$ - elastic modulus from ASTM C469

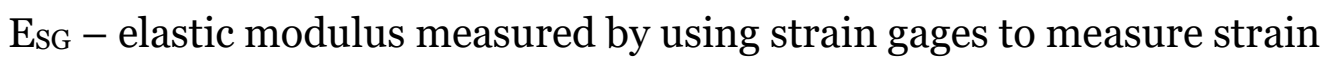

ERDC - U.S. Army Engineer Research and Development Center

ERS - Engineered Resilient Systems

FRP - fiber reinforced paste

FRP-0.11 - fiber reinforced paste with fibers to cementitious material ratio of 0.11 
FRP-0.17 - fiber reinforced paste with fibers to cementitious material ratio of 0.17

FRP-0.23 - fiber reinforced paste with fibers to cementitious material ratio of 0.23

HPC - High Performance Computing

HSR - High Sulfate Resistance

IVPPED - Integrated Virtual Prototyping for Product Engineering and Design

$\mathrm{M}$ - mortar

M-0.47 - mortar with a fine aggregate to cementitious material ratio of 0.47

M-0.56 - mortar with a fine aggregate to cementitious material ratio of 0.56

M-0.65 - mortar with a fine aggregate to cementitious material ratio of 0.65

MPa - megapascal

MSU - Mississippi State University

$\mathrm{N}$ - Newton

${ }^{\circ} \mathrm{C}-\mathrm{d}-$ measure of maturity that is degree Celsius * days

P - load

RVE - Representative Volume Element

SEM - Scanning Electron Microscope

SG - strain gage

St - tensile strength

UHPC - Ultra-high performance concrete 
$\mathrm{V}_{\mathrm{a}}$ - volume of air

$\mathrm{V}_{\mathrm{am}}$ - volume of admixture

$\mathrm{V}_{\mathrm{c}}$ - volume of cement

Vnoair - volume of the specimen if there were no air

$\mathrm{V}_{\mathrm{s}}$ - volume of sand

$\mathrm{V}_{\text {sf }}$ - volume of silica fume

$\mathrm{V}_{\text {sfl }}$ - volume of silica flour

$\mathrm{V}_{\text {Total }}$ - total volume

$\mathrm{V}_{\mathrm{w}}$ - volume of water

WD63 - Engineering Work Directive 0063

a - air

am - admixture

c-cement

$\mathrm{cm}$ - cementitious material (class $\mathrm{H}$ cement and silica fume)

$\mathrm{d}_{\text {dial }}$ - displacement of the compressometer dial

$\mathrm{f}-$ fibers

$\mathrm{f} / \mathrm{cm}$ ratio - ratio of fibers to cementitious materials

fa - fine aggregate (silica flour and silica sand)

$\mathrm{fa} / \mathrm{cm}$ - ratio of fine aggregate to cementitious materials

fc - compressive strength 
$1-$ length

l/D - aspect ratio

$\mathrm{m}_{\mathrm{b}-\text { per }}$ - batching mass percentage of constituent as a percent

$\mathrm{m}_{\mathrm{b}-\mathrm{tot}}-$ total mass of the batch

$\mathrm{m}_{\mathrm{con}}-$ mass of the constituent

$\mathrm{m}_{\text {con-spec }}-$ mass of each constituent in the specimen

$\mathrm{m}_{\text {spec }}-$ total mass of the specimen

mm - millimeter

psi - pounds per square inch

s - sand

sf - silica fume

sfl - silica flour

w - water

$\mathrm{w} / \mathrm{cm}$ - water to cementitious materials ratio

$\gamma-$ specific gravity

$\varepsilon-$ strain

$\varepsilon_{\max }$ - highest ultimate tensile or compressive strain

$v$ - Poisson's ratio

\%UltS - percent of ultimate stress 


\section{Experimental Program}

Cor-Tuf ultra-high performance concrete (UHPC) is composed of eight different volume constituents that have reported compressive strengths approaching 32,000 psi (220 MPa). An experimental program was undertaken, as documented in this report, in which 254 specimens were produced from Cor-Tuf constituents.

Testing, performed on the Mississippi State University (MSU) campus, made use of raw materials provided by ERDC. Some specimens were made and cured according to protocols used at ERDC. In addition to the ERDC protocols, variations in curing, constituent proportions, and specimen size were also performed.

Standardized test methods, such as those recommended by ASTM International, are widely used and can provide some insight into numerical modeling, but often they are not intended to provide a full description of a material's behavior. As such, this report deviated from traditional test methods in some areas, as the data contained are ultimately envisioned for use with numerical models.

Specimens were tested for several properties. Tests included compressive strength according to ASTM C39 (ASTM International 2016b), elastic modulus according to ASTM C469 (ASTM International 2014), and tensile strength according to ASTM C496 (ASTM International 2011b). Some specimens were also tested while instrumented with strain gages. Volume fractions were estimated by volumetric principles, imaging programs (ImageJ, Abaqus CAE 2014), and a computed topography (CT) scan.

\subsection{Constituent material properties}

Eight different constituents are used to make Cor-Tuf UHPC (Table 1). The remainder of this section summarizes properties provided within manufacturer literature relative to six of the eight constituents. Air (a) is a volumetric constituent for which no data are necessary, and tap water (w) was used as needed throughout the project where the specific gravity $(\gamma)$ was taken as 1.00. In this report, cementitious material $(\mathrm{cm})$ was defined as cement (c) plus silica fume (sf) on a mass basis. Also, fine aggregate (fa) was defined as silica flour (sfl) plus sand (s). 
Table 1. Properties of constituent materials.

\begin{tabular}{|c|c|c|c|c|}
\hline Constituent & Abbreviation & Category & $\mathrm{Y}^{1}$ & Description \\
\hline Air & $\mathrm{a}$ & -- & 0.00 & Air filling voids in UHPC \\
\hline Water & $\mathrm{w}$ & --- & 1.00 & Taken from laboratory tap \\
\hline Fibers & $\mathrm{f}$ & --- & 7.85 & Dramix $^{\circledR}$ 3D $55 / 30$ BG \\
\hline Admixture & $\mathrm{am}$ & --- & 1.08 & ADVA $^{\circledR} 190$ \\
\hline Cement & $\mathrm{c}$ & $\mathrm{cm}$ & 3.15 & API Class H (HSR) Cement \\
\hline Silica Fume & $\mathrm{sf}$ & $\mathrm{cm}$ & 2.25 & Elkem Microsilica ES 900-W \\
\hline Silica Flour & $\mathrm{sfl}$ & $\mathrm{fa}$ & 2.65 & SIL-CO-SIL ${ }^{\circledR} 75$ Ground Silica \\
\hline Sand & $\mathrm{s}$ & $\mathrm{fa}$ & 2.65 & F-50 Whole Grain Silica \\
\hline
\end{tabular}

${ }^{1} \mathrm{Y}=$ apparent specific gravity.

Fibers (f) that were made with low carbon or mild steel and conformed to ASTM A820 (ASTM 2016a) were taken from Bekaert. These fibers have a length (l) of $3 \mathrm{~cm}$, a $0.55-\mathrm{mm}$ diam (D), and an aspect ratio (l/D) of 55 . The fibers have a three-dimensional (3-D) geometry, a tensile strength of approximately $1.35 \mathrm{~N} / \mathrm{mm}^{2}$, and an elastic modulus (E) of approximately $210 \mathrm{~N} / \mathrm{mm}^{2}$. The primary roles of fibers within UHPC are ductility and tensile property improvements.

The admixture (am) was obtained from W.R. Grace and conformed to ASTM C494 (ASTM 2017a) Type A and F and to ASTM C1017 Type I (ASTM 2013). The admixture is a polycarboxlate-based high-range water reducer. Use of a high-range water reducer allowed the concrete to have a lower water-to-cementitious material $(\mathrm{w} / \mathrm{cm})$ ratio and higher strengths.

Cement (c) was supplied by Lafarge (a member of LafargeHolcim) out of its Joppa, IL, facility. The product meets American Petroleum Institute (API) Class $\mathrm{H}$ with high sulfate resistance (HSR). Table 2 summarizes properties from February to April of 2016 mill certificates. This cement is helpful for producing high ultimate strengths.

Silica fume (sf), obtained from Elkem (a Bluestar Company), had an $\mathrm{SiO}_{2}$ of greater than 85 percent, a $\mathrm{ZrO}_{2}$ of less than 10 percent, and a $\mathrm{CaO}$ of less than 4 percent. Particle sizes were approximately 0.5 microns. Silica fume lowers concrete permeability, increases corrosion resistance, and reduces the transition zone between paste and aggregates, thus increasing bond strength. 
Table 2. Cement properties from mill certificates.

\begin{tabular}{|c|c|c|c|c|}
\hline Property & February 2016 & March 2016 & April 2016 & Average \\
\hline Blaine fineness ${ }^{1}\left(\mathrm{~m}^{2} / \mathrm{kg}\right)$ & 311 & 302 & 311 & 308 \\
\hline $\mathrm{SiO}_{2}(\%)$ & 22.0 & 22.0 & 22.3 & 22.1 \\
\hline $\mathrm{Al}_{2} \mathrm{O}_{3}(\%)$ & 2.7 & 2.7 & 2.6 & 2.7 \\
\hline $\mathrm{Fe}_{2} \mathrm{O}_{3}(\%)$ & 4.5 & 4.5 & 4.4 & 4.5 \\
\hline $\mathrm{CaO}(\%)$ & 64.6 & 64.6 & 64.7 & 64.6 \\
\hline $\mathrm{MgO}(\%)$ & 2.1 & 2.3 & 2.3 & 2.2 \\
\hline $\mathrm{SO}_{3}(\%)$ & 2.8 & 2.8 & 2.8 & 2.8 \\
\hline $2 \mathrm{Free} \mathrm{lime} \mathrm{( \% )}$ & 0.5 & 0.6 & 0.4 & 0.5 \\
\hline $\mathrm{C}_{3} \mathrm{~S}(\%)$ & 63 & 63 & 62 & 63 \\
\hline $\mathrm{C}_{3} \mathrm{~A}(\%)$ & 0 & 0 & 0 & 0 \\
\hline
\end{tabular}

1Blaine Fineness measured via ASTM C204, and chemical properties measured via ASTM C114. 21: from X-ray diffraction (XRD)

Silica flour (sfl) was obtained from US Silica ${ }^{\mathrm{TM}}$ in Berkeley Springs, WV. This material is an inert crystalline form of silica, or ground silica sand. Approximately 99 percent of the material is finer than 75 microns, and approximately 88 percenet of the material is finer than 45 microns (No. 325 sieve). Silica flour's mineralogy is quartz with a pH of 7.0. Chemically, the materials are approximately 99.5 percent $\mathrm{SiO}_{2}$. This material is largely inert and can increase specimen density without adversely affecting hydraulic or pozzolanic reactions.

Sand (s) was obtained from US Silica ${ }^{\mathrm{TM}}$ in Ottawa, IL. The material has rounded particles of quartz mineralogy with a $\mathrm{pH}$ of 7.0. Approximately 98 percent of the particles pass a 425 micron (Number 40) sieve, approximately 17 percent pass a 212 micron (No. 70) sieve, approximately 3 percent pass a 150 micron (No. 100) sieve, and all are retained on a 75 micron (No. 200) sieve. Silica sand is inert, a characteristic which allows increased specimen density without affecting hydraulic or pozzolanic reactions.

\subsection{Specimen preparation and curing}

The materials described in Section 2.1 were utilized to make four categories of specimens for which Cor-Tuf was a baseline: UHPC, CP, (3) M, and FRP. These specimen categories are detailed in Section 2.3. Figure 1 provides photographs of key steps in the specimen preparation 
and curing process applicable to all four categories. All specimen categories were prepared in essentially the same manner except that, for example, specimens without fibers omitted appropriate steps. ERDC provided baseline proportions and batching instructions for Cor-Tuf UHPC (Table 3), which were used as a reference for all specimens produced.

Table 3. Batching quantities for $0.1 \mathrm{ft}^{3}$ $\left(2,832 \mathrm{~cm}^{3}\right)$ of Cor-Tuf (baseline condition).

\begin{tabular}{|c|c|}
\hline Constituent & Quantity \\
\hline Water & $1.03 \mathrm{lb}(467 \mathrm{~g})$ \\
\hline Fibers & $1.54 \mathrm{lb}(699 \mathrm{~g})$ \\
\hline Admixture & $35.3 \mathrm{~mL}$ \\
\hline Cement & $4.92 \mathrm{lb}(2,232 \mathrm{~g})$ \\
\hline Silica Fume & $1.92 \mathrm{lb}(871 \mathrm{~g})$ \\
\hline Silica Flour & $1.36 \mathrm{lb}(617 \mathrm{~g})$ \\
\hline Sand & $4.77 \mathrm{lb}(2,164 \mathrm{~g})$ \\
\hline
\end{tabular}

Dry materials (cement, silica fume, silica flour, and sand) were weighed individually by using a digital scale then placed together into a plastic bucket and lid. Fibers were batched separately into a bowl, and admixture was poured into a graduated cylinder. Water was batched into two containers, one containing 80 percent of the water needed and another containing 20 percent of the water needed.

Once all materials were batched, the cement, silica fume, silica flour, sand, and 80 percent of the water required were poured into a tabletop mixer with paddle attachment set to a low speed (Figure 1a). Most specimens were mixed in a Hobart HL200, whereas a few specimens were mixed in a Hobart N50 5-quart mixer. Once cement, silica fume, silica flour, and 80 percent of the water were blended together, the admixture was added with the remaining 20 percent of water, which is used to rinse the graduated cylinder to ensure all admixture is incorporated (Figure 1b). These materials were then mixed for 10-15 min or until the mixture was "broken over" (reached a fluid self-consolidating consistency). The mixing bowl edges were periodically scraped (before and after mixture breaking) to ensure complete mixing. Once the mix reached a good fluidity, fibers were slowly added. Once fibers were well dispersed, mixing was completed. A total mixing time of about 20 min was typical (Figure 1c). 
Figure 1. (a) Mixing dry materials and water, (b) adding admixture, (c) finished mixture, (d) vibration table, (e) specimens in curing room, (f) specimens in water bath, (g) end grinding, and $(\mathrm{h})$ shelved specimens awaiting testing.
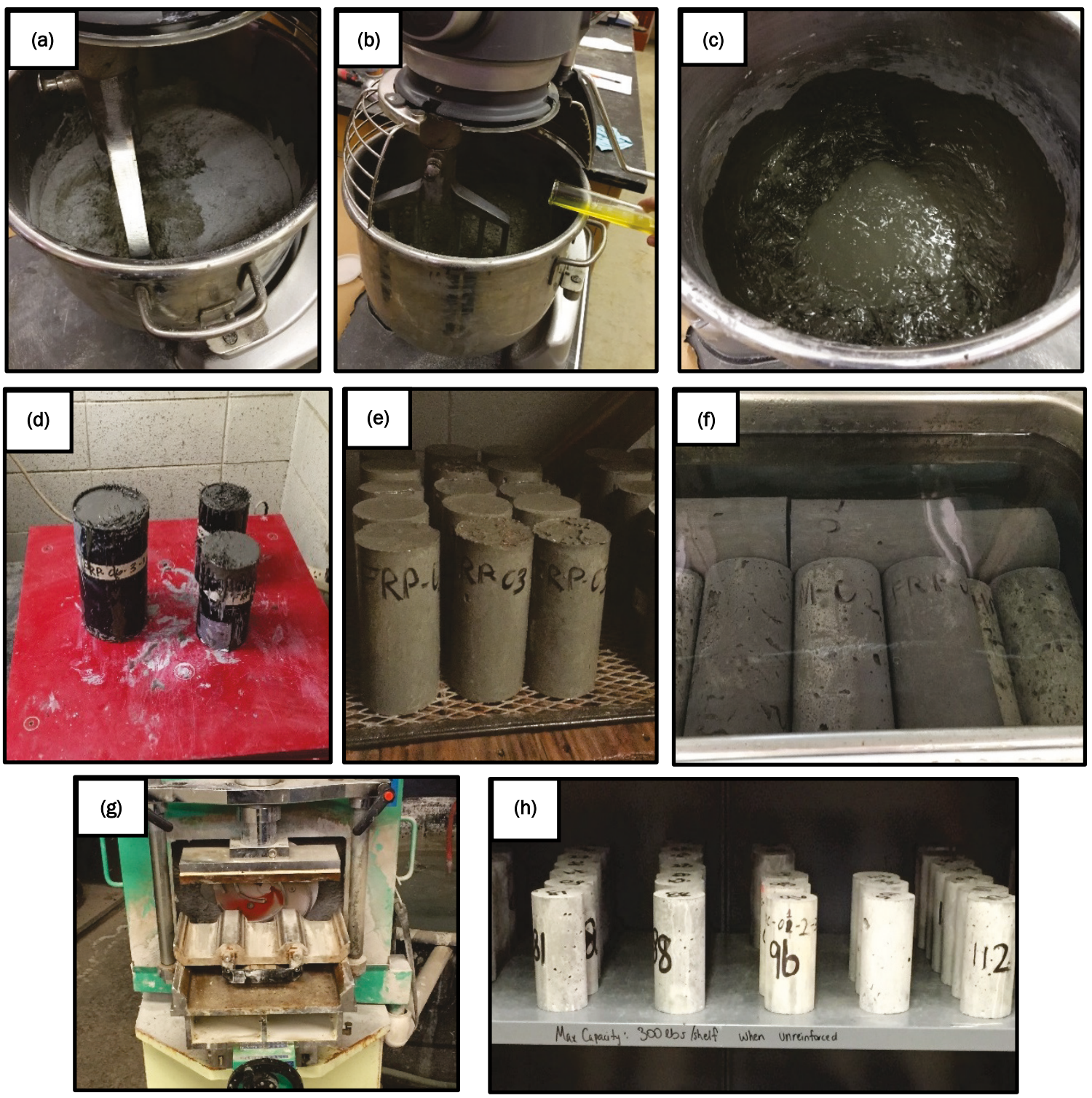

The mixture was then placed into plastic cylinder molds (2- by 4-, 3- by 6-, or 4-in. diam by 8-in. height) in two approximately equal lifts. A lift was placed, tapped around the perimeter to consolidate the mixture and remove entrapped air, and then vibrated. A vibrating table was used due to the presence of fibers, as rodding can affect fiber alignment and distribution. Vibration occurred for 1 to $2 \mathrm{~min}$ to remove the remaining air after tapping (Figure 1d). Once produced, specimens were stored in plastic molds with surfaces covered on a lab bench at ambient temperature for 24 to $30 \mathrm{hr}$ prior to removal from molds via air pressure. 
After mold removal, curing was performed with two methods: (1) a 100 percent humidity room nominally maintained at 70 to $77^{\circ} \mathrm{F}\left(21^{\circ} \mathrm{C}\right.$ to $\left.25^{\circ} \mathrm{C}\right)$ (Figure 1e) and (2) water baths nominally maintained at 80 or $90^{\circ} \mathrm{C}$ (Figure 1f). Water bath curing was used to replicate steam curing (i.e., placing specimens under a steam blanket and using a steam generator), as past experience at ERDC has shown submersion in $90^{\circ} \mathrm{C}$ water reasonably represents steam curing. Hydrated lime was not used during curing. Specimens were exposed to one of the four curing protocols, listed in the following paragraphs, prior to testing.

- Curing protocol $1\left(791^{\circ} \mathrm{C}-\mathrm{d}\right)$ : After being removed from the molds, specimens were placed in the curing room for six days ( $144 \mathrm{hr}$ ). Thereafter, specimens were placed in a water bath for 7 days (168 hr). Timing began when the specimens were placed in the bath, as it took only around $2 \mathrm{hr}$ for the water to heat to the nominal temperature. The water bath started at room temperature and was then heated to a nominal $90^{\circ} \mathrm{C}$ to avoid thermal shock. At the conclusion of water bath curing, the bath was turned off, and the specimens were allowed to cool to ambient temperature while in the water. Once the water was at room temperature, the specimens were shelved to dry. A total of just over 14 days is required for this protocol. This protocol is usually referred to hereafter as $791^{\circ} \mathrm{C}$-days or $791^{\circ} \mathrm{C}$-d. A fairly approximate application of the ASTM C 1074 (ASTM International 2011a) maturity concept was used to calculate the ${ }^{\circ} \mathrm{C}$-days for all curing protocols. The nominal laboratory bench and 100 percent humidity curing room temperature were taken as $23^{\circ} \mathrm{C}$, and the water bath temperature was taken as $90^{\circ} \mathrm{C}$ (both approximate, but reasonable). As such, $23^{\circ} \mathrm{C} * 7$ days plus $90^{\circ} \mathrm{C} * 7$ days is $791^{\circ} \mathrm{C}-\mathrm{d}$.

- Curing protocol $2\left(721^{\circ} \mathrm{C}-\mathrm{d}\right)$ : After being removed from molds, specimens were placed in the curing room for 6 days (144 hr). After 6 days, the specimens were placed in a water bath for 7 days $(168 \mathrm{hr})$. Timing began when the specimens were placed in the bath, as it took around $2 \mathrm{hr}$ for the water to heat to the nominal temperature. The water bath started at room temperature and was then heated to a nominal $80^{\circ} \mathrm{C}$ to avoid thermal shock. After 7 days, the specimens were cooled back to room temperature and shelved to dry. A total of just over 14 days was required for this protocol. The amount of curing for this protocol was approximated as $23^{\circ} \mathrm{C} * 7$ days plus $80^{\circ} \mathrm{C} * 7$ days $=$ $721^{\circ} \mathrm{C}-\mathrm{d}$. 
- Curing protocol $3\left(801^{\circ} \mathrm{C}-\mathrm{d}\right)$ : After being removed from molds, specimens were placed in the curing room for 6 days (144 hr). After 6 days, the specimens were placed in a water bath for 8 days (168 hr). Timing began when the specimens were placed in the bath, as it took only around $2 \mathrm{hr}$ for the water to heat to the nominal temperature. The water bath started at room temperature and was then heated to a nominal $80^{\circ} \mathrm{C}$ to avoid thermal shock. After 8 days, the specimens were cooled back to room temperature and shelved to dry. A total of just over 15 days was required for this protocol. The amount of curing for this protocol was approximated as $23^{\circ} \mathrm{C} * 7$ days plus $80^{\circ} \mathrm{C} * 8$ days $=$ $801^{\circ} \mathrm{C}-\mathrm{d}$.

- Curing protocol $4\left(2,783^{\circ} \mathrm{C}-\mathrm{d}\right)$ : After mold removal, specimens were placed in the 100 percent humidity curing room for 120 days. After 120 days, the specimens were removed from the curing room and shelved to dry. The amount of curing for this protocol was approximated as $23^{\circ} \mathrm{C} * 121$ days $=2,783^{\circ} \mathrm{C}$-d.

After specimens were cured and air dried for several days, they were transported to ERDC to have their ends ground to meet ASTM C39 (ASTM International 2016b) standards (Figure 1g). Once ground, mass, average diameter, and average height were measured for each specimen prior to storage ahead of mechanical property testing (Figure $1 \mathrm{~h}$ ).

\subsection{Mixtures tested}

Ten mixtures were produced and tested as described in Table 4. One of these mixtures was Cor-Tuf UHPC (mixture 1), while the remaining nine mixtures were subcategories of $\mathrm{CP}, \mathrm{M}$, and FRP with varying proportions. Table 4 shows the constituents and batch quantities that make up each mixture produced. In CP, M, and FRP, the constituents and batch quantities were selected to produce $0.1 \mathrm{ft} 3$ batches while maintaining desired $\mathrm{w} / \mathrm{cm}, \mathrm{fa} / \mathrm{cm}$, and/or $\mathrm{f} / \mathrm{cm}$ ratios.

UHPC (mixture 1) was used largely as a control and frame of reference for the other categories (CP, M, and FRP). Two types of UHPC specimens were evaluated herein. The first was laboratory molded, as described in Section 2.2, and is referred to hereafter as UHPC-Base or simply as UHPC. The second type of UHPC specimen came from cores taken from a tub cast at ERDC during the work of Scott et al. (2015). Figure 2 shows the process of coring 12 specimens from this tub, nine of which were 3- by 6-in. specimens and three of which were 4 - by 8 -in. specimens. The average 
density of these specimens was $2.52 \mathrm{~g} / \mathrm{cm}^{3}$ and ranged from $2.51 \mathrm{~g} / \mathrm{cm}^{3}$ to $2.54 \mathrm{~g} / \mathrm{cm}^{3}$. Three of the 3 - by 6 -in. cores were tested for compressive strength (elastic modulus was measured in two cases), while the remaining 9 specimens were tested for tensile strength. These cores were not cured beyond what they had already experienced upon arrival at MSU and what would occur in laboratory temperature and humidity conditions. The exact curing history of the tub was unknown.

Table 4. Batch proportions and identifiers for mixtures tested.

\begin{tabular}{|c|c|c|c|c|c|c|c|c|c|c|c|}
\hline \multirow{2}{*}{ Mixture } & \multirow[b]{2}{*}{ Identifier } & \multicolumn{3}{|c|}{ Proportioning ratios } & \multicolumn{7}{|c|}{ Batching quantities for $0.1 \mathrm{ft}^{3}\left(2,832 \mathrm{~cm}^{3}\right)$} \\
\hline & & $\mathrm{w} / \mathrm{cm}$ & $\mathrm{fa} / \mathrm{cm}$ & $\mathrm{f} / \mathrm{cm}$ & $\begin{array}{l}\text { Water } \\
\text { (g) }\end{array}$ & $\begin{array}{l}\text { Fibers } \\
\text { (g) }\end{array}$ & $\begin{array}{l}\text { Admixture } \\
(\mathrm{ml})\end{array}$ & $\begin{array}{l}\text { Cement } \\
\text { (g) }\end{array}$ & $\begin{array}{c}\text { Silica } \\
\text { fume } \\
\text { (g) }\end{array}$ & $\begin{array}{l}\text { Silica } \\
\text { flour } \\
\text { (g) }\end{array}$ & $\begin{array}{c}\text { Sand } \\
\text { (g) }\end{array}$ \\
\hline 1 & $\begin{array}{l}\text { UHPC- } \\
\text { base }\end{array}$ & 0.15 & 0.71 & 0.23 & 467 & 699 & 35 & 2,232 & 871 & 617 & 2,164 \\
\hline 1 & $\begin{array}{l}\text { UHPC- } \\
\text { core }\end{array}$ & 0.15 & 0.71 & 0.23 & -- & -- & --- & --- & -- & -- & --- \\
\hline 2 & CP-0.11 & 0.11 & 0.00 & 0.00 & 701 & --- & 71 & 4,463 & 1,742 & --- & -- \\
\hline 3 & CP-0.15 & 0.15 & 0.00 & 0.00 & 934 & --- & 71 & 4,463 & 1,742 & --- & --- \\
\hline 4 & CP-0.26 & 0.26 & 0.00 & 0.00 & 1,168 & --- & 71 & 4,463 & 1,742 & --- & --- \\
\hline 5 & $\mathrm{M}-0.47$ & 0.15 & 0.47 & 0.00 & 619 & --- & 47 & 2,957 & 1,154 & 817 & 1,125 \\
\hline 6 & $\mathrm{M}-0.56$ & 0.15 & 0.56 & 0.00 & 619 & --- & 47 & 2,957 & 1,154 & 817 & 1,500 \\
\hline 7 & M-0.65 & 0.15 & 0.65 & 0.00 & 619 & --- & 47 & 2,957 & 1,154 & 817 & 1,875 \\
\hline 8 & FRP-0.11 & 0.15 & 0.00 & 0.11 & 771 & 577 & 58 & 3,682 & 1,437 & --- & --- \\
\hline 9 & FRP-0.17 & 0.15 & 0.00 & 0.17 & 771 & 864 & 58 & 3,682 & 1,437 & --- & -- \\
\hline 10 & FRP-0.23 & 0.15 & 0.00 & 0.23 & 771 & 1,153 & 58 & 3,682 & 1,437 & --- & --- \\
\hline
\end{tabular}

-Water (w) was the batched amount.

--Note: all specimens were lab molded except for UHPC-Core.

--Note: batching data were not documented for UHPC-Core, but were assumed comparable to UHPC-base.

Figure 2. UHPC tub provided by ERDC (a) before, (b) during, and (c) after coring.
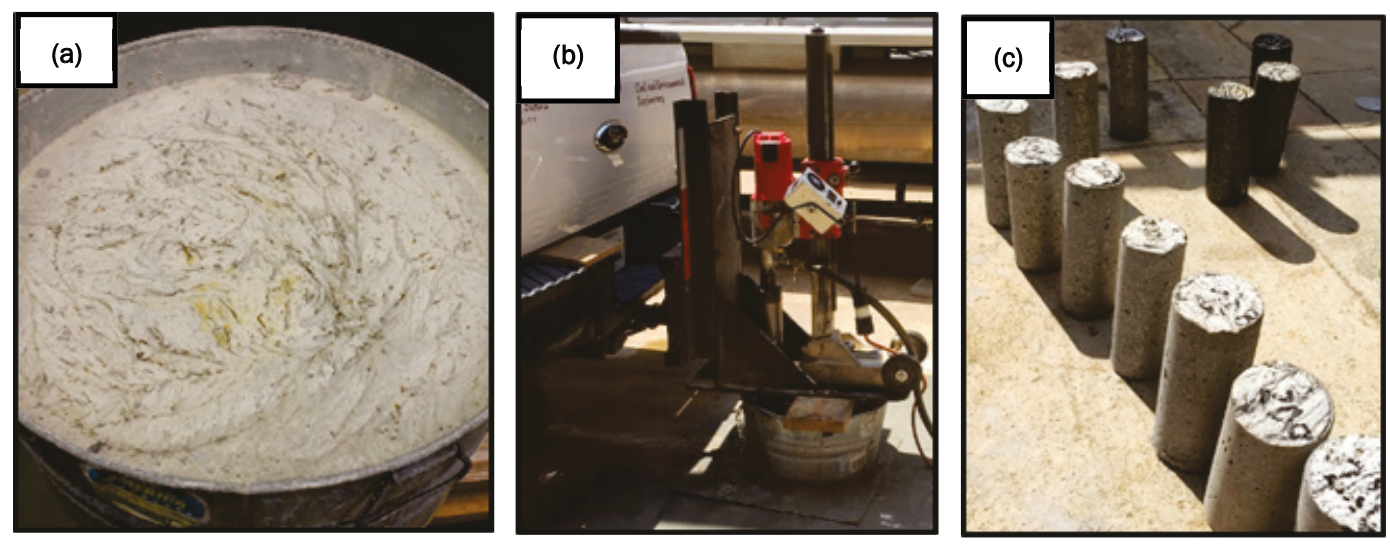

The rationale behind mixtures 2 to 10 was to vary constituent materials among categories (CP, M, and FRP) and then to vary relative proportions of constituent materials within categories (e.g., vary w/cm for $\mathrm{CP}$ or $\mathrm{f} / \mathrm{cm}$ 
for FRP). Having a suite of test results where constituents and relative proportions were varied with subsequent exposure to varied curing conditions provides a pool of mechanical properties that can be used for multi-scale modeling purposes in subsequent efforts. For CP, the water-tocementitious material $(\mathrm{w} / \mathrm{cm})$ ratio bracketed UHPC. For M, the fine aggregate to cementitious material $(\mathrm{fa} / \mathrm{cm})$ ratio was progressively lowered below that of UHPC. For FRP, the fiber-to-cementitious material $(\mathrm{f} / \mathrm{cm})$ ratio began at the UHPC level and was progressively lowered.

\subsection{Mechanical property test methods}

Mechanical property testing measured compressive strength (fc), tensile strength (St), elastic modulus (E), Poisson's ratio (v), and load (P) versus strain $(\varepsilon)$ relationships for instrumented specimens. Mechanical property testing was performed with a Forney compression machine having a 6oo-kip capacity at the Construction Materials Research Center (CMRC) at Mississippi State University (MSU).

\subsubsection{Compressive strength testing (non-instrumented)}

Compressive strength was measured according to ASTM C39 (ASTM International 2016b) as shown in Figure 3. Specimens with ground ends were placed directly into the compression machine absent pad caps, (i.e., the concrete was directly in contact with metal on both surfaces). The load at failure was divided by the original cross-sectional area to determine the compressive strength (fc). Testing time ranged from approximately 10 to 30 min, depending on specimen strength. ASTM C39's allowable load rate is 28 to $42 \mathrm{psi} / \mathrm{sec}$, which for the tested 3-in.-diam specimens equates to a load rate of 12 to $17.5 \mathrm{kips} / \mathrm{min}$. As shown in Figure 3, this load rate was successfully verified. 
Figure 3. Representative compressive strength test.
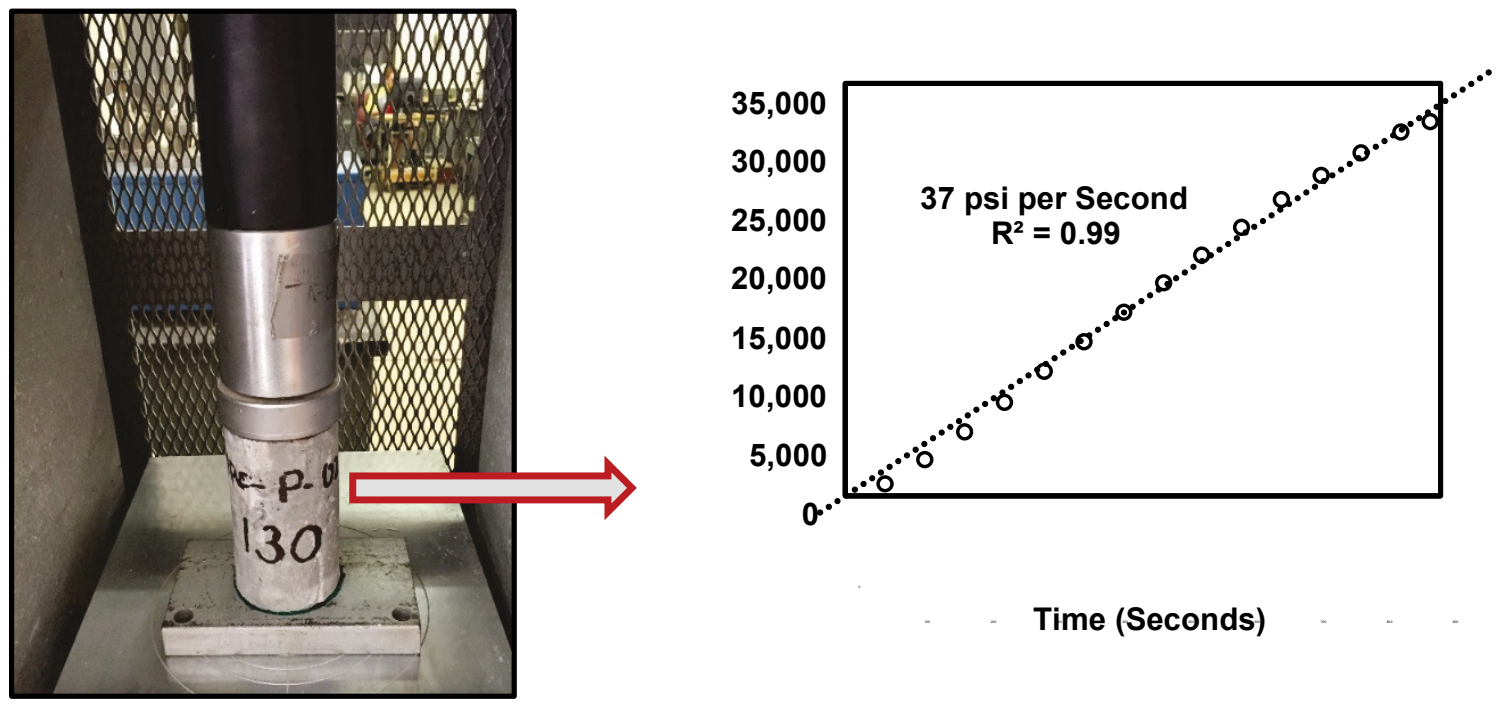

\subsubsection{Elastic modulus testing (non-instrumented)}

Elastic modulus was found for specimens with ends ground according to ASTM C469 (ASTM International 2014). Specimens were placed into the compression machine fitted with a compressometer (Figure 4). The compressometer recorded specimen elastic deformation with respect to applied load. By using Equation 1, the recorded deformation was able to be converted to strain.

$$
\varepsilon=\frac{\left(d_{d i a l}\right)(0.0001)}{8}
$$

where

$$
\begin{aligned}
\varepsilon & =\text { strain experienced by the specimen } \\
\mathrm{d}_{\text {dial }} & =\text { displacement as taken from the dial during testing }
\end{aligned}
$$

The load was then divided by the original cross-sectional area of the specimen to obtain stress. Elastic modulus was taken as the slope of the linear portion of the stress-strain curve and is denoted $\mathrm{E}_{469}$ herein to associate this measurement with ASTM C469 (ASTM International 2014) and differentiate this value from elastic modulus (E) measured from other methods. Elastic modulus testing via $\mathrm{C} 469$ took about $45 \mathrm{~min}$ per specimen to complete. 
Figure 4. Representative elastic modulus testing.

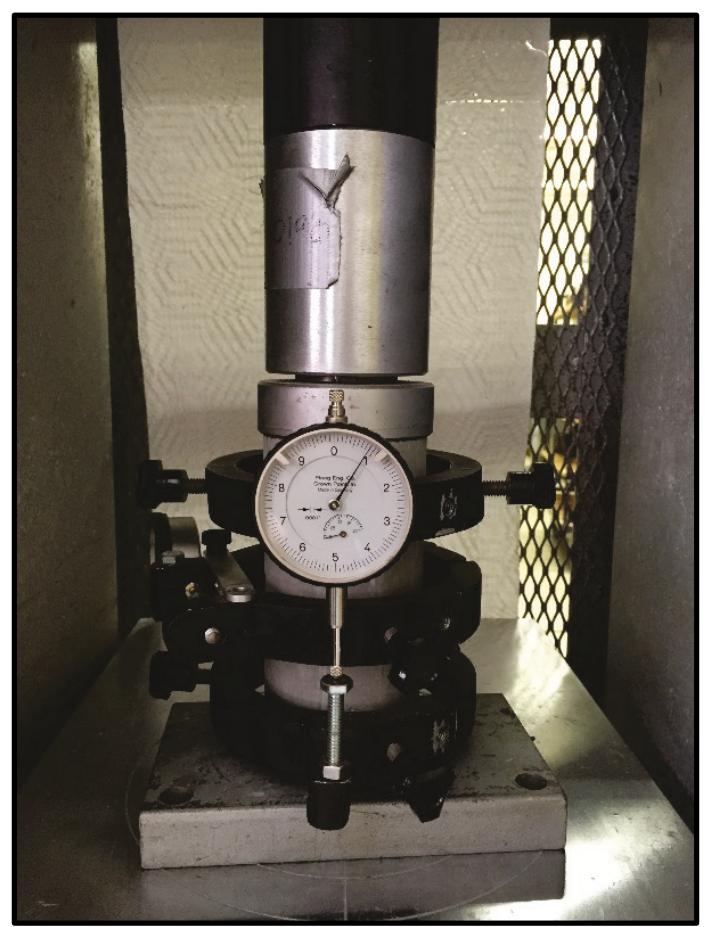

\subsubsection{Tensile strength testing (non-instrumented)}

Tensile strength was measured on specimens according to ASTM C496 (ASTM International 2011b; Figure 5). The specimens were placed on their sides and had two bearing strips (1/8-in.-thick plywood) placed between the machine and the specimen (i.e., there was always a barrier of wood between the specimen and the metal surfaces on the top and bottom). These thin pieces of wood helped distribute the applied load uniformly throughout the specimen. The maximum applied load was recorded and used to find tensile strength by using Equation 2. Since the load rate for this test was $3.3 \mathrm{psi} / \mathrm{sec}$ or less, experiments ranged from approximately 30 to $120 \mathrm{~min}$, depending on the specimen.

$$
\mathrm{St}=\frac{2 P}{\pi l D}
$$

where

$$
\begin{aligned}
\mathrm{St} & =\text { splitting tensile strength }(\mathrm{MPa}) \\
\mathrm{P} & =\text { maximum applied load }(\mathrm{N}) \\
\mathrm{l} & =\text { length of the specimen }(\mathrm{mm}) \\
\mathrm{D} & =\text { diameter of the specimen }(\mathrm{mm})
\end{aligned}
$$


Figure 5. Representative tensile testing.

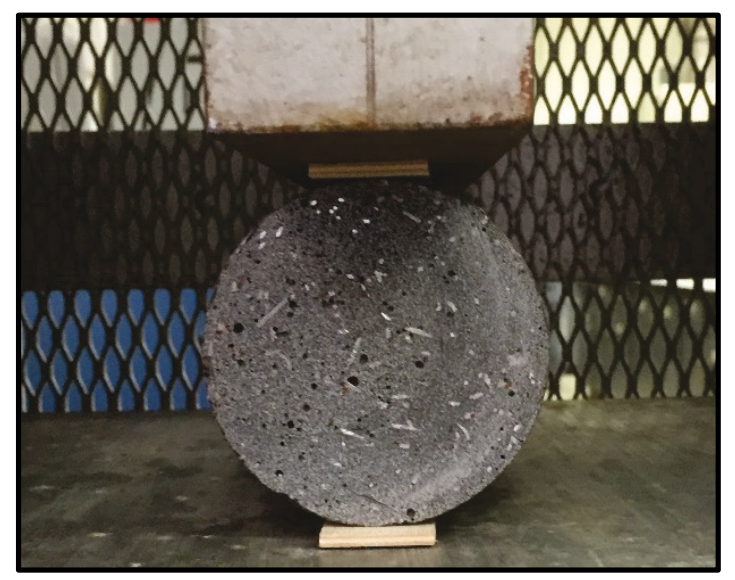

\subsubsection{Compressive and tensile testing instrumented with strain gages}

Foil strain gages (SG) are a versatile method for measuring responses that can be used for numerical modeling purposes. Example applications range from strain measurement on materials much less stiff than concrete, such as geogrids and geotextiles (Warren et al. 2010), to materials besides concrete with stiffnesses on the order of concrete, such as fiber reinforced polymers (Howard and GangaRao 2009), to materials stiffer than concrete, such as metal (Rushing et al. 2016).

Vishay Micro-Measurements $350 \Omega$ general purpose gages (C2A-06-125Lw-350 and C2A-06-250LW-350) were attached to specimens using MBond 200 glue and catalyst following instructions given by Vishay. The strain gages were then connected to a National Instruments NI CompaqDaq 9172 chassis and NI 9237 I/O modules that recorded all of the data collected from the gages at a rate of slightly less than $5 \mathrm{~Hz}$ by using a program written in LabVIEW. Instrumented specimens were tested in compression, and additional instrumented specimens were tested in tension (Figure 6). Appendix A provides drawings of strain gage locations, where strain gages are denoted SG-o through SG-3. Elastic modulus was also found locally by using strain gages and is reported in Section 3.4 as EsG-o through EsG-3. 
Figure 6. (a) Compressive testing, (b) elastic modulus testing, and (c) tension testing with strain gages.

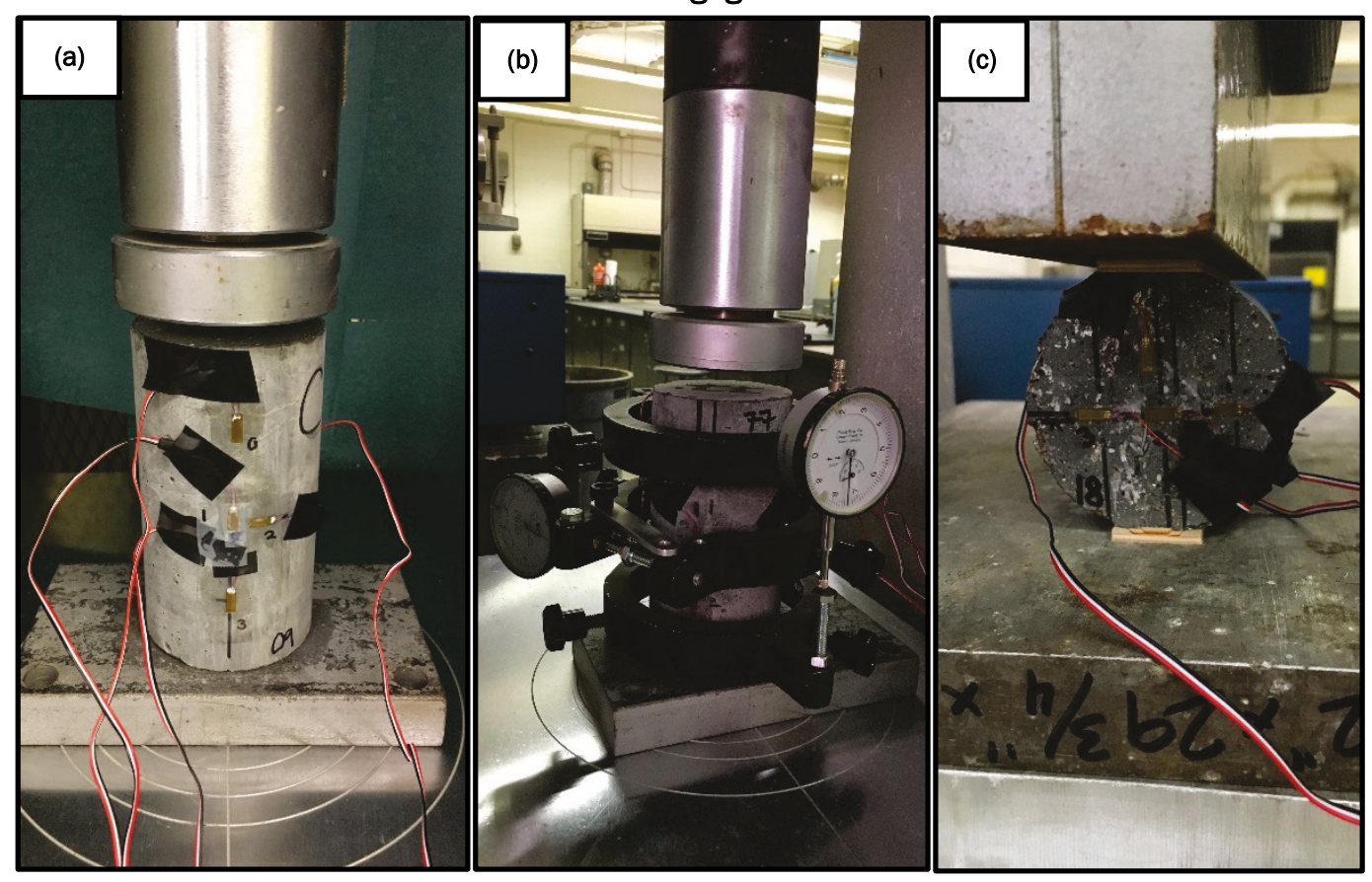

\subsection{Volume fractions}

\subsubsection{As-batched volume estimations}

Volume fractions were estimated by way of batch quantities and constituent material specific gravity values. To find these volumetric estimations, two critical assumptions were necessary. The first assumption was that the aggregates used do not absorb water. This is reasonable considering the fine aggregates used have less than 0.25 percent water absorption, based on past tests conducted by ERDC on these materials. The second assumption was that the amount of water batched remained constant until the specimen was tested. It is important to note that the volume fractions calculated from as-produced densities and as-batched quantities are estimates and do not account for volume change during hydration, nor do they provide any information on distribution and size of air voids. All of the batching masses for each constituent were recorded as well as the final weight of each specimen. From the batching masses, the mass percentage of the constituents was found for each specimen by using Equation 3.

$$
m_{b-p e r}=\frac{m_{c o n}}{m_{b-t o t}}
$$


where

$\mathrm{m}_{\text {con }}=$ mass of the constituent in grams

$\mathrm{mb}_{\mathrm{b} \text { tot }}=$ total mass of the batch in grams

$\mathrm{m}_{\mathrm{b}-\mathrm{per}}=$ batching mass percentage of constituent as a percent

This percentage was multiplied by the weight of each specimen to get the ideal weight of each constituent in each specimen shown in Equation 4.

$$
m_{\text {con-spec }}=\left(m_{b-p e r}\right)\left(m_{\text {spec }}\right)
$$

where

$\mathrm{m}_{\mathrm{b}-\mathrm{per}}=$ batching mass percentage of constituent as a percent

$\mathrm{m}_{\text {spec }}=$ total mass of the specimen in grams

$\mathrm{m}_{\text {con-spec }}=$ mass of each constituent in the specimen in grams

These masses were then divided by their specific gravity and then summed to find a specimen volume with no air, shown in Equation 5 .

$$
V_{\text {noair }}=\sum \frac{m_{\text {con-spec }}}{\gamma}
$$

where

$\mathrm{m}_{\text {con-spec }}=$ mass of each constituent in the specimen in grams

$\gamma=$ specific gravity of the constituent

$\mathrm{V}_{\text {noair }}=$ volume of the specimen if there was no air in $\mathrm{g} / \mathrm{cm}^{3}$

The volume of air $\left(\mathrm{V}_{\mathrm{a}}\right)$ was then found by finding the difference between the laboratory recorded volume of the specimen (found by taking average heights, diameters, and masses) and the ideal volume of the specimen with no air $\left(V_{\text {noair }}\right)$. $V_{\text {noair }}$ is the sum of cement volume $\left(V_{c}\right)$, silica fume volume $\left(V_{\text {sf }}\right)$, silica flour volume $\left(V_{\text {sfl }}\right)$, sand volume $\left(V_{s}\right)$, water volume $\left(V_{w}\right)$, fibers volume $\left(\mathrm{V}_{\mathrm{f}}\right)$, and admixture volume $\left(\mathrm{V}_{\mathrm{am}}\right)$. Each of these volumes was determined with its corresponding $m_{\text {con-spec }}$ and specific gravity.

\subsubsection{Volume fractions from imaging techniques}

Some specimens were used for an imaging analysis to estimate volume fractions. These volume fractions were found by taking pictures of the specimens then using the programs ImageJ and Abaqus to find volume fractions. Lower magnification images were taken using a ZEISS Axiovert 200 optical microscope at the Center for Advanced Vehicular Systems 
(CAVS) at Mississippi State University. A scanning electron microscope model SUPRA 40 FEG-SEM, also at CAVS, was used to take higher magnification images. The surfaces of the specimens were ground smooth before imaging to ensure quality pictures. The combination of the low and high magnification microscopes allowed for images to be taken at varying length scales to capture the size distributions of each constituent.

The image processing tool, ImageJ, was used for analyzing images (Schneider et al. 2012). This software was utilized to identify, isolate, and measure constituents (Figure 7). These results allowed for the determination of the average size, number density, area fraction, and nearest neighbor distance of each constituent. Image J was used on multiple images at varying length scales to ensure accurate results were found for each of the constituents.

Figure 7. ImageJ process for turning (a) scanning electron microscope images to a (b) binary image and then (c) isolating inclusions
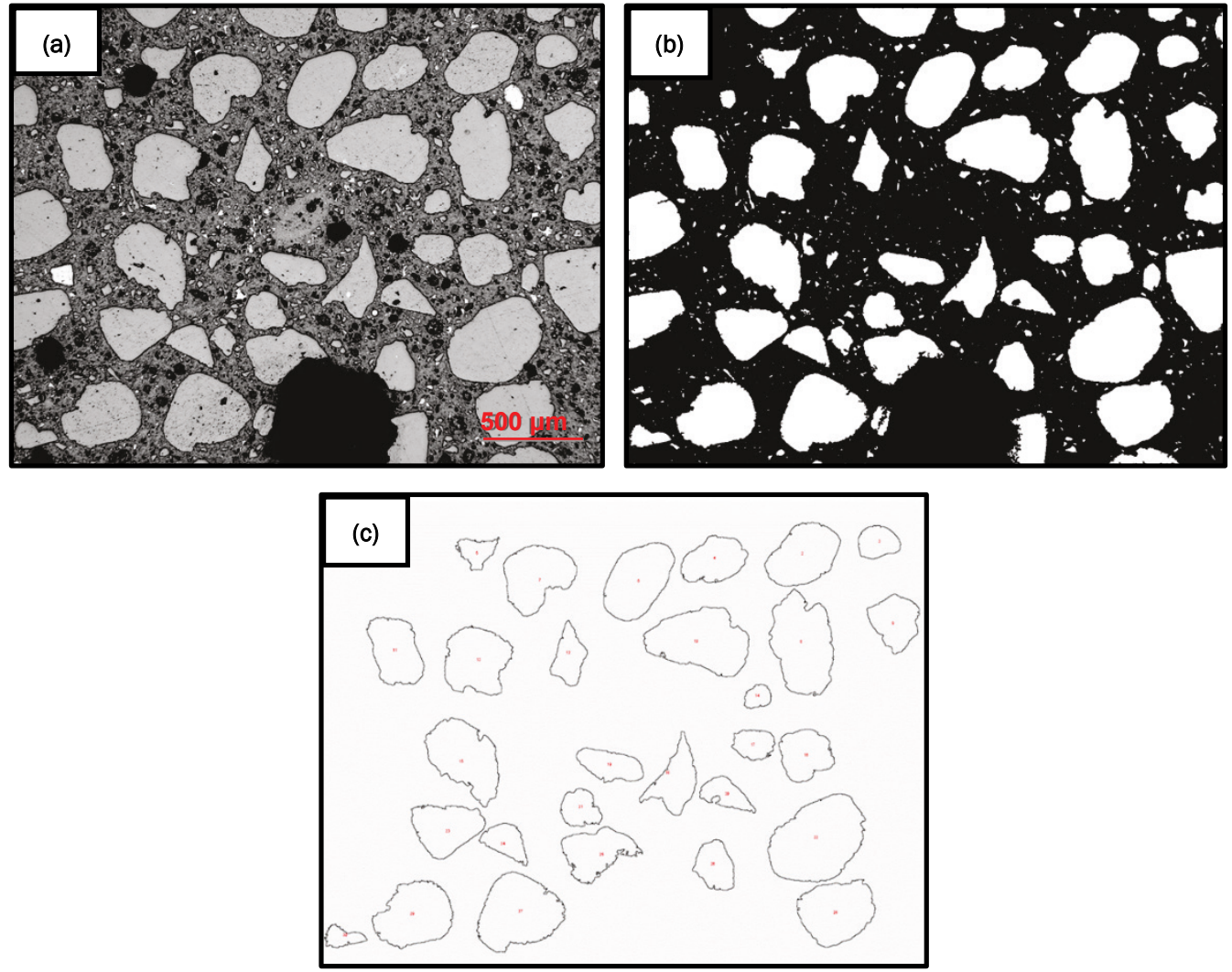

The finite element software Abaqus was used to generate representative volume element (RVE) cubes to portray UHPC (Abaqus 2014). It was determined that three length scales would aid modeling of UHPC mesoscale characteristics, as there were such differences in the size of 
constituents. The largest cube had sides of $35 \mathrm{~mm}$, and it included only steel fibers within the matrix. The middle length scale included large voids and silica sand grains and had sides of $0.54 \mathrm{~mm}$. The smallest length scale was a cube with sides of $0.04 \mathrm{~mm}$, and it included small voids and unhydrated cement grains.

To best portray the material, inclusions were randomly distributed throughout the matrix according to their measured distributions. Results from ImageJ gave an area fraction, while Abaqus required a volume fraction for geometry generation. The average size of each inclusion type was assumed to be the area of a circle, and the average radius was found. For the geometry generation, the area fraction was assumed to be the same as the volume fraction, and the average radius size was used to create spheres and cylinders.

A python script was written to generate these RVE cubes. This script required inputs for average inclusion size (found using ImageJ), and inclusions of that size were inserted into the matrix until the desired volume fraction was reached. Plots of constituent size versus number of occurrences revealed that using only the average constituent size left out the range of inclusion sizes found in UHPC. The size versus number of occurrences graph was fitted with a distribution curve, and a second script was created that required the mean and variance of this fitted curve. The inclusions inserted into the matrix by this second code were of sizes that varied according to the distribution curve.

Both random generation codes required the size of the cube, as well as the number, shape, and volume fraction of each constituent. Two shapes, spheres and cylinders, were used in modeling the inclusions in subsequent simulations. Spheres were used to model the voids, unhydrated cement grains, and sand grains; cylinders were used to model the steel fibers. The algorithms then randomly inserted and distributed these shapes, making sure none overlapped. Figure 8 represents the RVE generations. 
Figure 8. Geometries generated using the area fractions and length scales found through image analysis.

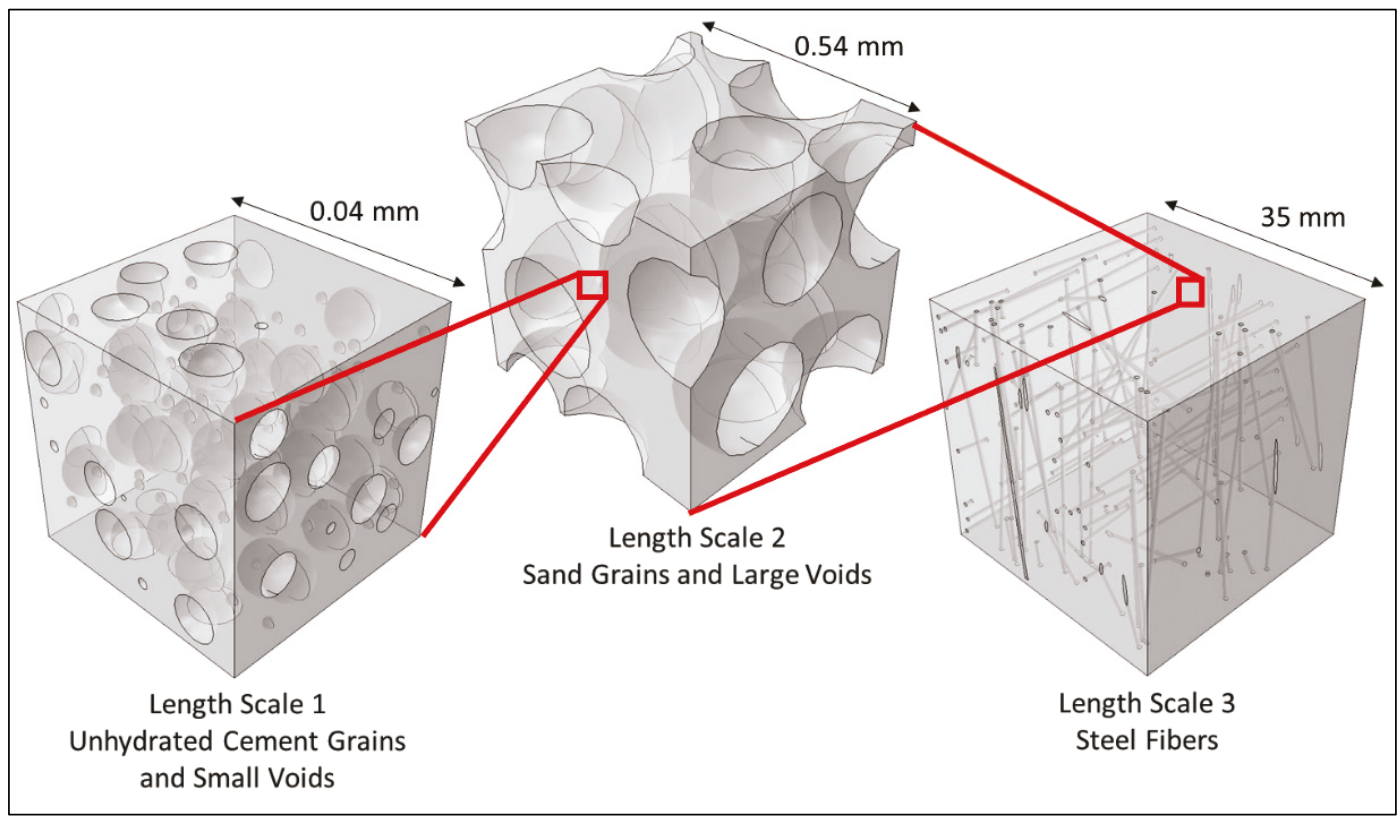

The Phoenix X-Ray Computed Topography (CT) system with dual focus, reaching one-micron resolution, located at CAVS, was used for 3-D imaging. CT scans were conducted on a UHPC cube with sides of approximately $50 \mathrm{~mm}$. The CT scan distinguished the larger constituents, large voids, and steel fibers, helping to determine the 3 -D characteristics of UHPC.

\subsection{Test matrix}

Table 5 is the test matrix for the 254 specimens produced and tested for this report. This matrix evaluated specimens of the four consistent categories (UHPC, CP, M, and FRP) at different specimen sizes ( 2 by 4 to 4 by 8 ) and after different amounts of curing ( 721 to $2,783^{\circ} \mathrm{C}-\mathrm{d}$ ) for mechanical properties and/or volume fractions. Eight of the mechanical property specimens were instrumented with strain gages, and several of the compression specimens were fitted with a compressometer for elastic modulus determination. Volume fractions were measured by imaging on the five specimens shown in Table 5 and were also estimated on the mechanical property specimens by way of mass proportions and specific gravities. 
Table 5. Testing matrix

\begin{tabular}{|c|c|c|c|c|c|}
\hline \multirow[b]{2}{*}{ Mix } & \multirow[b]{2}{*}{ Curing } & \multirow[b]{2}{*}{ Size } & \multicolumn{2}{|c|}{$\begin{array}{c}\text { Mechanical } \\
\text { property specimens }\end{array}$} & \multirow{2}{*}{$\begin{array}{r}\begin{array}{r}\text { Volume } \\
\text { fractions }\end{array} \\
\text { Imaging }\end{array}$} \\
\hline & & & Compression & Tension & \\
\hline UHPC & $2,783^{\circ} \mathrm{C}-\mathrm{d}$ & $3 \times 6$ & 6 & 6 & 0 \\
\hline CP-0.151 & $2,783^{\circ} \mathrm{C}-\mathrm{d}$ & $3 \times 6$ & 15 & 3 & 0 \\
\hline CP-0.151 & $2,783^{\circ} \mathrm{C}-\mathrm{d}$ & $2 \times 4$ & 9 & 0 & 0 \\
\hline M-0.56 & $2,783^{\circ} \mathrm{C}-\mathrm{d}$ & $3 \times 6$ & 6 & 3 & 0 \\
\hline FRP-0.232 & $2,783^{\circ} \mathrm{C}-\mathrm{d}$ & $3 \times 6$ & 10 & 11 & 0 \\
\hline FRP-0.232 & $2,783^{\circ} \mathrm{C}-\mathrm{d}$ & $4 \times 8$ & 2 & 3 & 0 \\
\hline UHPC & $791^{\circ} \mathrm{C}-\mathrm{d}$ & $3 \times 6$ & 6 & 3 & 2 \\
\hline CP-0.15 & $791^{\circ} \mathrm{C}-\mathrm{d}$ & $3 \times 6$ & 6 & 3 & 1 \\
\hline CP-0.11 & $791^{\circ} \mathrm{C}-\mathrm{d}$ & $3 \times 6$ & 6 & 3 & 0 \\
\hline CP-0.26 & $791^{\circ} \mathrm{C}-\mathrm{d}$ & $3 \times 6$ & 6 & 3 & 0 \\
\hline M-0.56 & $791^{\circ} \mathrm{C}-\mathrm{d}$ & $3 \times 6$ & 6 & 3 & 1 \\
\hline M-0.47 & $791^{\circ} \mathrm{C}-\mathrm{d}$ & $3 \times 6$ & 6 & 3 & 0 \\
\hline M-0.65 & $791^{\circ} \mathrm{C}-\mathrm{d}$ & $3 \times 6$ & 6 & 3 & 0 \\
\hline FRP-0.23 & $791^{\circ} \mathrm{C}-\mathrm{d}$ & $3 \times 6$ & 6 & 3 & 1 \\
\hline FRP-0.17 & $791^{\circ} \mathrm{C}-\mathrm{d}$ & $3 \times 6$ & 6 & 3 & 0 \\
\hline FRP-0.11 & $791^{\circ} \mathrm{C}-\mathrm{d}$ & $3 \times 6$ & 6 & 3 & 0 \\
\hline UHPC & $721^{\circ} \mathrm{C}-\mathrm{d}$ & $3 \times 6$ & 6 & 3 & 0 \\
\hline CP-0.15 & $721^{\circ} \mathrm{C}-\mathrm{d}$ & $3 \times 6$ & 6 & 3 & 0 \\
\hline M-0.56 & $721^{\circ} \mathrm{C}-\mathrm{d}$ & $3 \times 6$ & 6 & 3 & 0 \\
\hline FRP-0.23 & $721^{\circ} \mathrm{C}-\mathrm{d}$ & $3 \times 6$ & 6 & 3 & 0 \\
\hline $\mathrm{UHPC}^{3}$ & $801^{\circ} \mathrm{C}-\mathrm{d}$ & $3 \times 6$ & 6 & 3 & 0 \\
\hline CP-0.15 & $801^{\circ} \mathrm{C}-\mathrm{d}$ & $3 \times 6$ & 6 & 3 & 0 \\
\hline M-0.56 & $801^{\circ} \mathrm{C}-\mathrm{d}$ & $3 \times 6$ & 6 & 3 & 0 \\
\hline FRP-0.23 & $801^{\circ} \mathrm{C}-d$ & $3 \times 6$ & 6 & 3 & 0 \\
\hline UHPC-Core & Core & $3 \times 6$ & 3 & 6 & 0 \\
\hline UHPC-Core & Core & $4 \times 8$ & 0 & 3 & 0 \\
\hline \multicolumn{3}{|c|}{ All Specimens } & 159 & 89 & 5 \\
\hline
\end{tabular}

1: $2 \times 4$ and $3 \times 6$ specimens were sometimes produced in the same batch for paired comparisons.

2: $3 \times 6$ and $4 \times 8$ specimens were sometimes produced in the same batch for paired comparisons.

3: One additional specimen (shown in Figure 3) was produced for protocol development, but was not included in the data reported in Chapter 3 (i.e., there were 7 compression specimens, but only 6 were included in Chapter 3 ). 


\section{Test Results}

The Table 5 testing matrix was largely divided into behaviors of interest for reporting purposes. Some specimen types had multiple property measurements, and as a result, reporting the data in this manner seemed more logical.

\subsection{Varying proportions}

Of the 254 specimens produced, 90 were tested after $791^{\circ} \mathrm{C}-\mathrm{d}$ curing to assess the effects of varying proportions on fundamental properties; 10 different types of specimens were tested (Table 6). The densities of these specimens ranged from $2.14 \mathrm{~g} / \mathrm{cm}^{3}$ to $2.61 \mathrm{~g} / \mathrm{cm}^{3}$, and all were 3 -in. diam by 6 -in. height. Figures 9 and 10 show side-by-side comparisons of the variations data for compressive and tensile testing.

Table 6. Varying proportions test results.

\begin{tabular}{|c|c|c|c|c|c|c|c|c|c|}
\hline Mix ID & $\begin{array}{c}\text { fc Range } \\
(\mathrm{MPa})\end{array}$ & $\begin{array}{l}\text { fc } \\
\text { coV } \\
(\%)\end{array}$ & $\begin{array}{l}\text { fc Avg. } \\
\text { (MPa) }\end{array}$ & $\begin{array}{c}\text { St } \\
\text { Range } \\
\text { (MPa) }\end{array}$ & $\begin{array}{l}\text { St } \\
\text { COV } \\
(\%)\end{array}$ & $\begin{array}{c}\text { St } \\
\text { Avg. } \\
\text { (MPa) }\end{array}$ & $\begin{array}{c}\text { Density } \\
\text { Range } \\
\left(\mathrm{g} / \mathrm{cm}^{3}\right)\end{array}$ & $\begin{array}{l}\text { Density } \\
\text { COV } \\
(\%)\end{array}$ & $\begin{array}{c}\text { Density } \\
\text { Avg. } \\
\left(\mathrm{g} / \mathrm{cm}^{3}\right)\end{array}$ \\
\hline UHPC & $\begin{array}{c}152.4- \\
203.1\end{array}$ & 12.0 & 175 & $\begin{array}{c}19.5- \\
26.1\end{array}$ & 14.5 & 23 & $\begin{array}{c}2.467- \\
2.608\end{array}$ & 1.6 & 2.52 \\
\hline CP-0.11 & $68.1-141.0$ & 26.4 & 117 & $8.1-10.4$ & 13.6 & 10 & $\begin{array}{c}2.224- \\
2.286\end{array}$ & 0.9 & 2.27 \\
\hline CP-0.15 & $77.7-167.7$ & 24.6 & 117 & $9.7-12.8$ & 14.3 & 12 & $\begin{array}{c}2.230- \\
2.275\end{array}$ & 0.7 & 2.25 \\
\hline CP-0.26 & $81.5-137.8$ & 19.0 & 113 & $3.7-8.9$ & 40.1 & 7 & $\begin{array}{c}2.140- \\
2.183\end{array}$ & 0.7 & 2.17 \\
\hline M-0.47 & $\begin{array}{c}139.8- \\
175.4\end{array}$ & 7.6 & 161 & $7.7-13.7$ & 29.8 & 12 & $\begin{array}{c}2.247- \\
2.297\end{array}$ & 0.8 & 2.26 \\
\hline M-0.56 & $\begin{array}{c}122.2- \\
155.1\end{array}$ & 9.1 & 141 & $9.3-12.9$ & 17.3 & 12 & $\begin{array}{c}2.233- \\
2.314\end{array}$ & 1.1 & 2.27 \\
\hline M-0.65 & $\begin{array}{c}146.0- \\
192.5\end{array}$ & 11.2 & 164 & $9.4-15.3$ & 27.0 & 12 & $\begin{array}{c}2.254- \\
2.292\end{array}$ & 0.6 & 2.27 \\
\hline FRP-0.11 & $93.6-132.0$ & 12.5 & 116 & $19.1-25.1$ & 13.7 & 22 & $\begin{array}{c}2.347- \\
2.412\end{array}$ & 1.0 & 2.39 \\
\hline FRP-0.17 & $\begin{array}{c}109.3- \\
139.9\end{array}$ & 9.3 & 125 & $\begin{array}{c}13.9- \\
26.0\end{array}$ & 30.2 & 21 & $\begin{array}{c}2.436- \\
2.515\end{array}$ & 1.1 & 2.47 \\
\hline FRP-0.23 & $\begin{array}{c}120.7- \\
141.9\end{array}$ & 6.4 & 135 & $\begin{array}{c}26.3- \\
26.6\end{array}$ & 0.5 & 26 & $\begin{array}{c}2.465- \\
2.584\end{array}$ & 1.6 & 2.51 \\
\hline
\end{tabular}

--Note: Averages include 6 fc, 3 St, and 9 densities. 
UHPC had the highest compressive strength, followed by M, FRP, and CP. $\mathrm{CP}$ was not sensitive to $\mathrm{w} / \mathrm{cm}$ ratio changes within the range considered, $\mathrm{M}$ did not respond in a progressive manner as the $\mathrm{fa} / \mathrm{cm}$ ratio was changed, and FRP increased compressive strength as the $\mathrm{f} / \mathrm{cm}$ ratio increased. Several of the results from varying proportions were not intuitive.

FRP with the highest fiber loading produced the highest tensile strength. Overall, UHPC and FRP had comparable tensile strengths. M tensile strength was insensitive to $\mathrm{fa} / \mathrm{cm}$ ratio changes. $\mathrm{CP}$ behaved somewhat erratically in tension and produced the lowest overall strength. Overall, tensile strength behaviors were fairly intuitive.

Figure 9. Average compressive strength for $791^{\circ} \mathrm{C}-\mathrm{d}$ cured specimens.

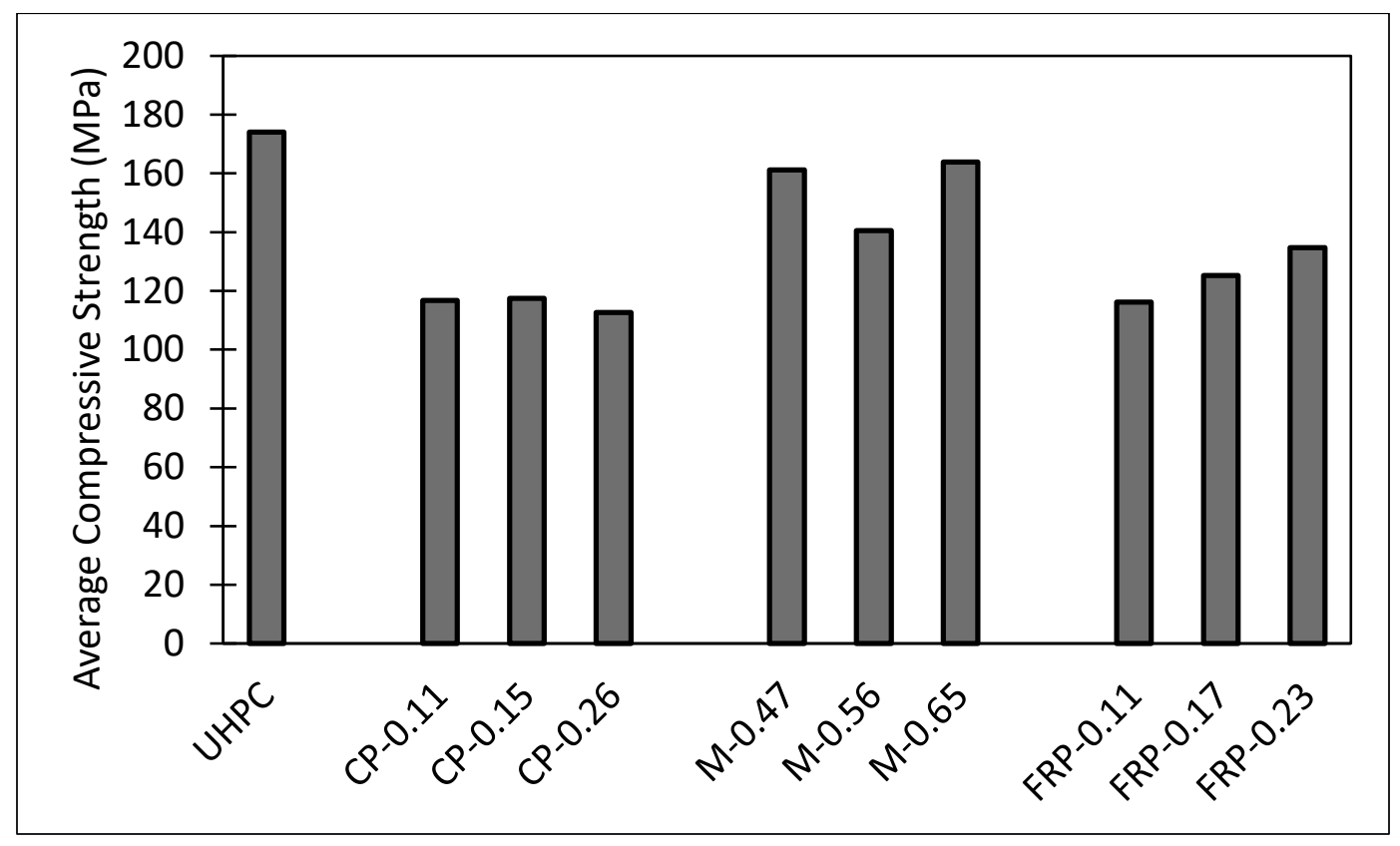


Figure 10. Average tensile strength for $791^{\circ} \mathrm{C}-\mathrm{d}$ cured specimens.

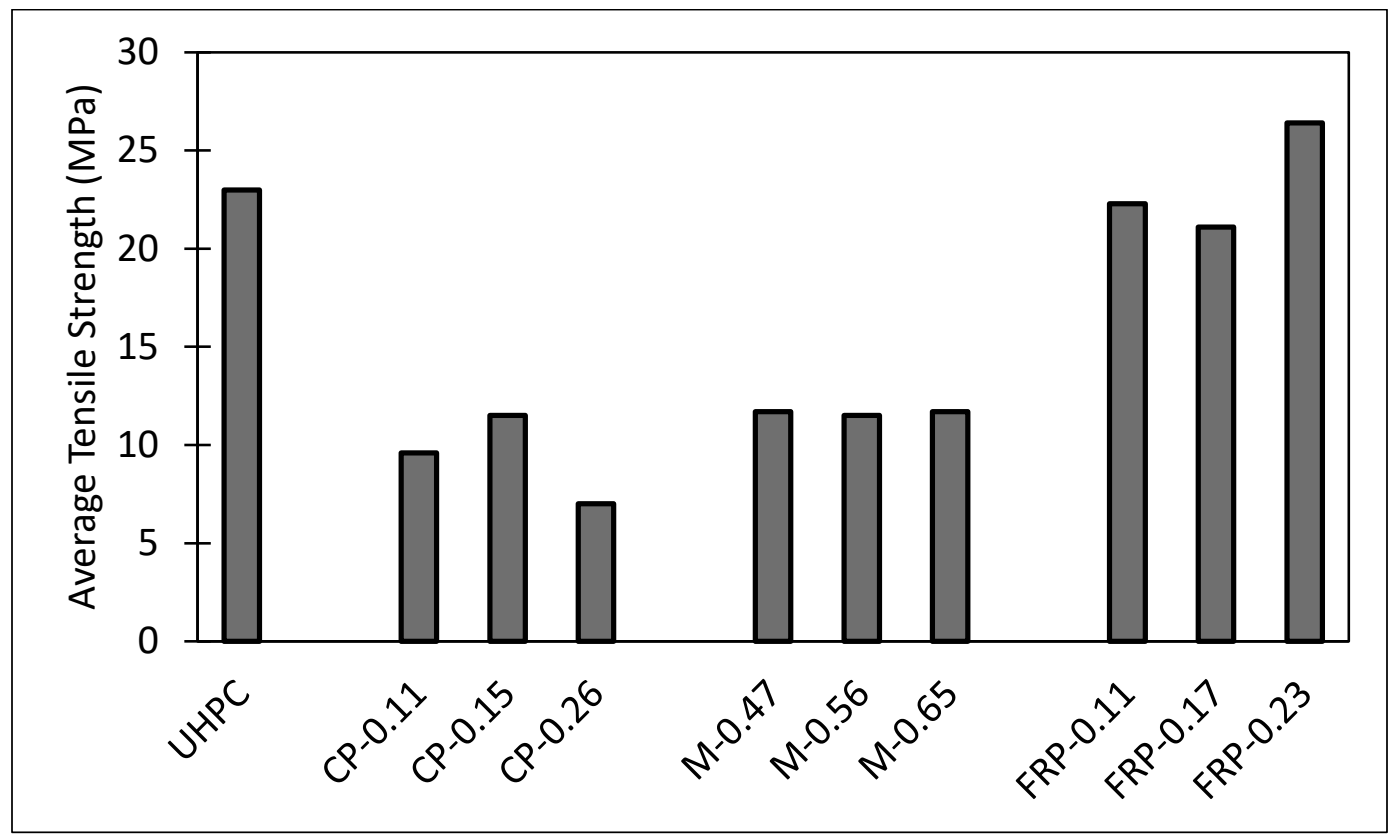

Elastic modulus was also found for specimens that underwent compressive testing in accordance to ASTM C469 (ASTM International 2014). The relationship between elastic modulus and compressive strength is often reported in the form of Equation 6. The constant relating elastic modulus and compressive strength is the parameter of primary interest, and Table 7 reports all $\mathrm{C}_{469}$ findings.

$$
E_{469}=C_{469} \sqrt{f_{c}}
$$

where

$$
\begin{aligned}
\mathrm{E}_{469}= & \text { elastic modulus from ASTM } \mathrm{C} 469(\mathrm{MPa} \text {; ASTM International } \\
& \text { 2014)) } \\
\mathrm{C}_{469}= & \text { constant } \\
\mathrm{f}_{\mathrm{c}}= & \text { compressive strength }(\mathrm{MPa})
\end{aligned}
$$


Table 7. Elastic modulus and ultimate strength constant for varying proportions.

\begin{tabular}{|c|c|c|c|c|c|c|c|}
\hline Mix ID & Curing & E469 Range (MPa) & $\begin{array}{c}\text { Avg. E469 } \\
(\mathrm{MPa})\end{array}$ & $\begin{array}{l}\text { COV } \\
(\%)\end{array}$ & $\begin{array}{c}\mathrm{C}_{469} \\
\text { Range }\end{array}$ & $\begin{array}{r}\text { COV } \\
(\%)\end{array}$ & $\begin{array}{l}\text { C469 } \\
\text { Avg. }\end{array}$ \\
\hline UHPC & $791^{\circ} \mathrm{C}-\mathrm{d}$ & $49,509-49,617$ & 49,600 & 0.1 & $3,848-4,013$ & 3.0 & 3,931 \\
\hline CP-0.15 & $791^{\circ} \mathrm{C}-\mathrm{d}$ & 33,826 - 36,682 & 35,300 & 5.7 & $3,235-3,433$ & 4.2 & 3,334 \\
\hline M-0.56 & $791^{\circ} \mathrm{C}-\mathrm{d}$ & $41,547-45,296$ & 43,400 & 6.1 & $3,489-3,637$ & 2.9 & 3,563 \\
\hline FRP-0.23 & $791^{\circ} \mathrm{C}-\mathrm{d}$ & $31,460-32,374$ & 31,900 & 2.0 & $2,776-2,947$ & 4.2 & 2,862 \\
\hline CP-0.11 & $791^{\circ} \mathrm{C}-\mathrm{d}$ & $40,884-41,786$ & 41,300 & 1.5 & $3,443-3,654$ & 4.2 & 3,548 \\
\hline CP-0.26 & $791^{\circ} \mathrm{C}-\mathrm{d}$ & $27,887-28,355$ & 28,100 & 1.2 & $2,576-3,142$ & 14.0 & 2,859 \\
\hline M-0.47 & $791^{\circ} \mathrm{C}-\mathrm{d}$ & $43,830-45,564$ & 44,700 & 2.7 & $3,371-3,637$ & 5.4 & 3,504 \\
\hline M-0.65 & $791^{\circ} \mathrm{C}-\mathrm{d}$ & $45,104-45,764$ & 45,434 & 1.0 & $3,564-3,726$ & 3.1 & 3,645 \\
\hline FRP-0.17 & $791^{\circ} \mathrm{C}-\mathrm{d}$ & $32,116-38,420$ & 35,300 & 12.6 & $2,873-3,674$ & 17.3 & 3,273 \\
\hline FRP-0.11 & $791^{\circ} \mathrm{C}-\mathrm{d}$ & $30,278-34,821$ & 32,500 & 9.9 & $2,811-3,600$ & 17.4 & 3,206 \\
\hline
\end{tabular}

--Note: Above averages include 2 E469 values and $2 \mathrm{C}_{469}$ values.

The American Concrete Institute (ACI) document 318 allows the constant relating elastic modulus to compressive strength in the form of Equation 6 to be 57,000 for U.S. customary units (i.e., psi). For SI units (i.e., MPa), this constant is approximately 4,700. The main observation from Table 7 is that the materials evaluated do not produce as high of an elastic modulus per unit of compressive strength as typical ready-mixed concrete.

\subsection{Curing effects}

Of the 254 specimens produced, 153 were utilized to assess curing effects on mechanical properties. Most of the data were from laboratory molded specimens, with a small assessment from nine cores. Laboratory molded data were reported first, followed by a brief assessment with the core test results.

\subsubsection{Curing effects measured on laboratory molded specimens}

Of the 254 specimens produced, 144 were utilized to assess curing effects on mechanical properties from laboratory molded specimens (Table 8). Note that $791^{\circ} \mathrm{C}$-d data are replicated between Table 6 and Table 8. Table 8 utilized six compression and three tensile specimens per mix at a given type of curing. All nine of these specimens were used to assess density, which ranged from 2.19 to $2.64 \mathrm{~g} / \mathrm{cm}^{3}$. 
Table 8. Curing effects test results.

\begin{tabular}{|c|c|c|c|c|c|c|c|c|c|c|}
\hline Mix ID & Curing & $\begin{array}{c}\text { fc } \\
\text { Range } \\
(\mathrm{MPa})\end{array}$ & $\begin{array}{c}\text { fc } \\
\text { COV } \\
(\%)\end{array}$ & $\begin{array}{c}\text { fc } \\
\text { Avg. } \\
\text { (MPa) }\end{array}$ & $\begin{array}{c}\text { St } \\
\text { Range } \\
(\mathrm{MPa})\end{array}$ & $\begin{array}{c}\text { St } \\
\text { COV } \\
(\%)\end{array}$ & $\begin{array}{c}\text { St } \\
\text { Avg. } \\
(\mathrm{MPa})\end{array}$ & $\begin{array}{c}\text { Density } \\
\text { Range } \\
\left(\mathrm{g} / \mathrm{cm}^{3}\right)\end{array}$ & $\begin{array}{c}\text { Density } \\
\text { COV } \\
(\%)\end{array}$ & $\begin{array}{l}\text { Density } \\
\text { Avg. } \\
\left(\mathrm{g} / \mathrm{cm}^{3}\right)\end{array}$ \\
\hline UHPC & \multirow{4}{*}{$\begin{array}{l}791 \\
{ }^{\circ} \mathrm{C}-d\end{array}$} & $\begin{array}{c}152.4- \\
203.1\end{array}$ & 12.0 & 175 & $\begin{array}{c}19.5- \\
26.1\end{array}$ & 14.5 & 23 & $\begin{array}{c}2.467- \\
2.608\end{array}$ & 1.6 & 2.52 \\
\hline CP-0.15 & & $77.7-167.7$ & 24.6 & 117 & $9.7-12.8$ & 14.3 & 12 & $\begin{array}{c}2.230- \\
2.275\end{array}$ & 0.7 & 2.25 \\
\hline $\mathrm{M}-0.56$ & & $\begin{array}{c}122.2- \\
155.1\end{array}$ & 9.1 & 141 & $9.3-12.9$ & 17.3 & 12 & $\begin{array}{c}2.233- \\
2.314\end{array}$ & 1.1 & 2.27 \\
\hline $\begin{array}{l}\text { FRP- } \\
0.23\end{array}$ & & $\begin{array}{c}120.7- \\
141.9\end{array}$ & 6.4 & 135 & $\begin{array}{c}26.3- \\
26.6\end{array}$ & 0.5 & 26 & $\begin{array}{c}2.465- \\
2.584\end{array}$ & 1.6 & 2.51 \\
\hline UHPC & \multirow{4}{*}{$\begin{array}{l}721 \\
{ }^{\circ} \mathrm{C}-\mathrm{d}\end{array}$} & $\begin{array}{c}156.2- \\
183.6\end{array}$ & 7.1 & 170 & $\begin{array}{c}22.1- \\
28.8\end{array}$ & 15.5 & 24 & $\begin{array}{c}2.487- \\
2.554\end{array}$ & 0.8 & 2.53 \\
\hline CP-0.15 & & $\begin{array}{c}106.4- \\
170.1\end{array}$ & 18.7 & 124 & $4.5-11.1$ & 41.6 & 9 & $\begin{array}{c}2.223- \\
2.261\end{array}$ & 0.6 & 2.24 \\
\hline $\mathrm{M}-0.56$ & & $\begin{array}{c}138.6- \\
208.4\end{array}$ & 15.4 & 179 & $\begin{array}{c}11.0- \\
12.6\end{array}$ & 7.2 & 12 & $\begin{array}{c}2.262- \\
2.347\end{array}$ & 1.4 & 2.30 \\
\hline $\begin{array}{l}\text { FRP- } \\
0.23\end{array}$ & & $88.3-120.5$ & 12.9 & 105 & $\begin{array}{c}17.3- \\
23.6\end{array}$ & 17.3 & 20 & $\begin{array}{c}2.460- \\
2.547\end{array}$ & 1.1 & 2.52 \\
\hline UHPC & \multirow{4}{*}{$\begin{array}{l}801 \\
{ }^{\circ} \mathrm{C}-\mathrm{d}\end{array}$} & $\begin{array}{c}155.5- \\
221.5\end{array}$ & 14.5 & 190 & $\begin{array}{c}18.7- \\
23.8\end{array}$ & 12.7 & 21 & $\begin{array}{c}2.453- \\
2.605\end{array}$ & 1.8 & 2.51 \\
\hline CP-0.15 & & $\begin{array}{c}108.9- \\
167.5\end{array}$ & 20.9 & 135 & $4.0-10.5$ & 44.6 & 8 & $\begin{array}{c}2.191- \\
2.265\end{array}$ & 1.1 & 2.23 \\
\hline $\mathrm{M}-0.56$ & & $\begin{array}{c}120.4- \\
187.4\end{array}$ & 18.3 & 161 & $\begin{array}{c}10.8- \\
14.0\end{array}$ & 13.0 & 13 & $\begin{array}{c}2.255- \\
2.309\end{array}$ & 0.9 & 2.28 \\
\hline $\begin{array}{l}\text { FRP- } \\
0.23\end{array}$ & & $74.9-145.9$ & 20.4 & 119 & $\begin{array}{c}22.2- \\
24.9\end{array}$ & 6.0 & 24 & $\begin{array}{c}2.479- \\
2.644\end{array}$ & 2.1 & 2.56 \\
\hline UHPC & \multirow{4}{*}{$\begin{array}{c}2,783 \\
{ }^{\circ} \mathrm{C}-\mathrm{d}\end{array}$} & $\begin{array}{c}131.5- \\
163.4\end{array}$ & 7.5 & 149 & $\begin{array}{c}18.8- \\
22.3\end{array}$ & 8.9 & 21 & $\begin{array}{c}2.527- \\
2.577\end{array}$ & 0.7 & 2.55 \\
\hline CP-0.15 & & $78.0-143.4$ & 21.0 & 109 & $4.7-10.1$ & 47.6 & 7 & $\begin{array}{c}2.188- \\
2.274\end{array}$ & 1.6 & 2.24 \\
\hline $\mathrm{M}-0.56$ & & $\begin{array}{c}126.3- \\
144.8\end{array}$ & 6.1 & 136 & $\begin{array}{c}10.3- \\
12.0\end{array}$ & 8.2 & 11 & $\begin{array}{c}2.253- \\
2.310\end{array}$ & 0.9 & 2.28 \\
\hline $\begin{array}{l}\text { FRP- } \\
0.23\end{array}$ & & $\begin{array}{c}113.9- \\
135.8\end{array}$ & 6.6 & 122 & $\begin{array}{c}19.6- \\
27.7\end{array}$ & 17.0 & 24 & $\begin{array}{c}2.457- \\
2.623\end{array}$ & 2.0 & 2.53 \\
\hline
\end{tabular}

-Note: Above averages include six fc, three St, and nine densities.

As seen in Table 5, there were often more than six compression and three tension specimens tested after $2,783^{\circ} \mathrm{C}$-d curing. In these cases, the first six compression measurements and/or the first three tension measurements were utilized in Table 8 for consistency across all curing protocols. The additional replicates for $2,783{ }^{\circ} \mathrm{C}$-d curing were performed for investigations reported later in this chapter. Figures 11 to 18 plot the results from 
Table 8. Figures 11 and 12 are bar charts comparing curing effects on tensile and compressive strength. Figures 13 to 18 are equality plots comparing curing protocols 721,801 , and $2,783^{\circ} \mathrm{C}-\mathrm{d}$ to ERDC's baseline protocol of $791^{\circ} \mathrm{C}-\mathrm{d}$, where the specimens are exposed to $90^{\circ} \mathrm{C}$ water.

Figure 11. Average compressive strength of curing variations.

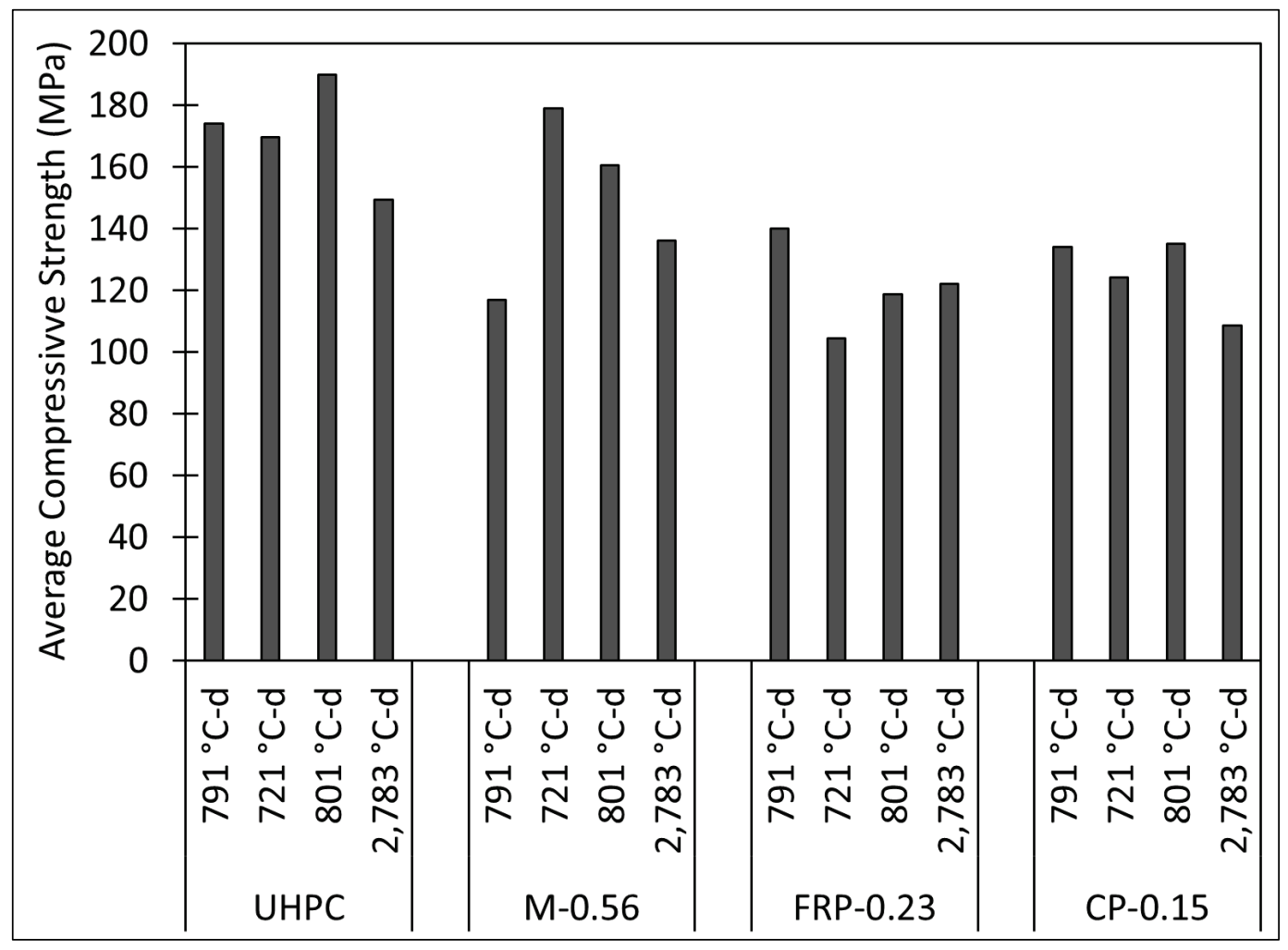


Figure 12. Average tensile strength of curing variations.

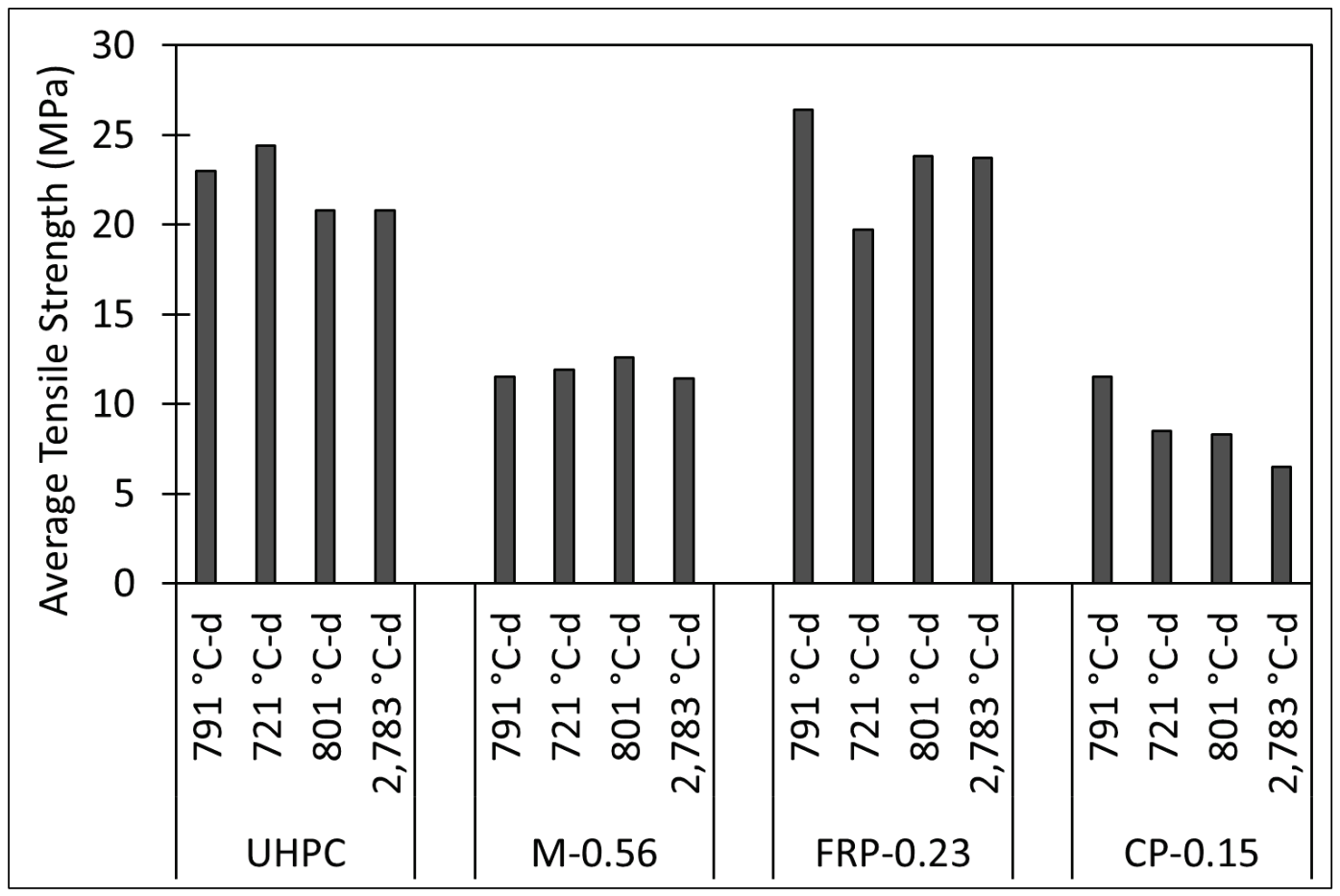

Figure $13.721^{\circ} \mathrm{C}-\mathrm{d}$ curing versus $791^{\circ} \mathrm{C}-\mathrm{d}$ curing in compression.

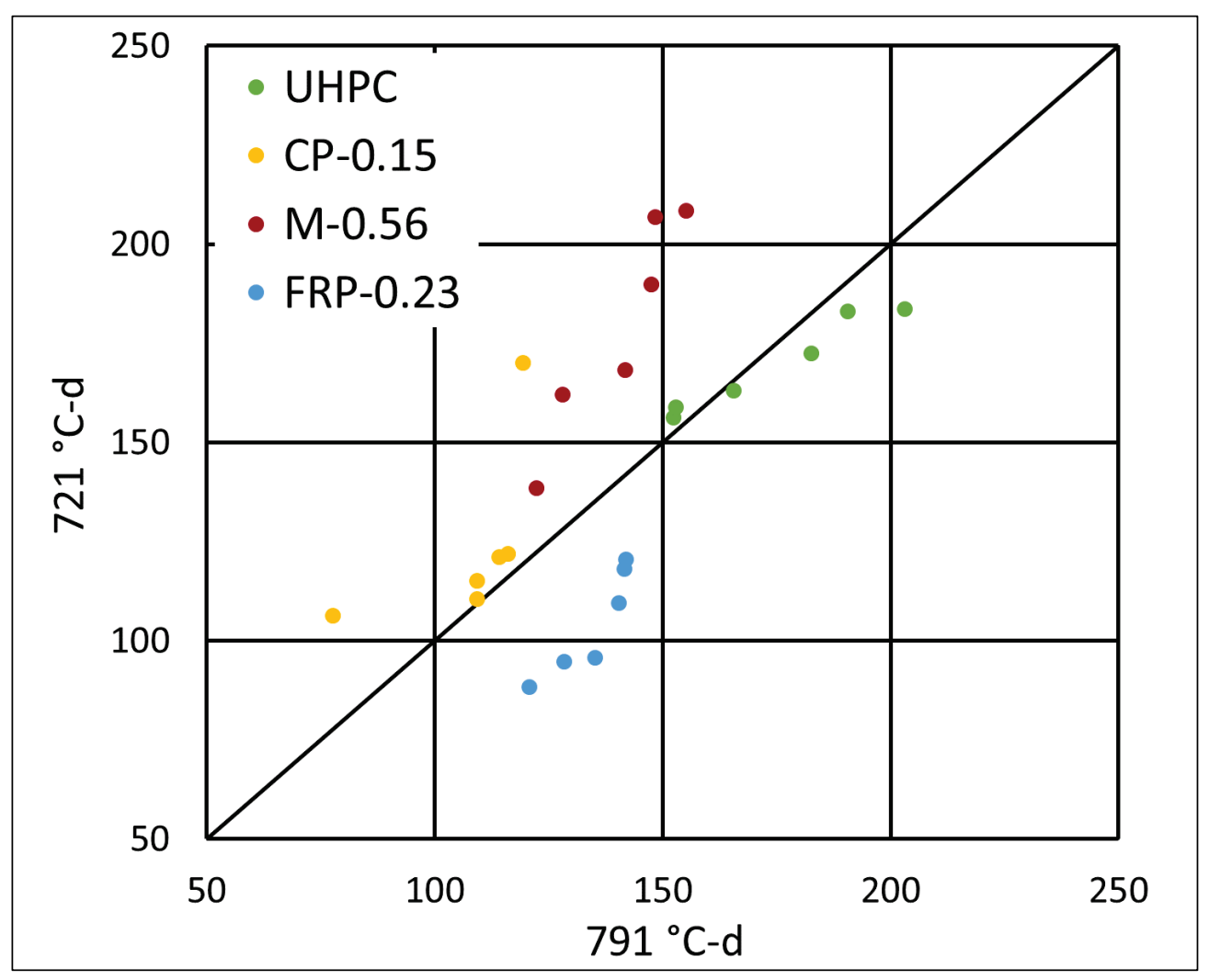


Figure $14.801^{\circ} \mathrm{C}-\mathrm{d}$ curing versus $791^{\circ} \mathrm{C}$-d curing in compression.

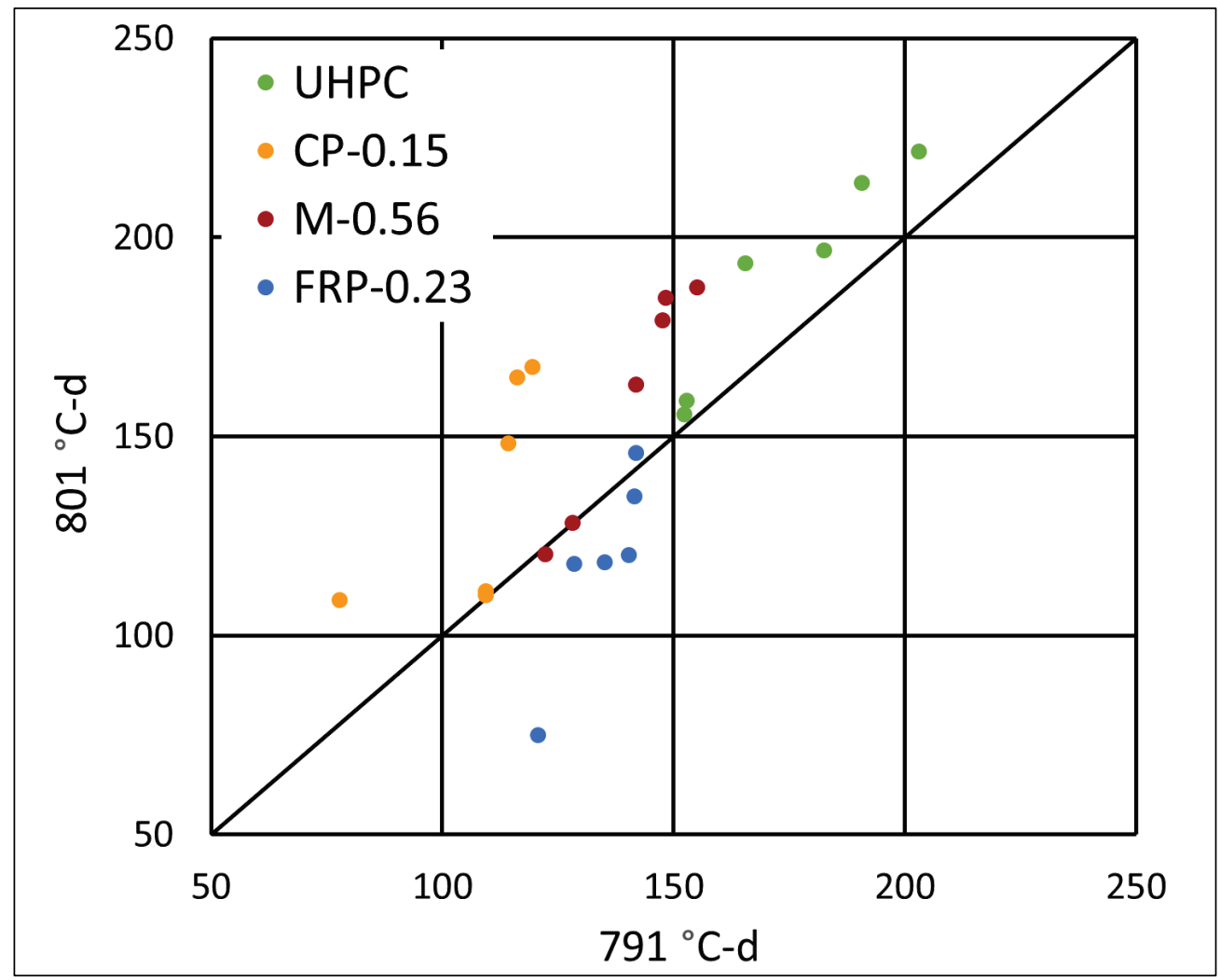

Figure $15.2,783^{\circ} \mathrm{C}-\mathrm{d}$ curing versus $791^{\circ} \mathrm{C}-\mathrm{d}$ curing in compression.

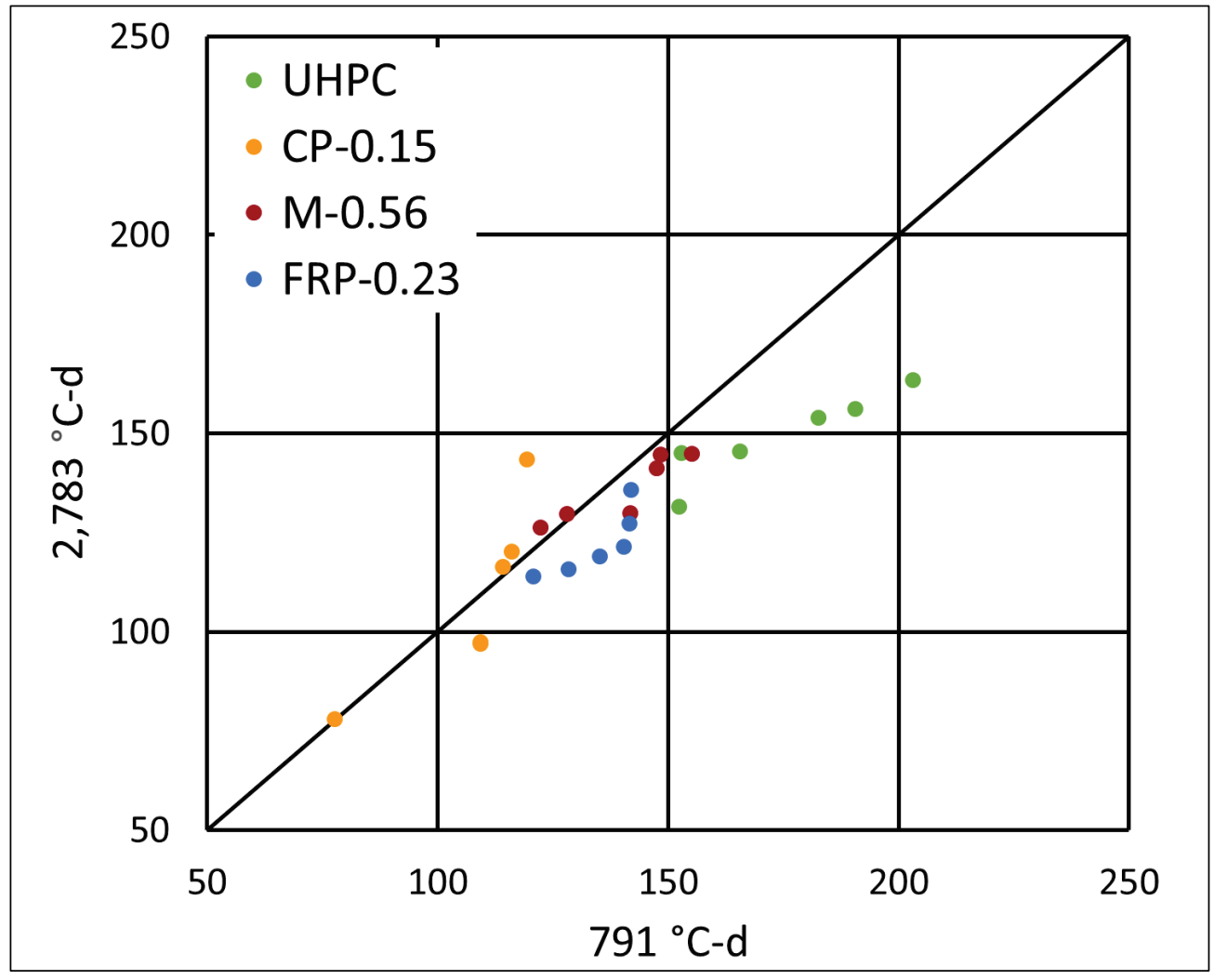


Figure 16. $721^{\circ} \mathrm{C}-\mathrm{d}$ curing versus $791^{\circ} \mathrm{C}-\mathrm{d}$ curing in tension.

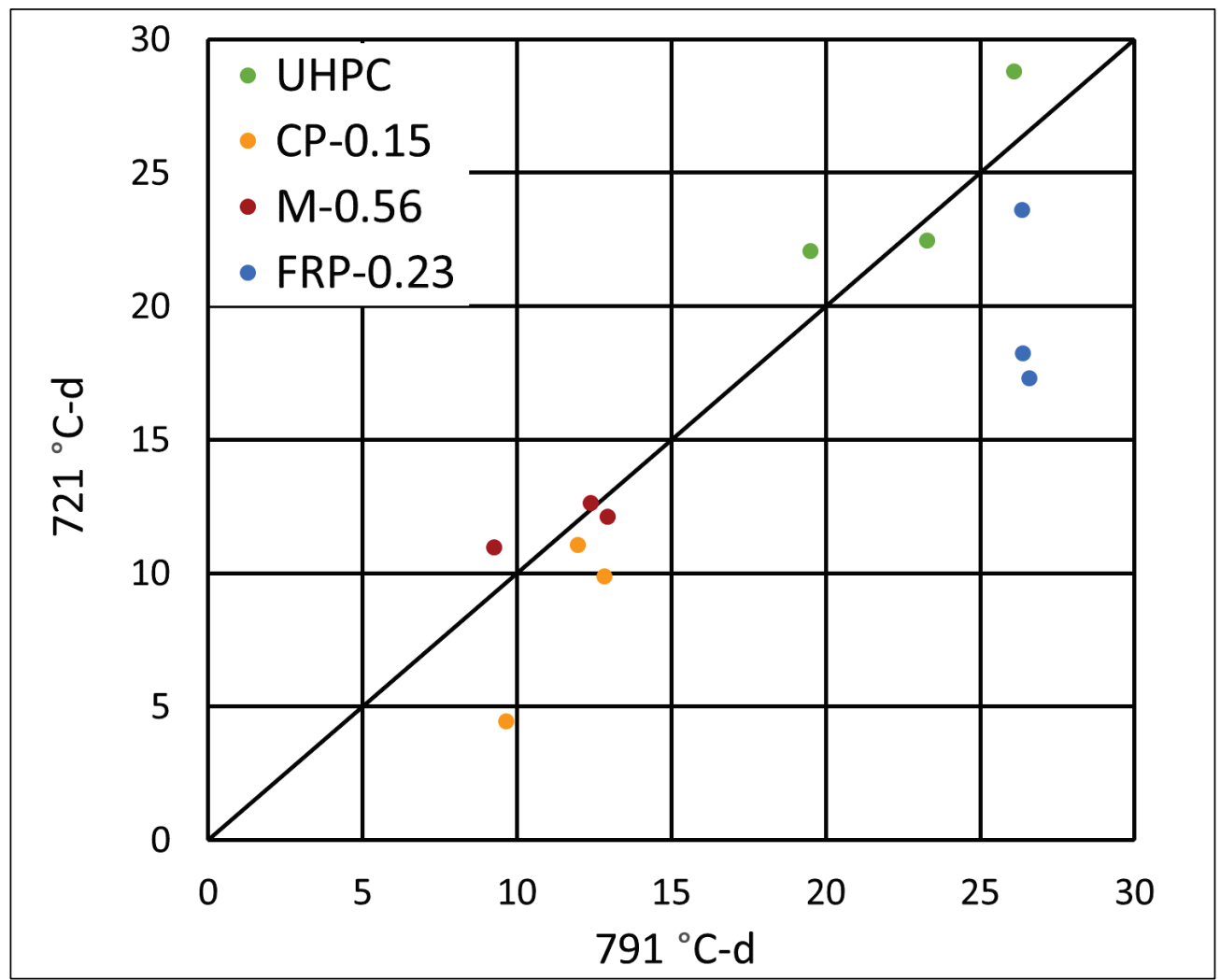

Figure $17.801^{\circ} \mathrm{C}-\mathrm{d}$ curing versus $791^{\circ} \mathrm{C}-\mathrm{d}$ curing in tension.

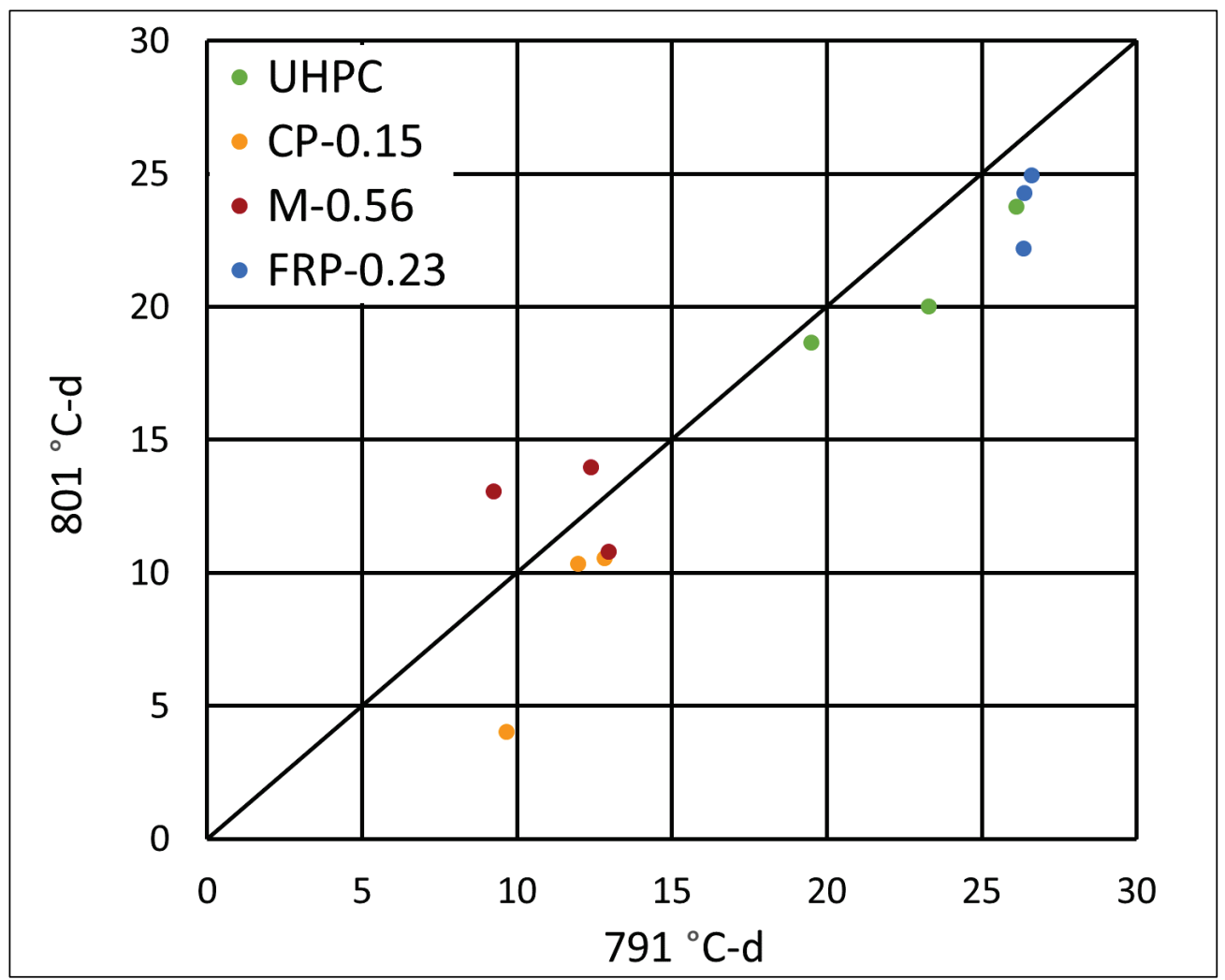


Figure $18.2,783^{\circ} \mathrm{C}-\mathrm{d}$ curing versus $791^{\circ} \mathrm{C}-\mathrm{d}$ curing in tension.

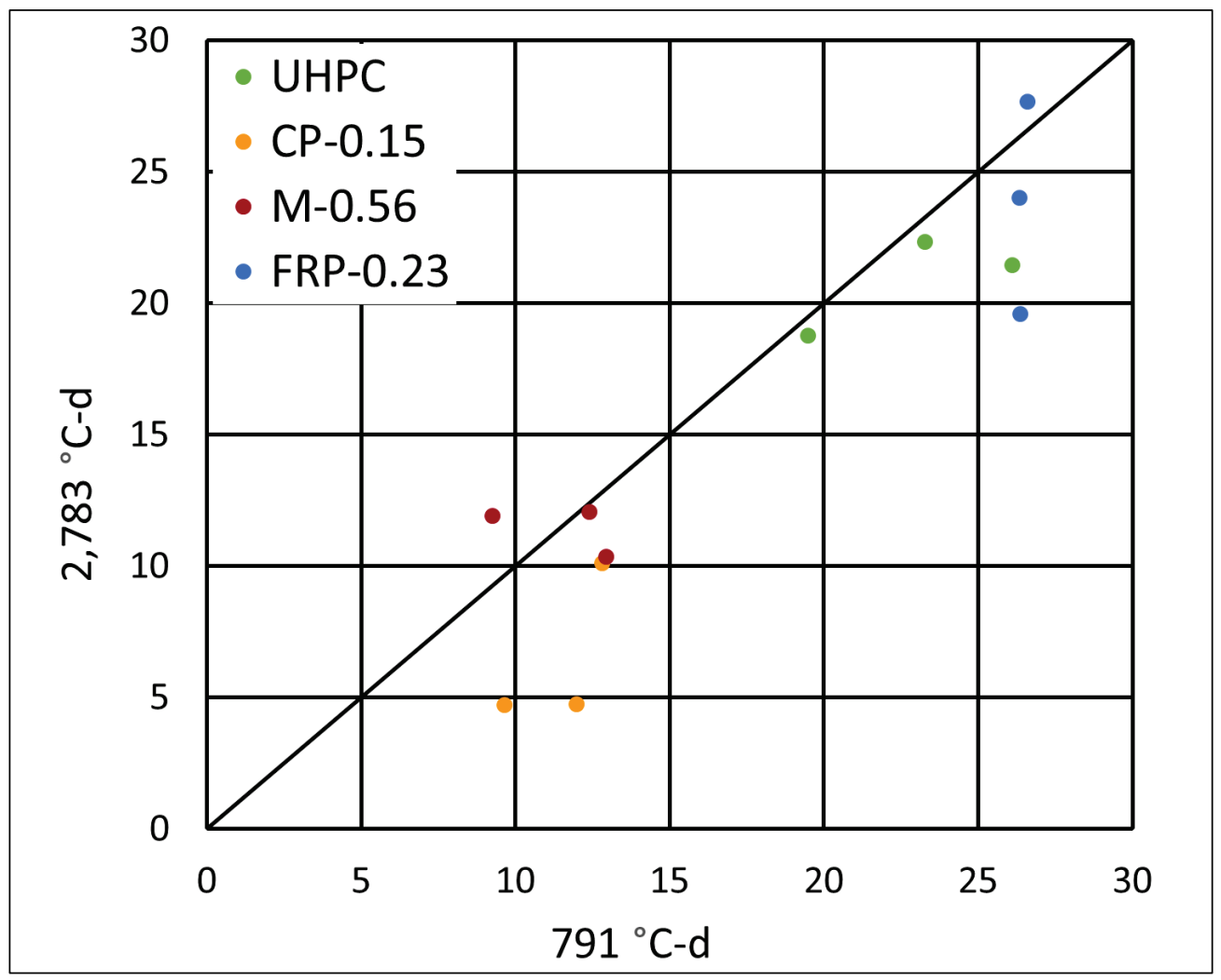

Curing protocols noticeably impacted compressive strength for all specimen types. Curing protocols noticeably affected UHPC, CP, and FRP tensile strength, but did not noticeably affect $\mathrm{M}$.

Figures 13 and 14 were used to make the following assessments regarding compressive strength. UHPC seemed to respond better to $80^{\circ} \mathrm{C}$ curing than $90^{\circ} \mathrm{C}$ curing for a comparable level of ${ }^{\circ} \mathrm{C}$-days. This same trend was observed with $\mathrm{M}$ and $\mathrm{CP}$, but not with FRP. FRP clearly deviated from the other categories for $80^{\circ} \mathrm{C}$ curing relative to $90^{\circ} \mathrm{C}$ curing, as $90^{\circ} \mathrm{C}$ curing produced higher strengths.

Figure 15 was used to make the following assessments about compressive strength. In compression, all UHPC and FRP specimens were stronger after $791^{\circ} \mathrm{C}$-d of curing, for which $90^{\circ} \mathrm{C}$ was utilized, relative to 3.5 times the amount of ${ }^{\circ} \mathrm{C}$-days $(2,783)$, for which temperature was $23^{\circ} \mathrm{C}$. $\mathrm{CP}$ was comparable, where $\mathrm{M}$ might have slightly favored $90^{\circ} \mathrm{C}$ curing for less ${ }^{\circ} \mathrm{C}-$ days. Overall, the data were below the equality line, indicating curing at higher temperatures for less ${ }^{\circ} \mathrm{C}$-days produced higher compressive strength than lower temperatures for more ${ }^{\circ} \mathrm{C}$-days. 
Figures 16 and 17 were used to make the following assessments about tensile strength. UHPC's response was not definitive. The $721^{\circ} \mathrm{C}-\mathrm{d}$ specimens with $80^{\circ} \mathrm{C}$ curing were modestly stronger than the $791^{\circ} \mathrm{C}$-day specimens with $90^{\circ} \mathrm{C}$ curing, suggesting $80^{\circ} \mathrm{C}$ curing was more favorable. The opposite behavior, however, was observed when $801^{\circ} \mathrm{C}-\mathrm{d}$ at $80^{\circ} \mathrm{C}$ curing was compared to $791^{\circ} \mathrm{C}-\mathrm{d}$ at $90^{\circ} \mathrm{C}$ curing. $\mathrm{CP}$ favored $90^{\circ} \mathrm{C}$ curing, which was opposite to compressive strength testing in Figures 13 and 14. $\mathrm{M}$ seemed largely indifferent to curing protocol when tested in tension. FRP favored $90^{\circ} \mathrm{C}$ curing, which agrees with the behavior observed in compression (Figures 13 and 14).

Figure 18 was used to make the following assessments about tensile strength. UHPC favored $90^{\circ} \mathrm{C}$ curing, which matched its behavior in compression in Figure 15 (i.e., that fewer ${ }^{\circ} \mathrm{C}$-days of a higher temperature produced better properties). $\mathrm{CP}$ also favored $90^{\circ} \mathrm{C}$ curing, which disagreed with its compressive strength behavior. M seemed largely indifferent to the curing protocol. FRP generally favored $90^{\circ} \mathrm{C}$ curing.

The main observation from Table 8 (and Figures 11 to 18 that plotted data from Table 8) is that the specific aspects of curing seem to affect compressive and tensile properties and that the effects are not consistent between tension and compression or between specimen category (UHPC, $\mathrm{CP}, \mathrm{M}$, or FRP). These data suggest that only accumulating ${ }^{\circ} \mathrm{C}$-days and using that number as a maturity index may lead to undesirable outcomes for some types of UHPC endeavors. For large placements of UHPC where very large temperature fluctuations with space and time are expected, more understanding of how UHPC responds to time, temperature, and their interaction seems useful. This same understanding is needed to further develop multiscale models of high-strength concrete.

Curing effects on elastic modulus are shown in Table 9. The main observation is that the materials evaluated do not produce as high of an elastic modulus per unit of compressive strength as typical ready-mixed concrete. 
Table 9. Elastic modulus and ultimate strength constant for varying curing.

\begin{tabular}{|c|c|c|c|c|c|c|c|}
\hline Mix ID & Curing & $\begin{array}{c}\text { E469 } \\
\text { Range } \\
(\mathrm{MPa})\end{array}$ & $\begin{array}{l}E_{469} \\
\text { COV } \\
(\%)\end{array}$ & $\begin{array}{l}\text { E469 } \\
\text { Avg. } \\
\text { (MPa) }\end{array}$ & $\begin{array}{c}\mathrm{C}_{469} \\
\text { Range }\end{array}$ & $\operatorname{cov}(\%)$ & $\begin{array}{l}\mathrm{C}_{469} \\
\text { Avg. }\end{array}$ \\
\hline UHPC & \multirow{4}{*}{$\begin{array}{l}791 \\
{ }^{\circ} \mathrm{C}-d\end{array}$} & $49,509-49,617$ & 0.1 & 49,600 & $3,848-4,013$ & 3.0 & 3,931 \\
\hline CP-0.15 & & $33,826-36,682$ & 5.7 & 35,300 & $3,235-3,433$ & 4.2 & 3,334 \\
\hline M-0.56 & & $41,547-45,296$ & 6.1 & 43,400 & $3,489-3,637$ & 2.9 & 3,563 \\
\hline FRP-0.23 & & $31,460-32,374$ & 2.0 & 31,900 & $2,776-2,947$ & 4.2 & 2,862 \\
\hline UHPC & \multirow{4}{*}{$\begin{array}{l}721 \\
{ }^{\circ} \mathrm{C}-\mathrm{d}\end{array}$} & $51,810-57,633$ & 5.3 & 54,800 & $4,059-4,611$ & 7.5 & 4,246 \\
\hline CP-0.15 & & $31,699-37,223$ & 8.7 & 35,200 & $3,073-3,425$ & 5.8 & 3,293 \\
\hline M-0.56 & & $44,626-50,060$ & 5.7 & 47,500 & $3,467-3,505$ & 0.6 & 3,484 \\
\hline FRP-0.23 & & $29,684-31,196$ & 2.5 & 30,400 & $2,890-3,206$ & 5.5 & 3,085 \\
\hline UHPC & \multirow{4}{*}{$\begin{array}{l}801 \\
{ }^{\circ} \mathrm{C}-\mathrm{d}\end{array}$} & $51,633-54,474$ & 2.7 & 52,900 & $3,660-3,747$ & 1.2 & 3,706 \\
\hline CP-0.15 & & $35,747-39,371$ & 4.9 & 37,400 & $3,034-3,390$ & 6.2 & 3,163 \\
\hline M-0.56 & & $44,095-47,617$ & 4.1 & 45,500 & $3,221-3,503$ & 4.8 & 3,409 \\
\hline FRP-0.23 & & $28,268-31,828$ & 5.9 & 30,100 & $2,579-2,924$ & 6.3 & 2,757 \\
\hline UHPC & \multirow{4}{*}{$\begin{array}{c}2,783 \\
{ }^{\circ} \mathrm{C}-\mathrm{d}\end{array}$} & $48,269-50,001$ & 1.9 & 49,000 & $3,922-4,209$ & 3.7 & 4,044 \\
\hline CP-0.15 & & $31,284-31,715$ & 0.7 & 31,500 & $2,638-3,542$ & 15.4 & 3,024 \\
\hline M-0.56 & & $42,339-43,389$ & 1.4 & 42,700 & $3,524-3,718$ & 2.7 & 3,616 \\
\hline FRP-0.23 & & $32,299-37,793$ & 8.4 & 34,500 & $2,959-3,513$ & 14.2 & 2,918 \\
\hline
\end{tabular}

--Note: $791{ }^{\circ} \mathrm{C}$-d averages for $\mathrm{E}_{469}$ and $\mathrm{C}_{469}$ include 2 specimens each. All other curing averages include $3 \mathrm{E}_{469}$ and $3 \mathrm{C}_{469}$.

\subsubsection{Curing assessment of cores and laboratory molded specimens}

The 3- by 6-in. UHPC cores that were tested for compressive strength were used as a general curing reference relative to the four laboratory protocols utilized herein. These three cores produced an average compressive strength of $157 \mathrm{MPa}$ and an average $\mathrm{E}_{469}$ of 55,900 MPa. These values were benchmarked with UHPC laboratory cast material into 3- by 6-in. cylinders that were reported earlier in this section. The range of average compressive strength and $\mathrm{E}_{469}$ were 149 to $190 \mathrm{MPa}$ and 48,300 to 57,600 , respectively.

The 3- by 6-in. UHPC cores that were tested for tensile strength were used as a general curing reference relative to the four laboratory protocols utilized herein. These six cores produced an average tensile strength of 19.8 MPa. These values were benchmarked with UHPC laboratory cast material into 3- by 6-in. cylinders that were reported earlier in this section. The range of average tensile strength was 20.8 to $24.4 \mathrm{MPa}$. 
Variability was compared for the two available sets of UHPC tensile strength data cured in different manners where six replicates were available for 3 - by 6 -in. specimens. The $2,783^{\circ} \mathrm{C}$-d cured specimens had a $\mathrm{COV}$ of 20.6 percent. Cores had a $\mathrm{COV}$ of 17.3 percent.

\subsection{Size effects}

Of the 254 specimens produced, 69 were used to assess specimen size effects on measured properties of UHPC, CP-0.15, and FRP-0.23. The data contained in this section are sporadic. The best available information was collected herein with materials and resources remaining after proportions and curing effects were assessed. The effects of size on UHPC were found by comparing cores of two different diameters to laboratory cast specimens of a given diameter. The effects of size on CP-0.15 and FRP0.23 were found by comparing lab made specimens of two different diameters that were identically cured. Some of the data utilized in this section were also used in Sections 3.1 or 3.2.

A general rule for producing specimens containing fibers is that the specimens' diameter must be at least three times the fiber length. For the fibers used in this project, that equates to 4 - by 8 -in. cylinders. Since 3- by 6-in. cylinders were mostly used herein to facilitate comparable testing with a range of constituents, 4 - by 8 -in. cylinders were made with fibers for comparative purposes. With regard to $\mathrm{CP}$, most work to date in this area has used 2- by 4-in. specimens. Since 3- by 6-in. cylinders were mostly used herein to facilitate comparable testing with a range of constituents, 2- by 4-in. cylinders were made with CP for comparative purposes. In most cases, the compared cylinders were produced from the same batch for direct comparison.

\subsubsection{Size effects - Ultra-High Performance Concrete (UHPC)}

Minimal size effects data were collected for UHPC. The only assessment available was comparing 3- by 6-in. cores to 4 - by 8 -in. cores where the cores were taken from the same tub. As such, fiber orientation was established prior to coring and was comparable in both specimen sizes. The six cores that were 3 - by 6-in. had an average tensile strength of 19.8 MPa, while the three cores that were 4- by 8 -in. had an average tensile strength of 17.0 MPa. 


\subsubsection{Size effects - Cement paste (CP)}

CP size effects data are summarized in Table 10, while Figure 19 plots the 24 individual specimens tested for compressive strength. All specimens were cured to $2,783{ }^{\circ} \mathrm{C}-\mathrm{d}$ in the $23^{\circ} \mathrm{C}$ curing room.

Of the 24 specimens utilized, six were from Section 3.2 curing effects that are repeated here and referred to as non-paired, since they were not made in the same batch as different sized specimens. The remaining 18 specimens were produced in three batches (six specimens per batch), where one batch produced three specimens that were 2 by 4 in. and three more specimens that were 3 by 6 in. These specimens could be viewed as matched pairs.

The paired $t$-test was performed on the nine matched pairs that could be produced from batches 1 to 3 . The measured compressive strengths for each batch and specimen size were sorted in ascending order to make the pairs. For example, the lowest compressive strength of a 2- by 4-in. specimen from batch 1 was paired with the lowest compressive strength from a 3- by 6-in. cylinder from batch 1 . The comparison was whether the mean difference of these pairs was statistically different from 0 at a 5 percent level of significance. The $p$-value was 0.33 , indicating the values were not significantly different. The average strength of the 3 - by 6 -in. specimens from batches 1 to 3 was $124 \mathrm{MPa}$, while the average strength of the 2- by 4-in. specimens was $119 \mathrm{MPa}$.

If all 3- by 6-in. specimens were averaged (non-pairs and batches 1 to 3 ), the average strength was $118 \mathrm{MPa}$, which is within $1 \mathrm{MPa}$ of the 2- by 4-in. specimens. When all data were considered, the standard deviation of the 3- by 6-in. specimens was $17 \mathrm{MPa}$, while the standard deviation for the 2by 4-in. specimens was $21 \mathrm{MPa}$. Overall, there were no obvious differences between strengths produced with 2- by 4 -in. specimens and those produced with 3 - by 6-in. specimens. 
Table 10. Size effects on CP data.

\begin{tabular}{|l|c|c|c|c|c|c|c|c|}
\hline Mix ID & Size & Batch & $\begin{array}{c}\mathrm{fc} \\
\text { Range } \\
(\mathrm{MPa})\end{array}$ & $\begin{array}{c}\mathrm{fc} \\
\mathrm{COV} \\
(\%)\end{array}$ & $\begin{array}{c}\mathrm{fc} \\
\text { Avg. } \\
(\mathrm{MPa})\end{array}$ & $\begin{array}{c}\text { Density Range } \\
\left(\mathrm{g} / \mathrm{cm}^{3}\right)\end{array}$ & $\begin{array}{c}\text { Density } \\
\text { coV } \\
(\%)\end{array}$ & $\begin{array}{c}\text { Density } \\
\text { Avg. (g/cm }\end{array}$ \\
\hline $\mathrm{CP}-0.15$ & $3 \times 6$ & Non-Paired & $78.0-143.4$ & 21.0 & 108.7 & $2.188-2.271$ & 1.8 & 2.232 \\
\hline $\mathrm{CP}-0.15$ & $2 \times 4$ & 1 & $94.6-144.0$ & 20.7 & 119.5 & $2.241-2.246$ & 0.1 & 2.244 \\
\hline CP-0.15 & $3 \times 6$ & 1 & $127.3-129.9$ & 1.1 & 128.4 & $2.247-2.254$ & 0.2 & 2.250 \\
\hline CP-0.15 & $2 \times 4$ & 2 & $121.6-143.8$ & 9.3 & 129.9 & $2.270-2.295$ & 0.6 & 2.284 \\
\hline CP-0.15 & $3 \times 6$ & 2 & $119.9-138.7$ & 7.4 & 130.5 & $2.248-2.267$ & 0.4 & 2.256 \\
\hline CP-0.15 & $2 \times 4$ & 3 & $84.7-131.9$ & 22.4 & 106.5 & $2.251-2.263$ & 0.3 & 2.255 \\
\hline CP-0.15 & $3 \times 6$ & 3 & $111.9-116.0$ & 1.9 & 114.4 & $2.209-2.230$ & 0.5 & 2.222 \\
\hline
\end{tabular}

--Notes: non-paired specimens - $6 \mathrm{fc}, 6$ densities

Batches 1, 2, and 3 had 3 fc and 3 densities for each specimen size.

Figure 19. Compressive strength of $\mathrm{CP}-0.15$ size variation specimens.

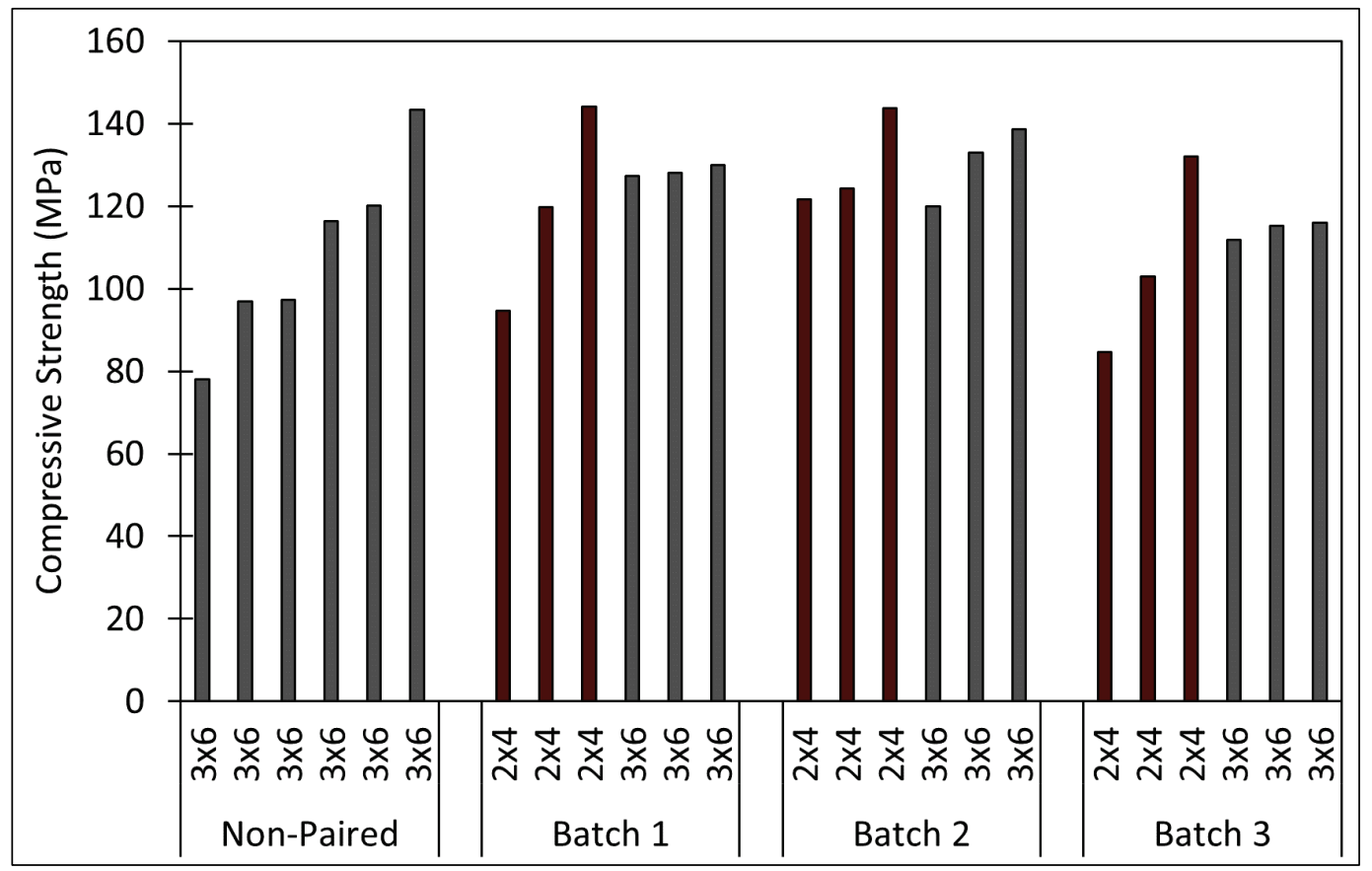

\subsubsection{Size effects - Fiber Reinforced Paste (FRP)}

FRP size effects data are summarized in Tables 11 (compression) and 12 (tension), while Figures 20 (compression) and 21 (tension) plot the 27 individual specimens tested. All specimens were cured to $2,783^{\circ} \mathrm{C}$ - $\mathrm{d}$ in the $23{ }^{\circ} \mathrm{C}$ curing room.

Of the 27 specimens utilized, 12 were tested in compression, and 14 were tested in tension. In compression, six were non-paired (as described in 
Section 3.3.2), and six were produced in two batches of three specimens each. Each batch produced two specimens that were 3 by 6 in. and one specimen that was 4 by 8 in. In tension, five were non-paired, and nine were produced in three batches of three specimens each. Each batch produced two specimens that were 3 by 6 in. and one specimen that was 4 by 8 in.

In compression, the 10 specimens that were 3 by 6 in. had an average compressive strength of $124 \mathrm{MPa}$ with a range of 114 to $136 \mathrm{MPa}$. The two specimens that were 4 by 8 in. had strengths that were 119 and $135 \mathrm{MPa}$. Two observations can be made from these data, which are shown in Table 11 and Figure 20. First, the 4- by 8-in. specimens fell in the range of the $3^{-}$ by 6 -in. specimens. Second, for each batch from which multiple specimens were made, one of the 3 - by 6-in. specimens was essentially the same as one of the 4 - by 8 -in. specimens.

Table 11. Size effects of FRP-0.23 in compression.

\begin{tabular}{|c|c|c|c|c|c|c|c|c|}
\hline Mix ID & Size & Batch & $\begin{array}{c}\mathrm{fc} \\
\text { Range } \\
(\mathrm{MPa})\end{array}$ & $\begin{array}{c}\mathrm{fc} \\
\mathrm{cov} \\
(\%)\end{array}$ & $\begin{array}{c}\mathrm{fc} \\
\text { Avg. } \\
(\mathrm{MPa})\end{array}$ & $\begin{array}{c}\text { Density } \\
\text { Range } \\
\left(\mathrm{g} / \mathrm{cm}^{3}\right)\end{array}$ & $\begin{array}{c}\text { Density } \\
\text { CoV } \\
(\%)\end{array}$ & $\begin{array}{c}\text { Density } \\
\text { Avg. } \\
\left(\mathrm{g} / \mathrm{cm}^{3}\right)\end{array}$ \\
\hline FRP-0.23 & $3 \times 6$ & Non-Paired & $113.9-135.8$ & 6.6 & 122.2 & $2.457-2.623$ & 1.8 & 2.531 \\
\hline FRP-0.23 & $3 \times 6$ & 1 & $119.1-135.9$ & 9.3 & 127.5 & $2.527-2.538$ & 0.3 & 2.532 \\
\hline FRP-0.23 & $4 \times 8$ & 1 & 134.6 & - & - & 2.541 & - & - \\
\hline FRP-0.23 & $3 \times 6$ & 2 & $119.1-128.5$ & 5.3 & 123.8 & $2.489-2.512$ & 0.6 & 2.500 \\
\hline FRP-0.23 & $4 \times 8$ & 2 & 118.9 & - & - & 2.560 & - & - \\
\hline
\end{tabular}

-Note: non-paired specimens - $6 \mathrm{fc}, 6$ densities

$3 \times 6$ batched specimens -2 fc, 2 densities

$4 \times 8$ batched specimens -1 fc, 1 density 
Figure 20. Compressive strength of FRP variation specimens.

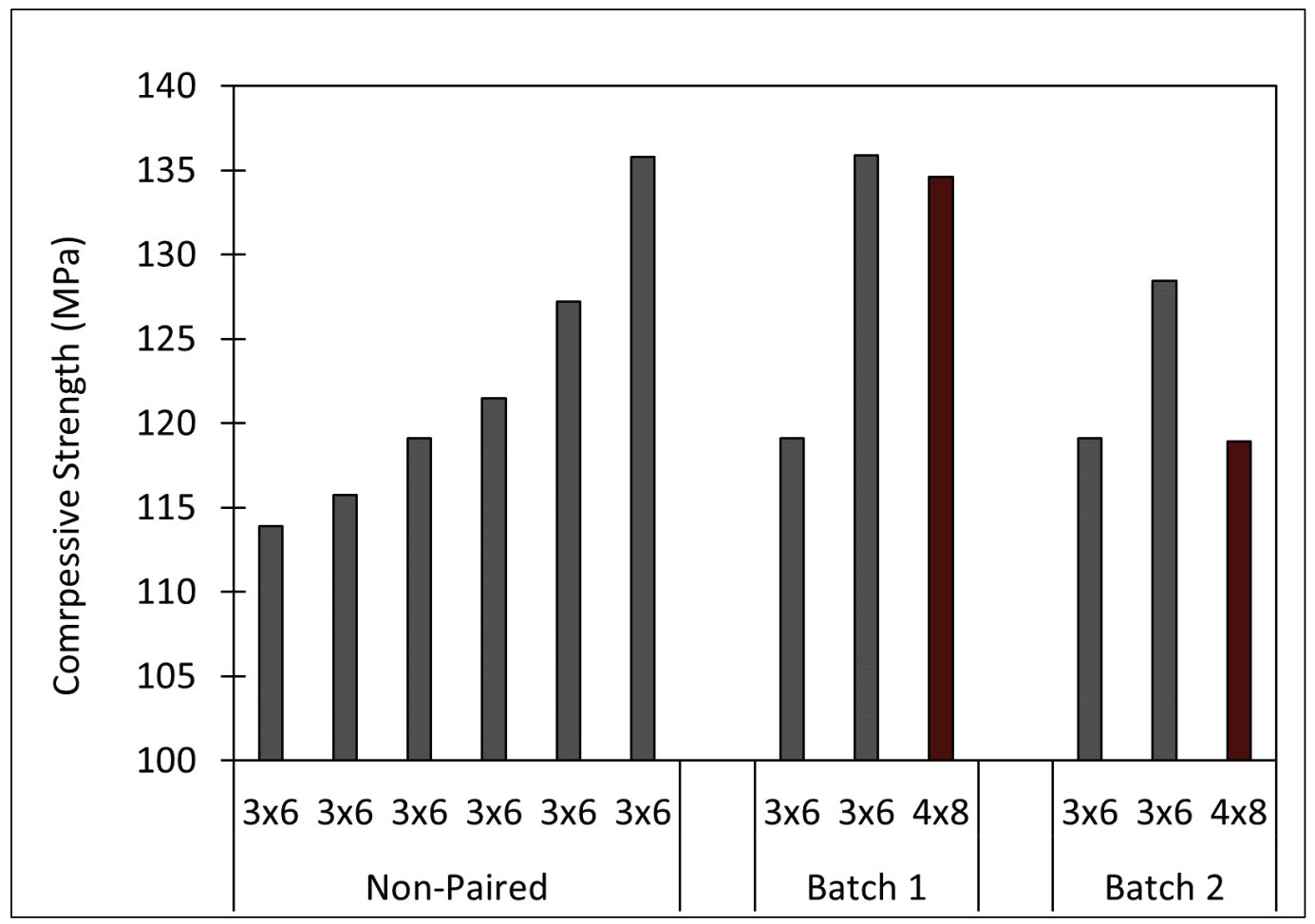

In tension, the 11 specimens that were 3 by $6 \mathrm{in}$. had an average tensile strength of 22.2 MPa with a range of 17.7 to $27.6 \mathrm{MPa}$. The three specimens that were 4 by 8 in. had strengths that were 17.5, 18.4, and 20.4 MPa with an average value of $18.8 \mathrm{MPa}$. Three observations can be made from these data, which are shown in Table 12 and Figure 21. First, the 4- by 8-in. specimens fell on the lower end of, to slightly below, the 3- by 6-in. specimens' range. Second, the average strength of 4 - by 8-in. specimens was 85 percent of that from the 3 - by 6 -in. specimens. Third, the 4- by 8 -in. specimen always had the lowest tensile strength in a given batch. 
Table 12. Size effects on FRP-0.23 in tension.

\begin{tabular}{|c|c|c|c|c|c|c|c|c|}
\hline Mix ID & Size & Batch & $\begin{array}{c}\text { St } \\
\text { Range } \\
(\mathrm{MPa})\end{array}$ & $\begin{array}{c}\text { St } \\
\text { CoV } \\
(\%)\end{array}$ & $\begin{array}{c}\text { St } \\
\text { Avg. } \\
(\mathrm{MPa})\end{array}$ & $\begin{array}{c}\text { Density } \\
\text { Range } \\
\left(\mathrm{g} / \mathrm{cm}^{3}\right)\end{array}$ & $\begin{array}{c}\text { Density } \\
\text { CoV } \\
(\%)\end{array}$ & $\begin{array}{c}\text { Density } \\
\text { Avg. } \\
\left(\mathrm{g} / \mathrm{cm}^{3}\right)\end{array}$ \\
\hline FRP-0.23 & $3 \times 6$ & Non-Paired & $17.7-27.7$ & 17.8 & 22.0 & $2.457-2.545$ & 1.3 & 2.511 \\
\hline FRP-0.23 & $3 \times 6$ & 3 & $20.0-22.9$ & 9.8 & 21.5 & $2.485-2.519$ & 1.0 & 2.502 \\
\hline FRP-0.23 & $4 \times 8$ & 3 & 17.5 & - & - & 2.560 & - & - \\
\hline FRP-0.23 & $3 \times 6$ & 4 & $21.9-22.6$ & 2.2 & 22.2 & $2.497-2.513$ & 0.5 & 2.505 \\
\hline FRP-0.23 & $4 \times 8$ & 4 & 20.4 & - & - & 2.565 & - & - \\
\hline FRP-0.23 & $3 \times 6$ & 5 & $22.3-25.0$ & 8.0 & 23.6 & $2.519-2.545$ & 0.7 & 2.532 \\
\hline FRP-0.23 & $4 \times 8$ & 5 & 18.4 & - & - & 2.567 & - & - \\
\hline
\end{tabular}

--Note: non-paired specimens - 5 st, 5 densities

$3 \times 6$ batched specimens -2 st, 2 densities

$4 \times 8$ batched specimens -1 st, 1 density

Figure 21. Tensile strength of FRP variation specimens.

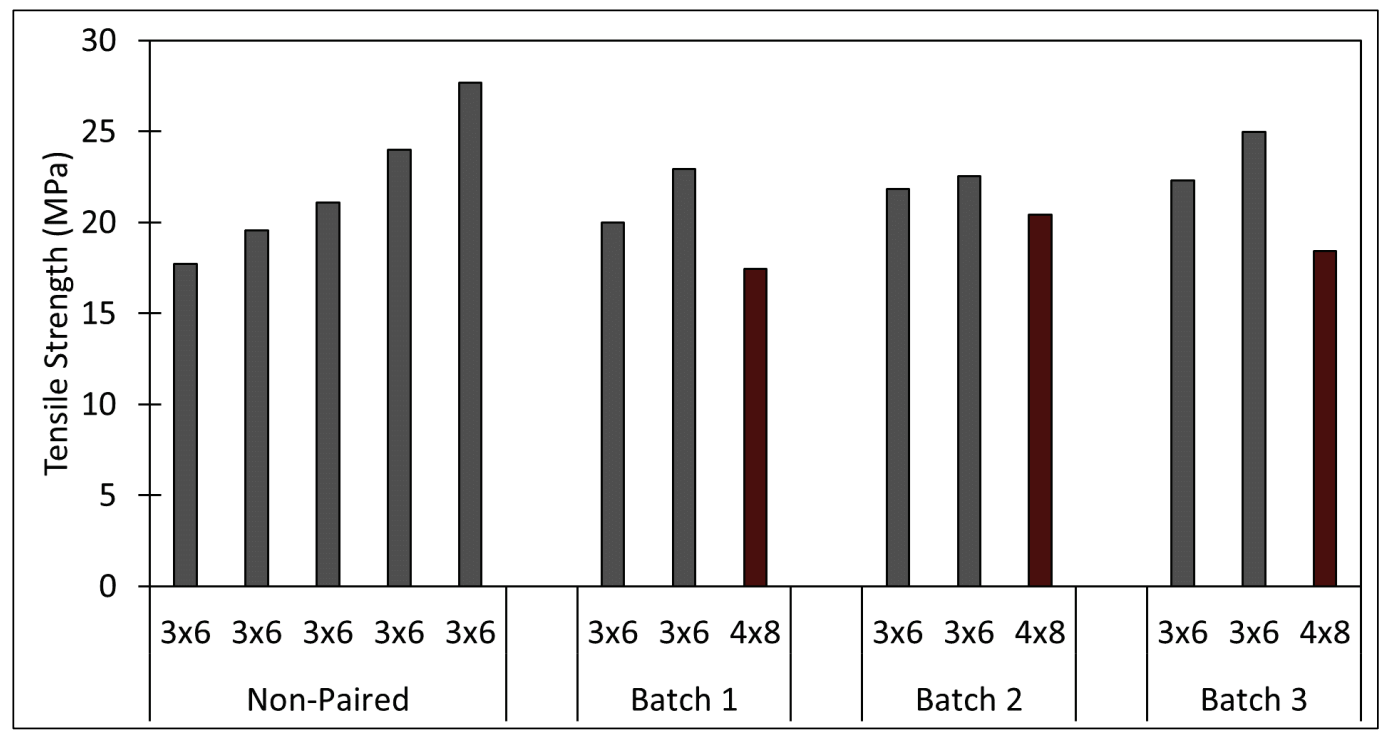

\subsection{Instrumentation test results}

Of the 254 specimens produced, eight were instrumented with strain gages after $791^{\circ} \mathrm{C}-\mathrm{d}$ curing. Each specimen was fitted with four strain gages, as shown in Appendix A. Of the 32 total strain gages, 27 measured data successfully. As noted earlier in the report, strain readings were taken with a data acquisition system independent of the concrete compression machine: load versus time was measured with the compression machine, and strain versus time was measured with the data acquisition system. These two time scales were synchronized within, at most, a few seconds so that stress versus 
strain plots could be generated. The synchronization process was approximate but was reasonable for the purposes of this report.

In compression UHPC, CP-0.15, M-0.56, and FRP-0.23 were produced without replication where three strain gages were oriented vertically (parallel to axis of loading) and one gage was oriented horizontally.

Figure 22 plots all strain readings taken in compression relative to the specimen's compressive strength (fc), which was determined by taking the stress at any instant in time, dividing by fc, and converting to a percentage. Strain readings were plotted for all gages up to 100 percent, and thereafter the curves were visually examined. Stress versus strain plots were truncated when visual evidence showed gage failure (e.g., a 1,000 microstrain change in strain from one reading to the next is likely gage debonding and not specimen response).

In tension UHPC, CP-0.15, M-0.56, and FRP-0.23 were produced without replication where three strain gages were oriented horizontally (perpendicular to axis of loading) and one gage was oriented vertically. Figure 23 plots strain readings relative to the specimen's tensile strength (St) in the same manner as Figure 22.

Figure 22. Percent of ultimate compressive stress versus strain for (a) UHPC, (b) CP-0.15, (c) M-0.56, and (d) FRP-0.23.

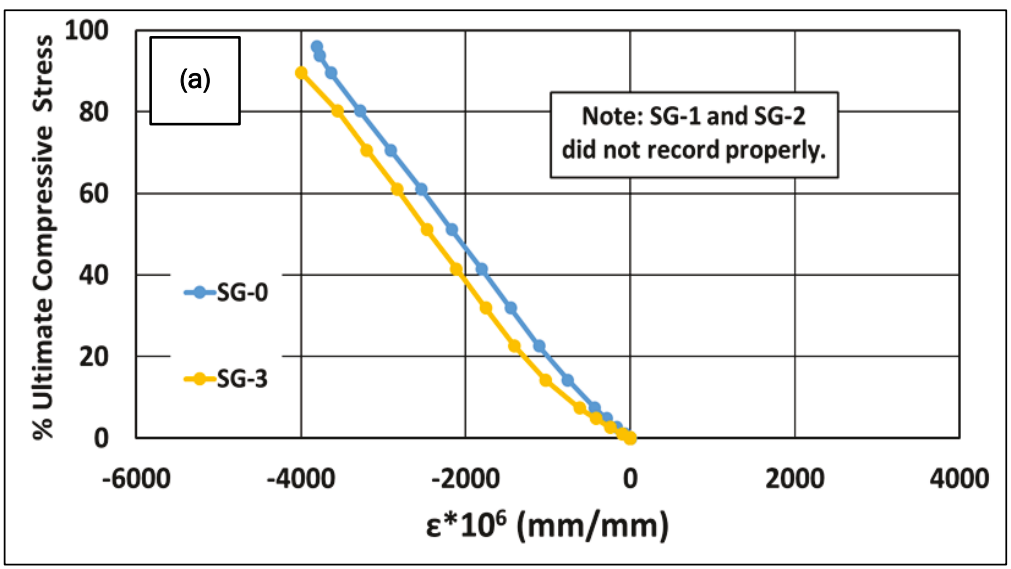



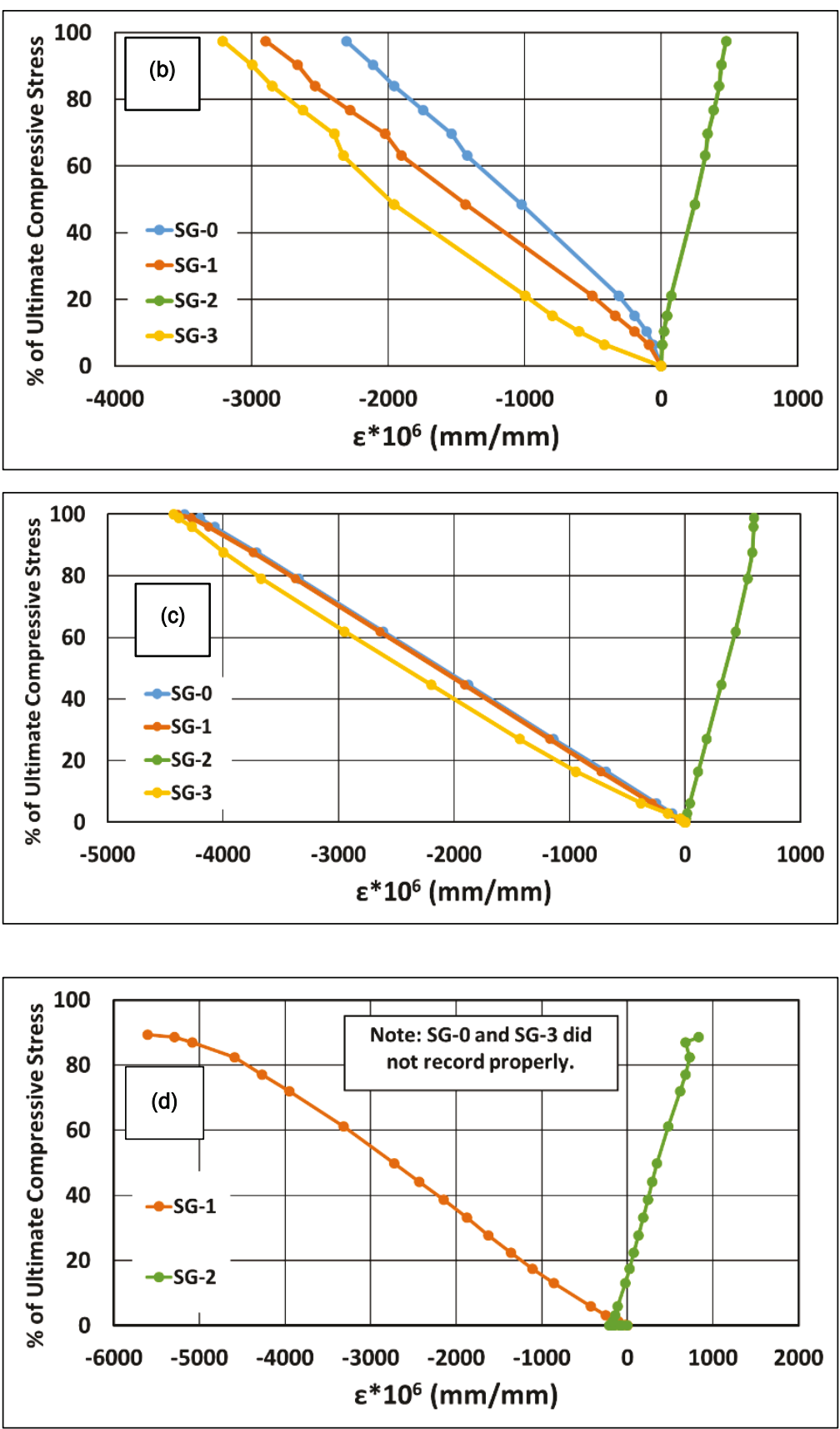
Figure 23. Percent of ultimate tensile stress versus strain for (a) UHPC, (b) CP-0.15, (c) M-0.56, and (d) FRP-0.23.
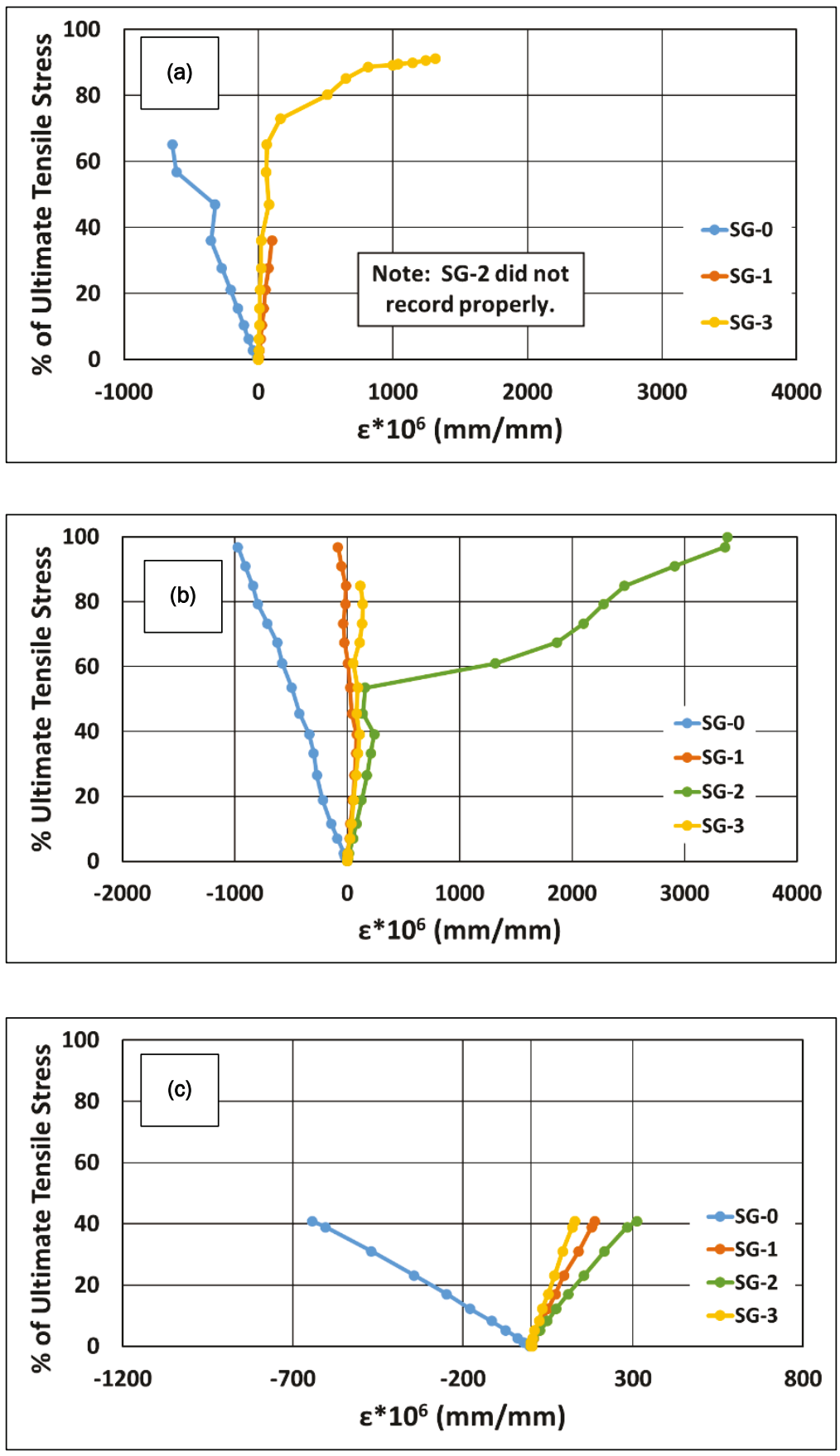


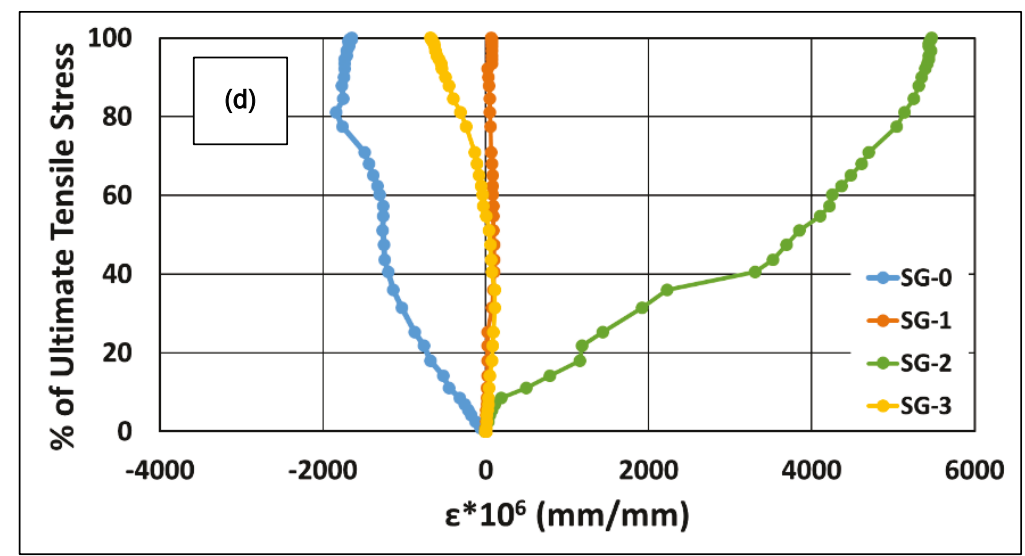

Numerical modeling of UHPC (or any of its constituents) benefits from knowing how high stresses can get before material behavioral changes are documented. When unconfined and tested as modest load rates, concrete materials are generally linear in their stress-strain behavior. A question, though, is how high can stresses get and linearity remain? As seen in Figures 22 and 23, linearity was often maintained at stresses nearing ultimate values, especially in compression. In tension, behaviors were somewhat more erratic.

Table 13 summarizes the highest ultimate tensile or compressive strain $\left(\varepsilon_{\max }\right)$ recorded by each gage in Figures 22 and 23 that was deemed reasonable from the aforementioned truncation process. Alongside this strain value is the percent of ultimate stress (\%UltS) where this strain was recorded. For compressive loadings, linear behavior until 90 percent or more of \%UltS was generally observed. Note that sampling rates were relatively low, and no useful information was collected as specimens approached failure.

Table 13. Strain gage data for compression and tension.

\begin{tabular}{|c|c|c|c|c|c|c|c|c|c|}
\hline \multicolumn{2}{|c|}{} & \multicolumn{2}{c|}{ SG-0 } & \multicolumn{2}{c|}{ SG-1 } & \multicolumn{2}{c|}{ SG-2 } & \multicolumn{2}{c|}{ SG-3 } \\
\hline \multirow{2}{*}{ Mix } & Mode & $\boldsymbol{\varepsilon}_{\max }$ & $\%$ UltS & $\boldsymbol{\varepsilon}_{\max }$ & $\%$ UltS & $\boldsymbol{\varepsilon}_{\max }$ & $\%$ UltS & $\boldsymbol{\varepsilon}_{\max }$ & $\%$ UltS \\
\hline \multirow{2}{*}{ UHPC } & Compression & $-3,807$ & $96 \%$ & - & - & - & - & $-3,996$ & $90 \%$ \\
\cline { 2 - 11 } & tension & -973 & $97 \%$ & -83 & $97 \%$ & 3,381 & $100 \%$ & 117 & $85 \%$ \\
\hline \multirow{2}{*}{ CP-0.15 } & Compression & $-2,307$ & $98 \%$ & $-2,897$ & $98 \%$ & 475 & $98 \%$ & $-3,210$ & $98 \%$ \\
\cline { 2 - 11 } & tension & -639 & $65 \%$ & 100 & $36 \%$ & - & - & 1,315 & $91 \%$ \\
\hline \multirow{2}{*}{ M-0.56 } & Compression & $-4,331$ & $100 \%$ & $-4,393$ & $100 \%$ & 600 & $99 \%$ & $-4,426$ & $100 \%$ \\
\cline { 2 - 10 } & tension & -644 & $41 \%$ & 188 & $41 \%$ & 311 & $41 \%$ & 129 & $41 \%$ \\
\hline \multirow{2}{*}{ FRP-0.23 } & Compression & - & - & $-5,604$ & $89 \%$ & 831 & $89 \%$ & - & - \\
\cline { 2 - 10 } & tension & $-1,649$ & $100 \%$ & 63 & $100 \%$ & 5,472 & $100 \%$ & -678 & $100 \%$ \\
\hline
\end{tabular}


The linear portions of Figure 22 (vertical gages only) were used to produce stress-strain plots up to approximately 40 percent of ultimate stress for elastic modulus determination (Figure 24); elastic moduli calculated from strain gage measurements were denoted EsG-o to ESG-3. The ASTM C469 (ASTM International 2014) compressometer was also fitted to these same specimens to measure $\mathrm{E}_{469}$ so a direct comparison of strain gage and compressometer values could be made on the same specimen. Results are summarized in Table 14.

Figure 24. Truncated stress versus vertical strain plots for (a) UHPC, (b) CP-0.15, (c) M-0.56, and (d) FRP-0.23 in compression.
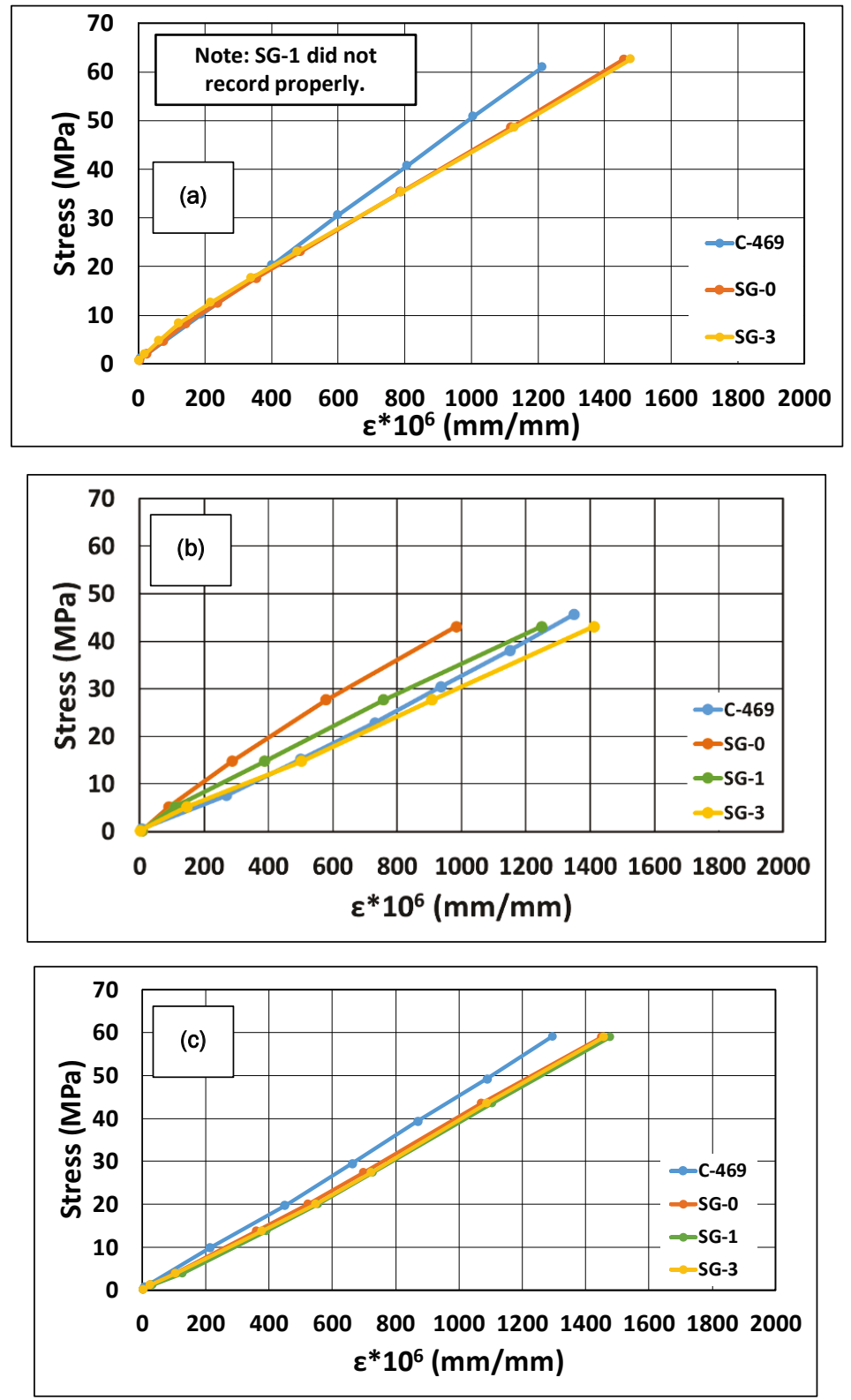


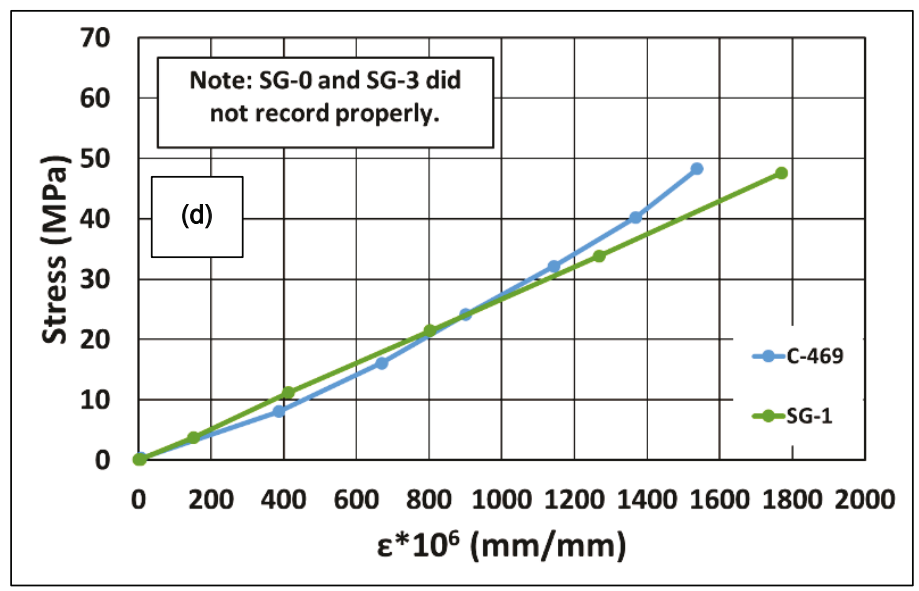

Table 14. Comparison of elastic moduli from strain gages and compressometer.

\begin{tabular}{|c|c|c|c|c|c|}
\hline Mix ID & EsG-0 (MPa) & EsG-1 $_{\text {(MPa) }}$ & EsG-3 $_{\text {(MPa) }}$ & EsG-AvG $_{\text {(MPa) }}$ & E469 $_{\text {(MPa) }}$ \\
\hline UHPC & 42,100 & - & 41,100 & 41,600 & 49,610 \\
\hline CP-0.15 & 43,700 & 34,200 & 30,300 & 36,000 & 33,800 \\
\hline M-0.56 & 40,700 & 40,000 & 40,300 & 40,300 & 45,300 \\
\hline FRP-0.23 & - & 26,800 & - & 26,800 & 31,400 \\
\hline
\end{tabular}

--Note: All measurements shown in a given row were made on the same specimen.

In three cases, E469 resulted in higher values than strain gages (12 to 19 percent higher on average), and in 1 case, E469 resulted in lower values than strain gages (7 percent lower on average). Overall, strain gages and the compressometer reported elastic modulus values that were in the same general range based on this fairly limited data set.

From compression testing with strain gages, Poisson's ratio (v) was approximated by relating the horizontal and vertical displacement using SG-2 (horizontally oriented) and SG-1 (vertically oriented). Figure 25 provides the plots used, which are truncations of Figure 22, and the corresponding Poisson's ratio values. 
Figure 25. Poisson's ratio results from compression testing.

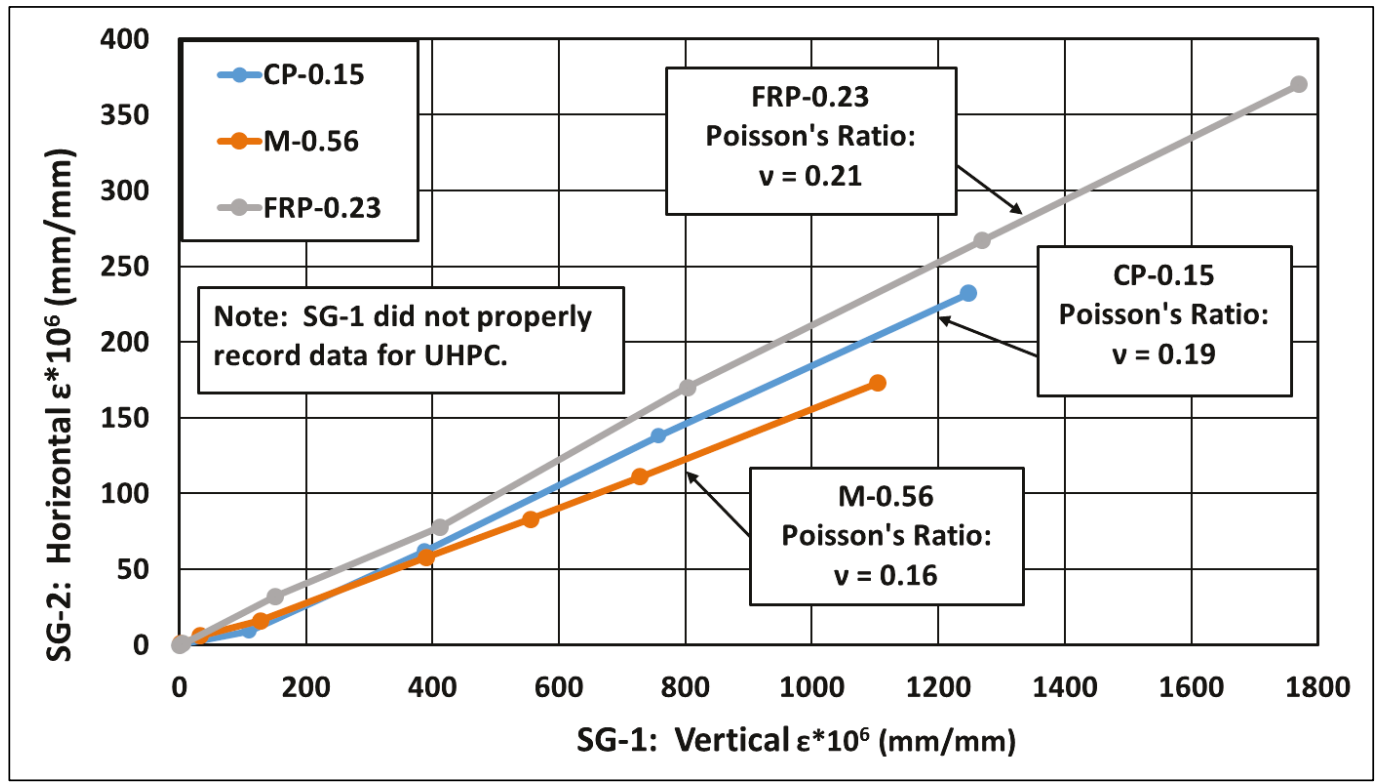

\subsection{Volume fractions estimated from batch quantities}

Table 15 shows the results of the volume fraction estimates from batch quantities and specific gravities of individual ingredients. All specimens tested except for cores are represented in Table 15. These fractions are approximations used for general reference and for comparison with the Image $J$ and Abaqus results presented in the following section.

Table 15. Average volume fractions estimated from batch quantities.

\begin{tabular}{|c|c|c|c|c|c|c|c|c|c|}
\hline Mix & $\begin{array}{c}\mathrm{V}_{\mathrm{c}} \\
(\%)\end{array}$ & $\begin{array}{c}\mathrm{V}_{\text {sf }} \\
(\%)\end{array}$ & $\begin{array}{c}\mathrm{V}_{\text {sfl }} \\
(\%)\end{array}$ & $\begin{array}{c}\mathrm{V}_{\mathbf{s}} \\
(\%)\end{array}$ & $\begin{array}{c}\mathrm{V}_{\mathrm{w}} \\
(\%)\end{array}$ & $\mathrm{V}_{\mathrm{f}}(\%)$ & $\begin{array}{c}\mathrm{V}_{\mathrm{am}} \\
(\%)\end{array}$ & $\begin{array}{c}\mathrm{V}_{\mathrm{a}} \\
(\%)\end{array}$ & $\begin{array}{c}\mathrm{V}_{\text {TOTAL }} \\
(\%)\end{array}$ \\
\hline UHPC & 25.3 & 13.8 & 8.3 & 29.1 & 16.7 & 3.2 & 1.3 & 2.4 & 100 \\
\hline $\mathrm{CP}-0.15$ & 44.0 & 24.0 & ---- & ---- & 29.0 & ---- & 2.2 & 0.7 & 100 \\
\hline M-0.56 & 30.2 & 16.5 & 9.9 & 18.2 & 19.8 & --- & 1.5 & 3.9 & 100 \\
\hline FRP-0.11 & 41.7 & 22.7 & ---- & ---- & 27.5 & 5.2 & 2.1 & 0.9 & 100 \\
\hline CP-0.11 & 46.0 & 25.1 & ---- & ---- & 22.8 & --- & 2.3 & 3.8 & 100 \\
\hline CP-0.26 & 41.3 & 22.6 & ---- & ---- & 34.1 & --- & 2.1 & 0.01 & 100 \\
\hline M-0.47 & 31.5 & 17.2 & 10.4 & 14.3 & 20.8 & ---- & 1.6 & 4.2 & 100 \\
\hline M-0.65 & 28.5 & 15.6 & 9.4 & 21.5 & 18.8 & ---- & 1.4 & 4.8 & 100 \\
\hline FRP-0.17 & 42.4 & 23.2 & ---- & ---- & 28.0 & 4.0 & 2.1 & 0.3 & 100 \\
\hline FRP-0.23 & 42.7 & 23.3 & ---- & ---- & 28.2 & 2.7 & 2.1 & 1.0 & 100 \\
\hline
\end{tabular}




\subsection{Volume fractions estimated from imaging}

Of the 254 specimens produced, five specimens (all cured for $791^{\circ} \mathrm{C}-\mathrm{d}$ ) were allocated for image testing. Four of these specimens (UHPC, CP-0.15, M-0.56, and FRP-0.23) underwent imaging with an SEM that resulted in two dimensional (2-D) pictures, and the fifth specimen (UHPC) underwent a CT scan to get a 3-D representation of the UHPC.

Area fractions for the UHPC specimen evaluated with SEM techniques were found using ImageJ software. Table 16 compares the volume fractions in Table 15 to ImageJ values. It is important to note that the area fraction of cement found through imaging should not match the batching volume fraction. ImageJ found unhydrated cement grains, while the batching measures all cement put into the mixture.

One specimen also underwent a CT scan (Figure 26). Large voids, which can occur during mixing, were observed. Fiber orientation was assumed to be random, but the CT scan aided in observing the locations of the fibers within the matrix. The scan found that fibers were 3 percent of the total volume, which is close to what was calculated from batch quantities and found using imaging area.

Table 16. Comparison of average UHPC volume fractions from batching and ImageJ.

\begin{tabular}{|c|c|c|}
\hline Inclusion & $\begin{array}{c}\text { Estimated from batching } \\
\text { quantities } \\
\text { (\%) }\end{array}$ & $\begin{array}{c}\text { ImageJ } \\
\text { (\%) }\end{array}$ \\
\hline Air voids & 2.4 & 6.8 \\
\hline Cement & 25.3 & 11.7 \\
\hline Sand & 29.1 & 22.3 \\
\hline Fibers & 3.2 & 3.7 \\
\hline
\end{tabular}


Figure 26. CT scan of UHPC showing (a) approximately $3 \%$ steel fibers and (b) large voids illustrated.

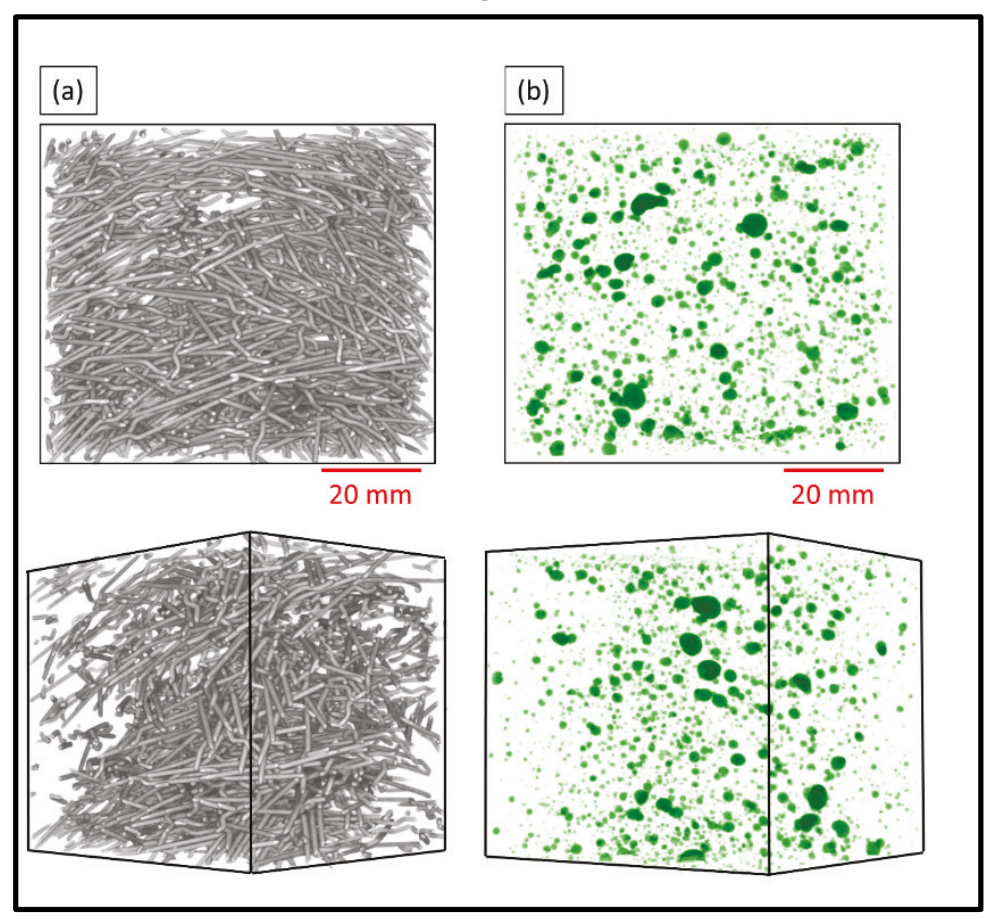




\section{Summary}

In simple terms, concrete properties are governed by aggregate properties, paste properties, and the bond between paste and aggregates when constituent materials and proportions are constant. However, understanding the true nature of how concrete properties are governed by these items is much more complex (even for constant materials). To provide some fundamental data on Cor-Tuf UHPC, a series of fundamental experiments was performed and is documented in this report, the ultimate purpose of which is to further numerical modeling efforts.

Cor-Tuf has seven constituent ingredients that lead to eight volume fractions when air voids are included. Ten mixtures were produced by using varying amounts of these seven ingredients and were exposed to varying curing times and temperatures. These mixtures can be divided into UHPC (all seven ingredients), FRP (no aggregates), M (no fibers), and $\mathrm{CP}$ (no aggregates or fibers). Mechanical property testing at low load rates and without confinement measured compressive strength, tensile strength, elastic modulus, Poisson's ratio, and load versus strain relationships. The majority of the specimens produced were 3 in. in diameter and had a height of 6 in., since this is a mid-range size for the types of mixtures produced. Some specimens were 2 in. by 4 in. or 4 in. by 8 in. to assess size effects.

This report is intended primarily to document these experiments and contain the data collected, since a systematic evaluation of this nature related to constituent effects is not readily available to the knowledge of the authors. Specific conclusions are avoided herein as the intent is to use these data in future efforts that will be more appropriate to draw more meaningful conclusions about ways to better model and ultimately improve UHPC. An intended purpose for these data is high-performance computing (HPC) environments where multi-scale modeling is performed. Fundamental understanding of individual components, proportions, and their interface behavior is needed for sophisticated numerical models capable of predicting behavior of structural systems built with UHPC. The experimental data collected have the possibility to be used three ways for numerical modeling purposes: (1) exploratory efforts to assist in defining first principles, (2) calibration, and (3) validation. 
The following list summarizes key observations from this report.

1. Instrumented compression specimens showed mostly linear behavior to stress levels of 90 percent (or more) of failure levels.

2. Specimens produced with UHPC constituent materials did not produce as high of an elastic modulus per unit of compressive strength as does typical ready mixed concrete.

3. With $\mathrm{CP}$, there were no overall obvious compressive strength differences between 2- by 4-in. specimens and 3- by 6-in. specimens.

4. With FRP, compressive strengths from 4- by 8-in. specimens fell in the range of those from 3- by 6-in. specimens. Tensile strengths from 4- by 8-in. specimens fell on the lower end of to slightly lower than 3 - by 6-in. specimens. Note that 4- by 8-in. specimen data were limited.

5. Specific aspects of curing seem to affect compressive and tensile properties, and the effects are not consistent between tension and compression or between types of specimen. These data suggest that only accumulating ${ }^{\circ} \mathrm{C}$-days and using that number as a maturity index may lead to undesirable outcomes for some types of UHPC endeavors, such as mass concrete. 


\section{References}

Abaqus CAE (version 6.14). 2014. Dassault Systems.

American Concrete Institute. 2014. Building code requirements for structural concrete (ACI 318-05) and commentary (ACI 318R-05). Farmington Hills, MI: American Concrete Institute.

American Petroleum Institute. 1991. Specification for well cements, API specification IOA. $21^{\text {st }}$ ed. September, 1991. Washington DC: American Petroleum Institute.

ASTM International (ASTM). 2011a. Standard practice for estimating concrete strength by the maturity method. Designation C1074-11. West Conshohocken, PA: ASTM International. Doi: 10.1520/C1074-11. www.astm.org/

2011b. Standard test method for splitting tensile strength of cylindrical concrete specimens. Designation C496/C496M. West Conshohocken, PA: ASTM International. Doi 10.1520/C0496_Co496M-11. https://www.astm.org/

2013. Standard specification for chemical admixtures for use in producing flowing concrete. Designation C1017/C1017M-13E01. West Conshohocken, PA: ASTM International. Doi 10.1520/C1017_C 1017M-13E01. https://www.astm.org/

2014. Standard test method for static modulus of elasticity and Poisson's ration of concrete in compression. Designation: $\mathrm{C} 469 / \mathrm{C} 469 \mathrm{M}$. West Conshohocken, PA: ASTM International. Doi: 10.1520/Co469M-14. https://www.astm.org/

2015. Standard test methods for chemical analysis of hydraulic cement. Designation: C114/C114M. West Conshohocken, PA: ASTM International. Doi: 10.1520/Co114-15. https://www.astm.org/

2016a. Standard specification for steel fibers for fiber-reinforced concrete. West Conshohocken, PA: ASTM International. Doi: 10.1520/Ao820_A0820M-16. https://www.astm.org/

. 2016b. Standard test method for compressive strength of cylindrical concrete specimens. Designation: C39/C39M. West Conshohocken, PA: ASTM International. Doi: 10.1520/CoO39_CoO39M-16. https://www.astm.org/

2017a. Standard specification for chemical admixtures for concrete. Designation: C494/C494M. West Conshohocken, PA: ASTM International. Doi: 10.1520/Co494_Co494M-17. https://www.astm.org/

2017b. Standard test methods for fineness of hydraulic cement by airpermeability apparatus. Designation: C204/C204M. West Conshohocken, PA: ASTM International. Doi: 10.1520 Co204-17. https://www.astm.org/

Chandler, M., J. Peters, and D. Pelessone. 2012. Modeling nanomechanical behavior of calcium-silicate-hydrate. ERDC/GSL TR-12-30. Vicksburg, MS: U.S. Army Engineer and Research and Development Center. 
Green, B., R. Moser, D. Scott, and W. Long. 2014. Ultra-high performance concrete history and usage by the Corps of Engineers. Advances in Civil Engineering Materials 4(2): 132-143. https://doi.org/10.1520/ACEM20140031.

Howard, I. L., and H. V. GangaRao. 2009. Testing and evaluation of adhesive bonded fiber reinforced polymer bridge decks. Journal of Advanced Materials 41(2): 2846.

Roth, M. J. 2008. Flexural and tensile properties of thin, very high-strength, fiberreinforced concrete panels. ERDC/GSL TR-08-24. Vicksburg, MS: U.S. Army Engineer Research and Development Center.

Rushing, T. W., I. L. Howard, J. B. Jordan, and P. G. Allison. 2016. Laboratory characterization of fatigue performance of AM2 aluminum airfield matting. Journal of Materials in Civil Engineering 28(11): 04016134.

Schneider, C. A., W. S. Rasband, and K. W. Eliceiri. 2012. NIH image to ImageJ: 25 years of image analysis. Nature Methods 9(7): 671-75.

Scott, D., W. Long, R. Moser, B. Green, J. O'Daniel, and B. Williams. 2015. Impact of steel fiber size and shape on the mechanical properties of ultra-high performance concrete. ERDC/GSL TR-15-22. Vicksburg, MS: U.S. Army Engineer Research and Development Center.

Warren, K. A., B. Christopher, and I. L. Howard. 2010. Geosynthetic strain gage installation procedures and alternative strain measurement methods for roadway applications. Geosynthetics International 17(6): 403-430. 


\section{Appendix A: Strain Gage Locations}

Figure A1. Strain gage locations of UHPC in compression.

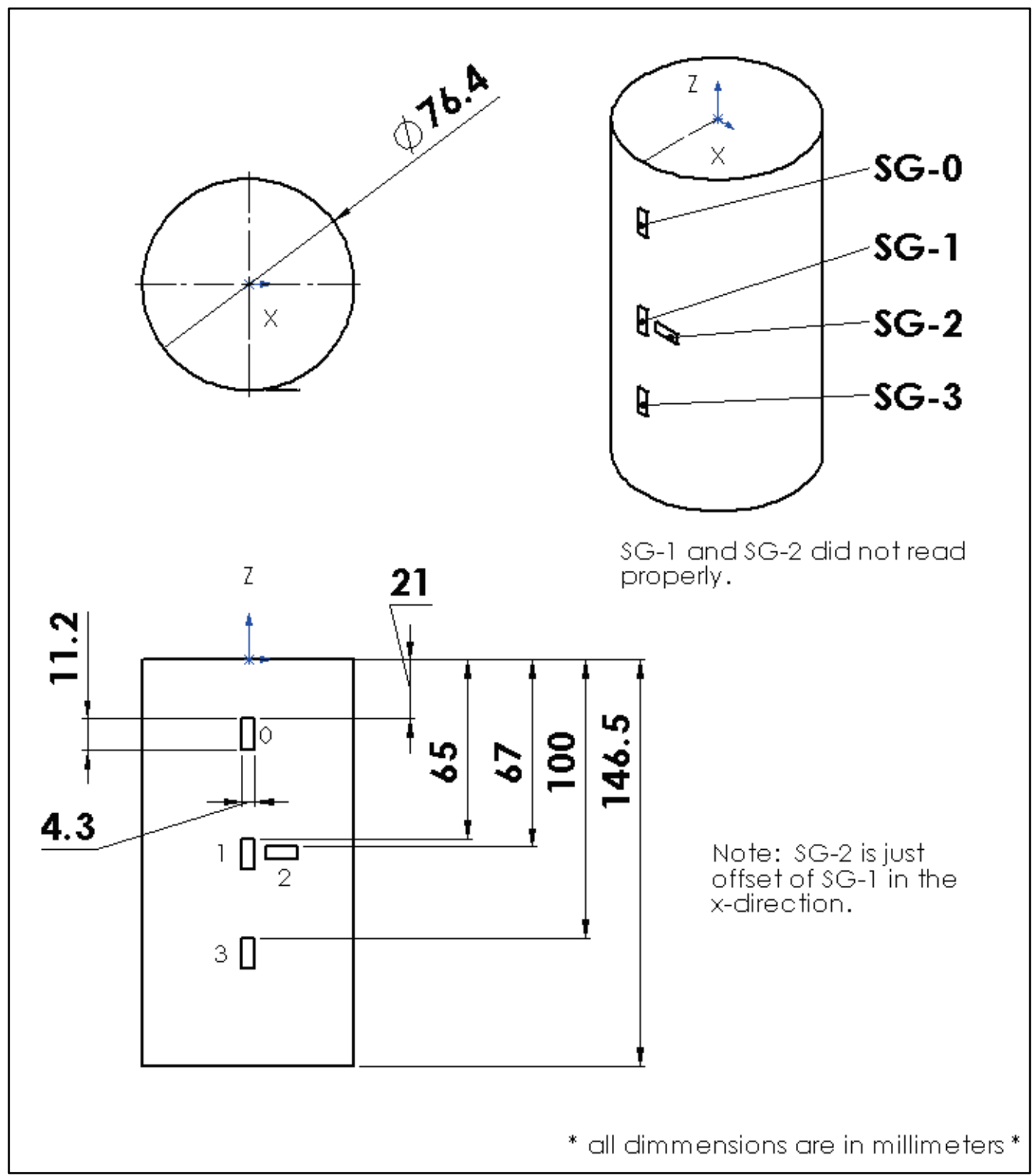


Figure A2. Strain gage locations for $\mathrm{CP}$ in compression.

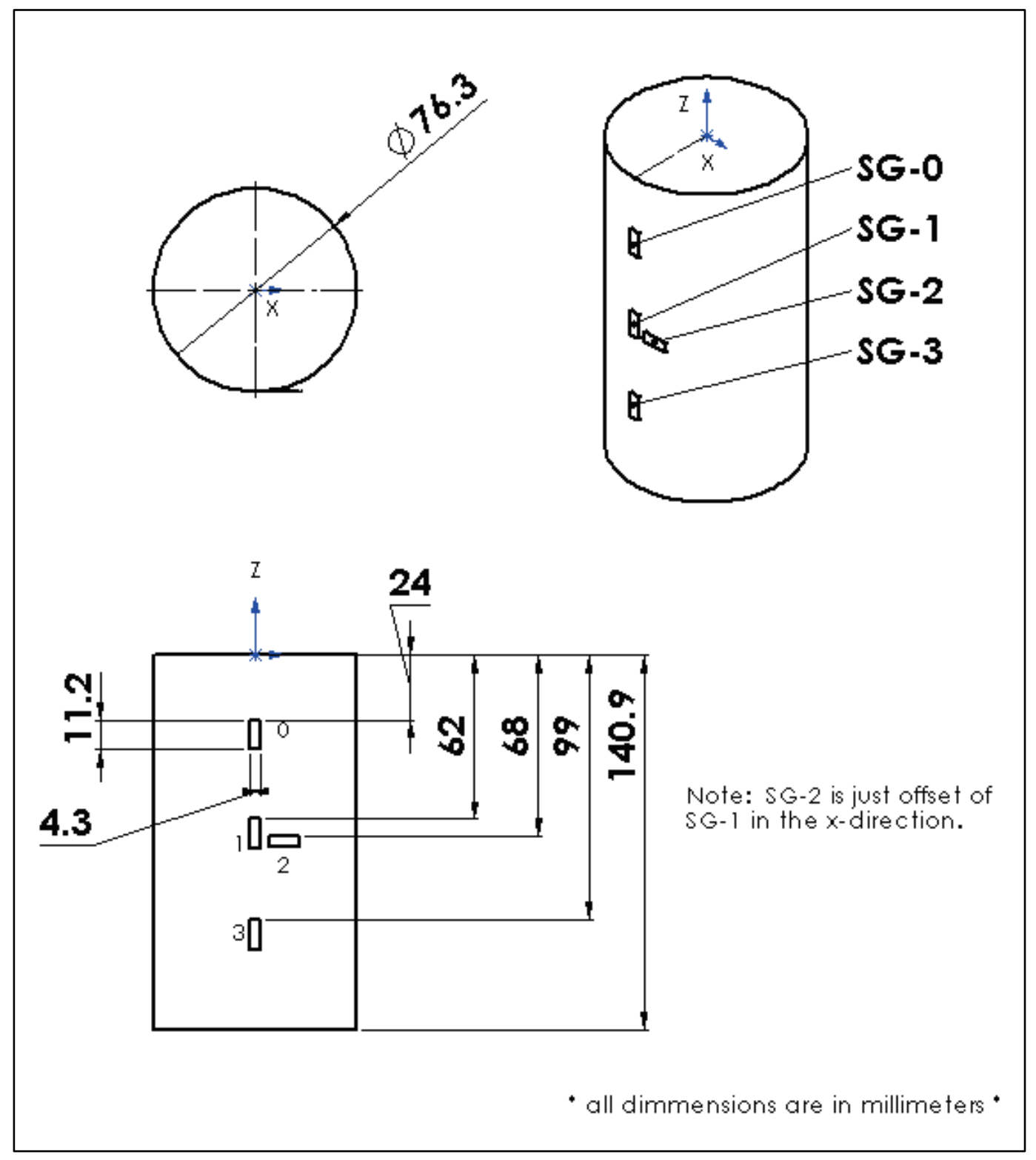


Figure A3. Strain gage locations for M in compression.

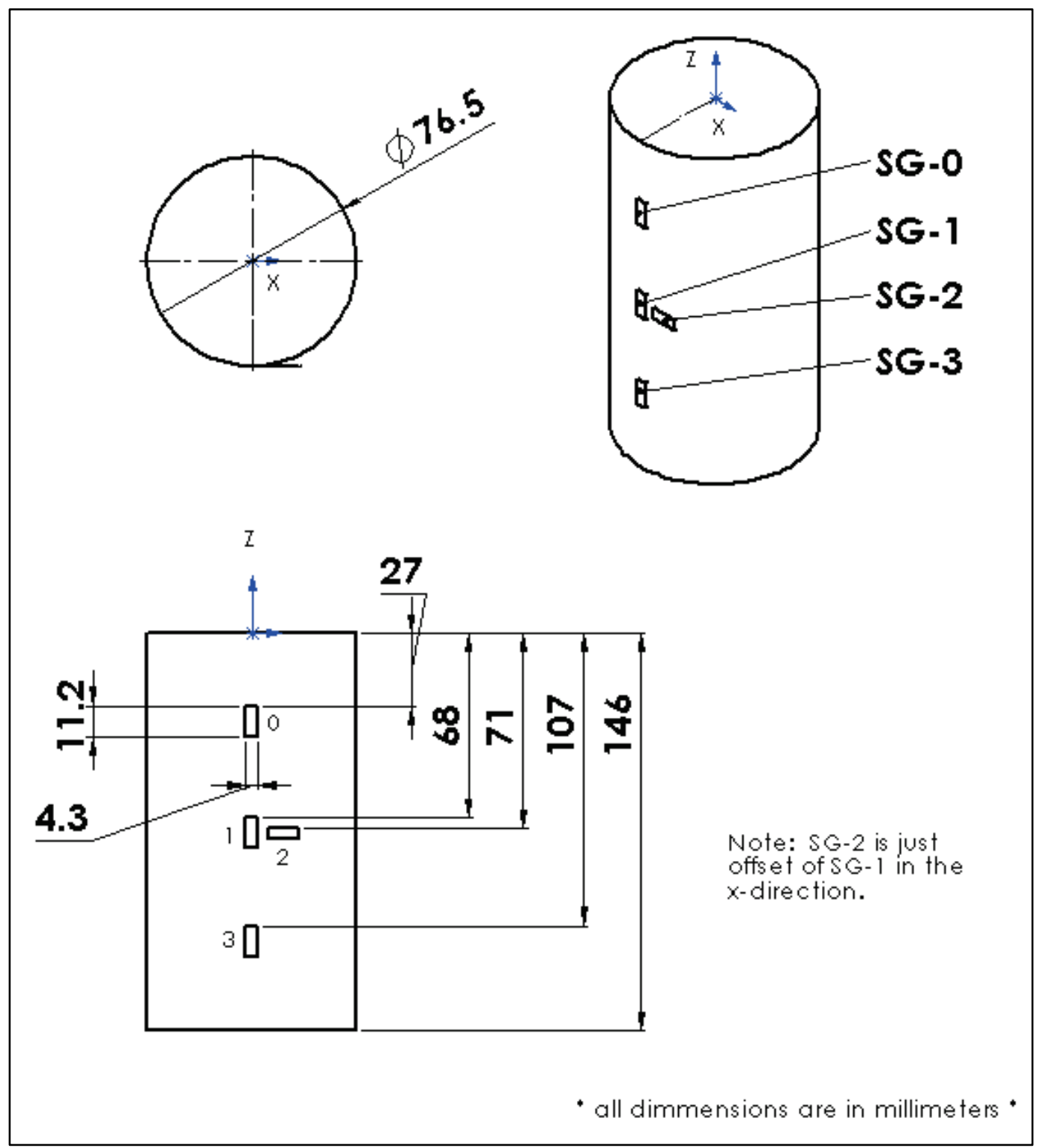


Figure A4. Strain gage locations for FRP in compression.

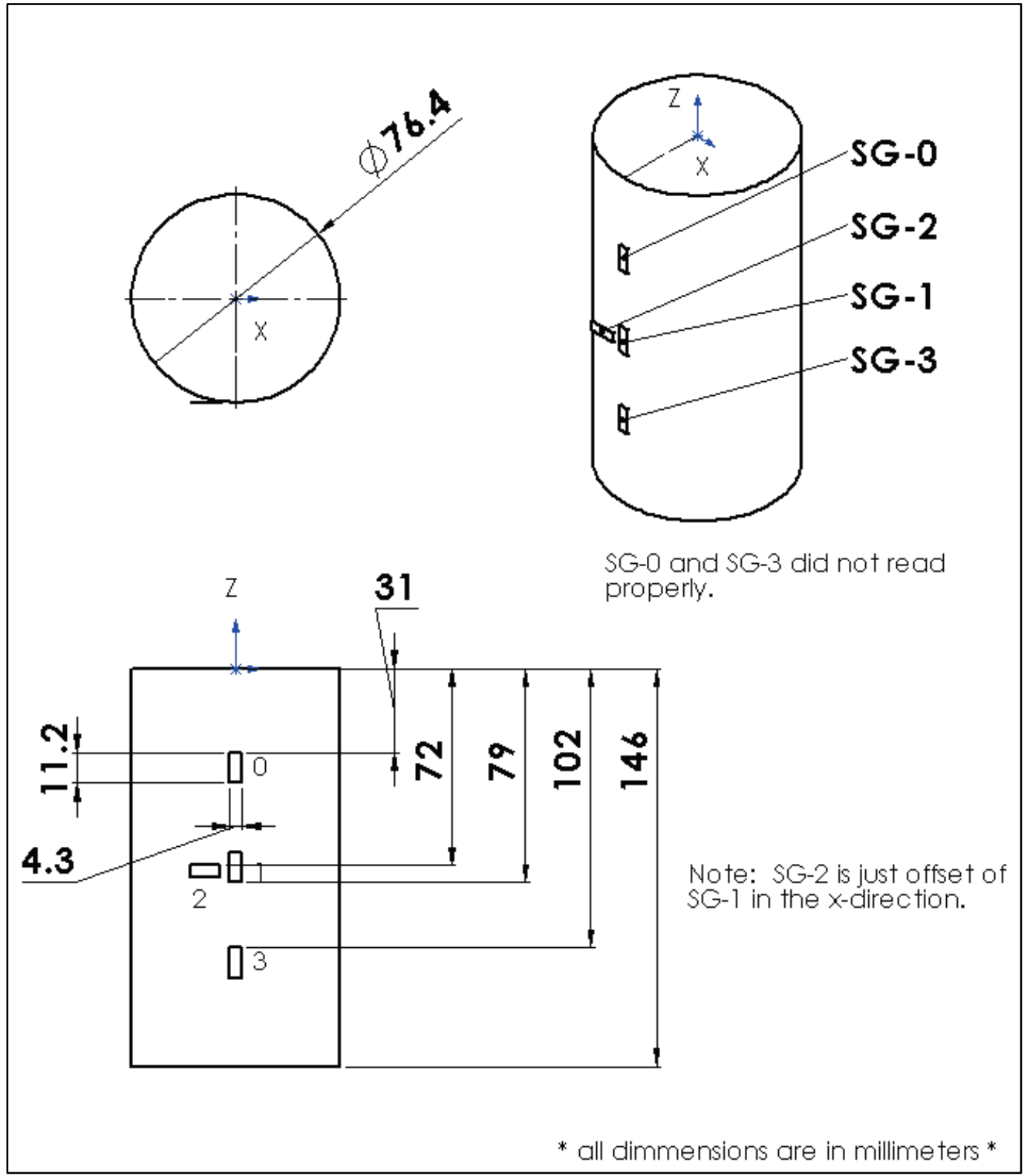


Figure A5. Strain gage locations for UHPC in tension.

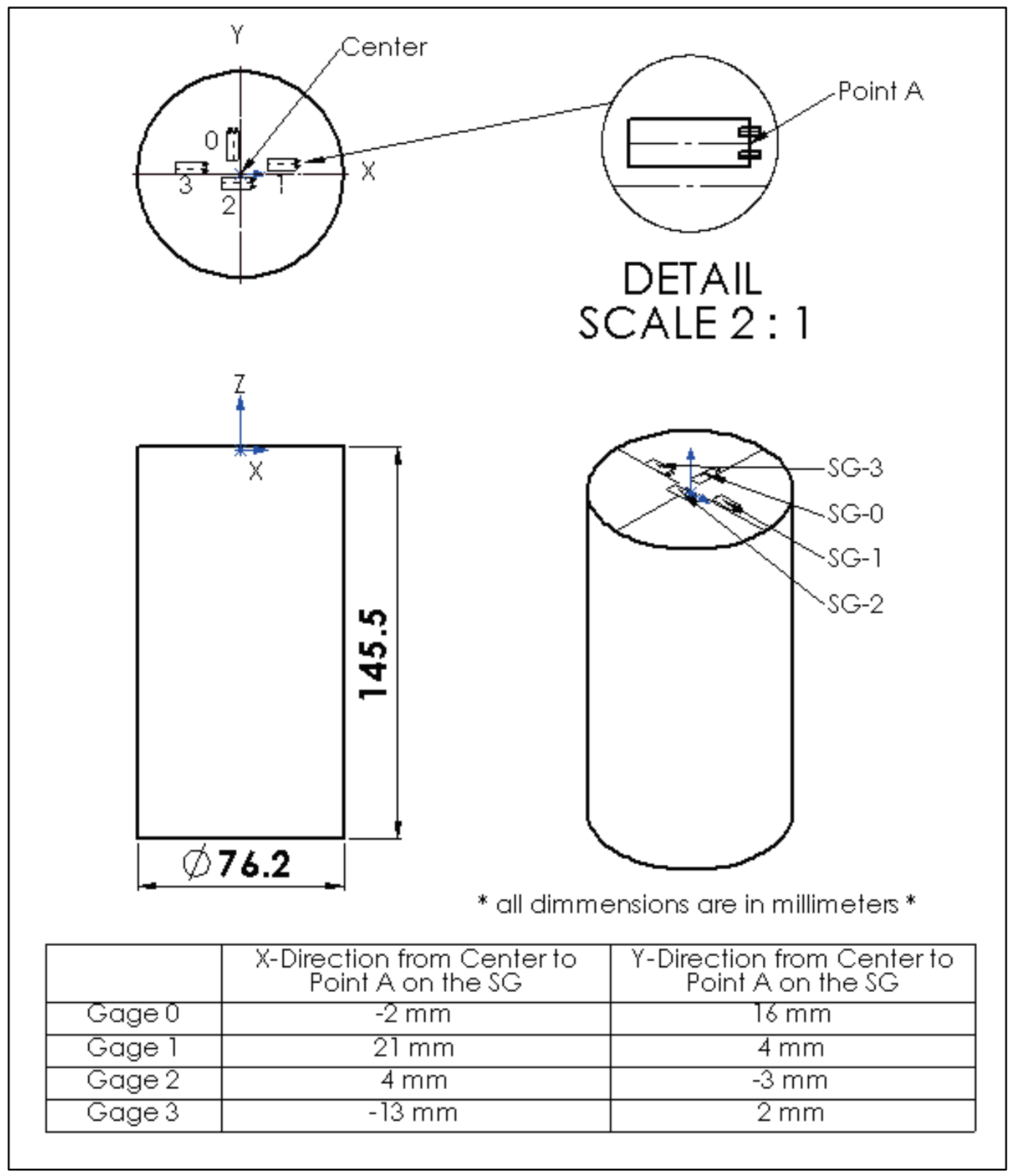


Figure A6. Strain gage locations for $\mathrm{CP}$ in tension.

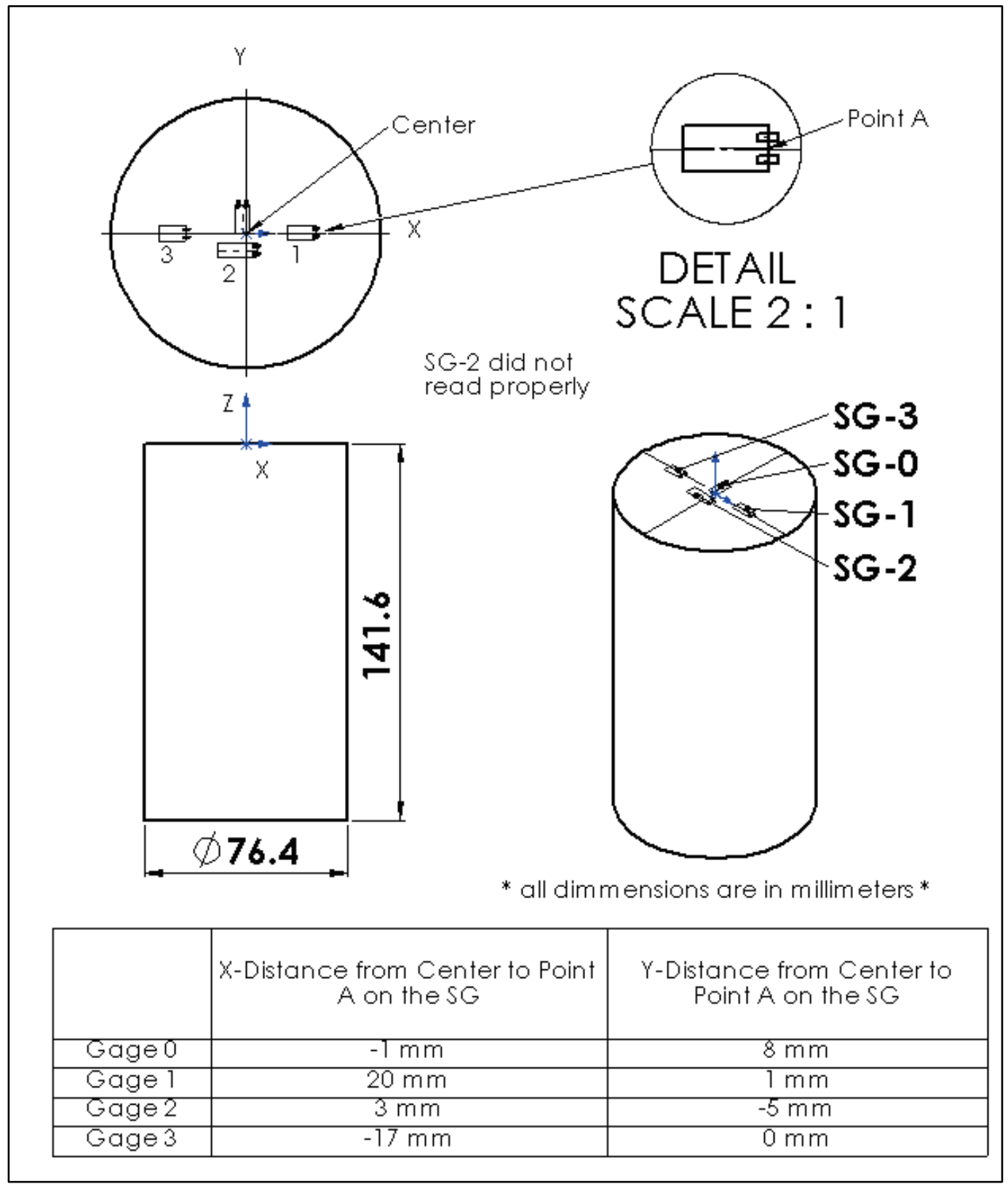


Figure A7. Strain gage locations for M in tension.

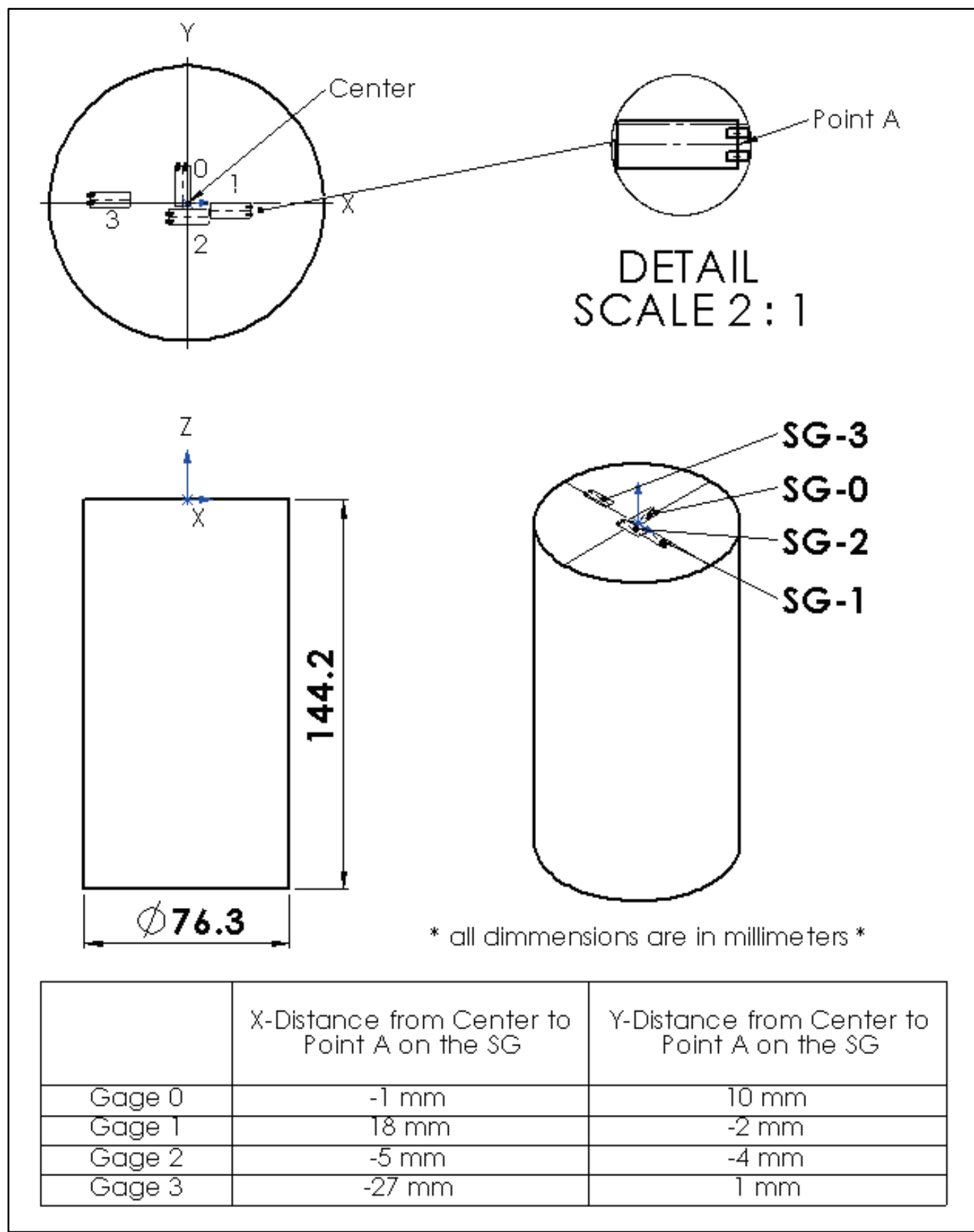


Figure A8. Strain gage locations for FRP in tension.

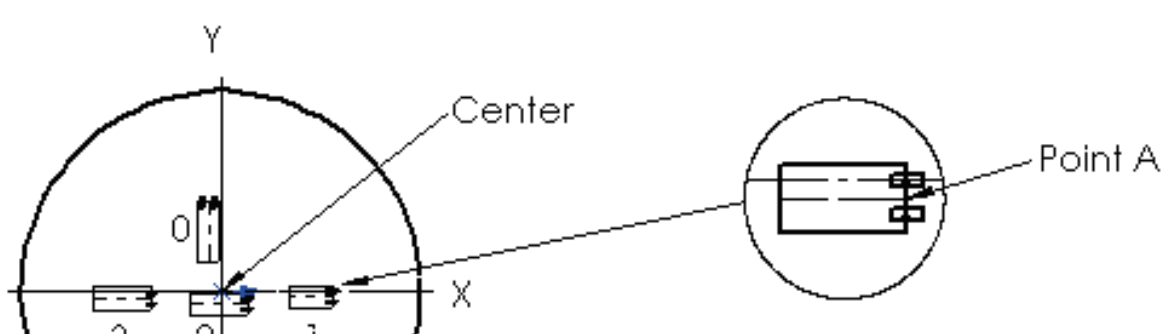

DETAIL SCALE $2: 1$
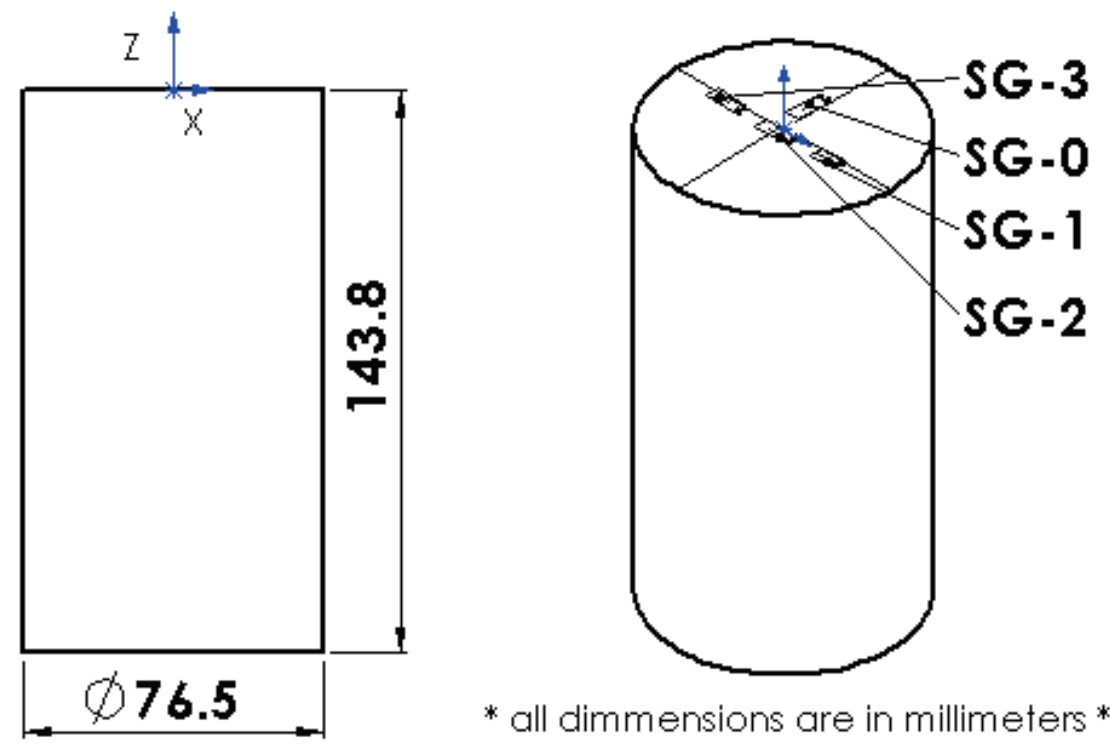

* all dimmensions are in millimeters *

\begin{tabular}{|l|c|c|}
\hline & $\begin{array}{c}\text { X-Distance from Center to } \\
\text { Point A on the SG }\end{array}$ & $\begin{array}{c}\text { Y-Distance from Center to } \\
\text { Point } A \text { on the } S G\end{array}$ \\
\hline Gage 0 & $-2 \mathrm{~mm}$ & $17 \mathrm{~mm}$ \\
\hline Gage 1 & $21 \mathrm{~mm}$ & $-1 \mathrm{~mm}$ \\
\hline Gage 2 & $5 \mathrm{~mm}$ & $-3 \mathrm{~mm}$ \\
\hline Gage 3 & $-13 \mathrm{~mm}$ & $-2 \mathrm{~mm}$ \\
\hline
\end{tabular}




\section{REPORT DOCUMENTATION PAGE}

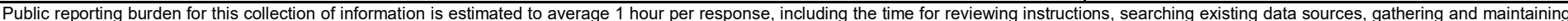

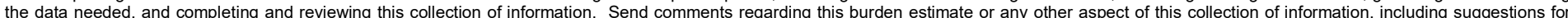

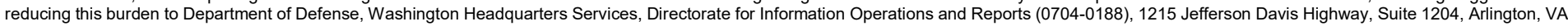

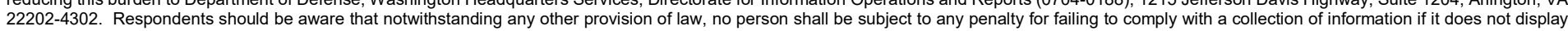
a currently valid OMB control number. PLEASE DO NOT RETURN YOUR FORM TO THE ABOVE ADDRESS.
1. REPORT DATE (DD-MM-YYYY)
2. REPORT TYPE
October 2018

\section{Final report}

\section{TITLE AND SUBTITLE}

Mechanical Behavior of Cor-Tuf Ultra-High-Performance Concrete Considering Aggregate and Paste

Effects

\section{DATES COVERED (From - To)}

5a. CONTRACT NUMBER

W56HZV-17-C-0095

5b. GRANT NUMBER

5c. PROGRAM ELEMENT NUMBER

\section{AUTHOR(S)}

Isaac L. Howard, Ashley Carey, Megan Burcham, Dylan A. Scott, Jameson D. Shannon, Robert D. Moser, and Mark F. Horstemeyer

\section{PERFORMING ORGANIZATION NAME(S) AND ADDRESS(ES)}

U.S. Army Engineer Research and Development Center

Geotechnical and Structures Laboratory

3909 Halls Ferry Road

Vicksburg, MS 39180-6199

\section{SPONSORING / MONITORING AGENCY NAME(S) AND ADDRESS(ES)}

U.S. Army Corps of Engineers

Washington DC 20314-1000

\section{5d. PROJECT NUMBER}

458161

5e. TASK NUMBER

5f. WORK UNIT NUMBER

J495LJ

8. PERFORMING ORGANIZATION REPORT NUMBER

ERDC/GSL TR-18-31

10. SPONSOR/MONITOR'S ACRONYM(S)

11. SPONSOR/MONITOR'S REPORT NUMBER(S)

\section{DISTRIBUTION / AVAILABILITY STATEMENT}

Approved for public release; distribution is unlimited.

\section{SUPPLEMENTARY NOTES}

\section{ABSTRACT}

This research primarily focused on properties from varying the constituents that make up ultra-high performance concrete (UHPC) with the ultimate goal to enable improved characterization and modeling of this material. Several variations of UHPC were made to see the differences in properties as a function of constituents. Compressive strength, elastic modulus, and tensile strength were measured at low loading rates. Fundamental test methods were used for most experiments with a smaller subset of tests with strain gages and imaging techniques. This report is intended primarily to document these experiments and the collected data. Specific conclusions are avoided herein, as the intent is to use these data in future efforts that will be more appropriate to draw more meaningful conclusions about ways to better model and ultimately improve UHPC.

\section{SUBJECT TERMS}

UHPC, Cor-Tuf, Concrete-Mechanical properties, Characterization, microCT,

\section{SECURITY CLASSIFICATION OF:}

\begin{tabular}{|l|l|l|}
\hline a. REPORT & b. ABSTRACT & c. THIS PAGE \\
UNCLASSIFIED & UNCLASSIFIED & UNCLASSIFIED
\end{tabular}

Concrete-Mixing, Concrete-Additives, High strength concrete, Modeling, Concrete,

17. LIMITATION
OF ABSTRACT

\section{NUMBER OF PAGES}

74
Aggregates (Building materials)

19a. NAME OF RESPONSIBLE PERSON Robert D. Moser

19b. TELEPHONE NUMBER (include area code) 601.634 .3261 